\title{
The Impact of Affective Information on Working Memory: A Pair of Meta-Analytic Reviews of Behavioral and Neuroimaging Evidence
}

\author{
Susanne Schweizer \\ University College London
}

Shir Atzil

Hebrew University of Jerusalem

Caitlin Hitchcock

University of Cambridge

Lisa Feldman Barrett

Massachusetts General Hospital, Boston, Massachusetts, and Northeastern University
Ajay B. Satpute

Northeastern University

\author{
Andy P. Field \\ University of Sussex
}

Melissa Black

University of Cambridge and Cambridgeshire and Peterborough NHS Foundation Trust, Cambridge, United Kingdom

Tim Dalgleish

University of Cambridge and Cambridgeshire and Peterborough NHS Foundation Trust, Cambridge, United Kingdom

\begin{abstract}
Everyday life is defined by goal states that are continuously reprioritized based on available, often affective information. To pursue these goals, individuals need to process and maintain goal-relevant information, while ignoring potentially salient information that distracts resources from these goals. Empirically, this ability has typically been operationalized as working memory (WM) capacity. A growing body of research is investigating the impact of information's affective salience on WM capacity. In the present review we address this question by exploring the potential differential impact of affective compared with neutral information on WM, and the underlying neural substrates. One-hundred and 65 studies $(N=7,433)$ were included in the meta-analysis. Results showed negligible to small $(\hat{d}=-.07-.20)$ effects of affective information on behavioral measures of WM in healthy individuals $(n=4,936)$ that varied as a function of valence and task-relevance. Heterogeneity analyses were significant, demonstrating the need to identify further study-specific factors and individual differences that moderate affective WM. At the neural level (33 studies; $n=$ 683), processing affective versus neutral material during WM tasks was associated with more frequent recruitment of the vlPFC, the amygdala, and the temporo-occipital cortex. In contrast to healthy individuals, across behavioral studies those suffering from mental health problems $(n=$ $2,041)$ showed impaired WM accuracy $(\hat{d}=-0.21)$ in the presence of affective material. These findings highlight the importance of integrating behavioral and neural levels of analysis. Finally, these findings suggest that affective WM capacity may be a transdiagnostic mechanism associated with poor mental health.
\end{abstract}

This article was published Online First April 25, 2019.

Susanne Schweizer, Institute of Cognitive Neuroscience, University College London; Ajay B. Satpute, Department of Psychology, Northeastern University; Shir Atzil, Department of Psychology, Hebrew University of Jerusalem; Andy P. Field, School of Psychology, University of Sussex; Caitlin Hitchcock, Medical Research Council, Cognition and Brain Sciences Unit, University of Cambridge; Melissa Black, Medical Research Council, Cognition and Brain Sciences Unit, University of Cambridge and Cambridgeshire and Peterborough NHS Foundation Trust, Cambridge, United Kingdom; Lisa Feldman Barrett, Athinoula A. Martinos Center for Biomedical Imaging, Massachusetts General Hospital, Boston, Massachusetts, and Department of Psychology, Northeastern University; Tim Dalgleish, Medical Research Council, Cognition and Brain Sciences Unit, University of Cambridge and Cambridgeshire and Peterborough NHS Foundation Trust.
This research was supported by funding from the United Kingdom Medical Research Council (Project code: MC_US_A060_0019). Susanne Schweizer was supported by the Gates Cambridge Trust and a Sir Henry Wellcome Fellowship (209127/Z/17/Z)

This article has been published under the terms of the Creative Commons Attribution License (http://creativecommons.org/licenses/by/3.0/), which permits unrestricted use, distribution, and reproduction in any medium, provided the original author and source are credited. Copyright for this article is retained by the author(s). Author(s) grant(s) the American Psychological Association the exclusive right to publish the article and identify itself as the original publisher.

Correspondence concerning this article should be addressed to Susanne Schweizer, Institute of Cognitive Neuroscience, University College London, 17 Queen Square, London WC1N 3AR, United Kingdom. E-mail: s.schweizer@ucl.ac.uk 
Public Significance Statement

The behavioral and neuroimaging meta-analyses showed that in psychologically healthy individuals there was limited support for behavioral working memory (WM) performance to be affected by affective information, whereas at the neural level WM in the presence of affective relative to neutral information was associated with differential recruitment of the salience network and the frontoparietal control network. These findings highlight the importance of combining behavioral and neuroimaging research syntheses. Second, in individuals with mental health problems WM was significantly impaired by affective material. This suggests that WM performance on tasks including affective compared with neutral information may be a sensitive and transdiagnostic cognitive marker of mental health status.

Keywords: working memory, emotion, mental health, frontoparietal control network, salience network

Supplemental materials: http://dx.doi.org/10.1037/bul0000193.supp

Working memory ${ }^{1}$ (WM) constitutes a capacity-limited resource that temporally maintains and stores information (Baddeley, 2003) in the service of higher cognitive functions (fluid intelligence, for instance; Kane, Hambrick, \& Conway, 2005). The vicissitudes of daily life frequently require such cognitive functions to operate in affectively laden contexts where much of the goal-relevant and goal-irrelevant information being processed has affective characteristics. Despite this, the impact of affective information on WM and the mechanisms through which that impact is realized remain poorly understood (Baddeley, 2003, 2013; Pessoa, 2009). Indeed, a consideration of WM in relation to affective phenomena has only recently attracted concerted discussion (Baddeley, 2013; Barrett, Tugade, \& Engle, 2004; Okon-Singer, Hendler, Pessoa, \& Shackman, 2015). Here, we review the literature and synthesize the research data comparing the impact of affective versus neutral information on WM, and the underlying neural substrates.

\section{WM in the Laboratory Versus WM in the Outside World}

Traditionally, WM has been experimentally assessed using paradigms that require individuals to update affectively neutral information such as numbers, letters or shapes in their memory store while simultaneously trying to minimize interference from other affectively neutral irrelevant material (e.g., Conway et al., 2005; Owen, McMillan, Laird, \& Bullmore, 2005). These "affectneutral" tasks are traditionally conducted in laboratory settings allowing extreme precision in the goal-demands placed on participants. However, in real-world contexts WM is deployed in the face of ever-changing goal-demands where the information that needs to be updated and maintained in WM to meet current goals can shift rapidly. Dynamic reprioritization of active goal-states typically occurs as salient and/or novel representations are selectively attended to (Corbetta \& Shulman, 2002; Klink, Jentgens, \& Lorteije, 2014). Salience can be perceptual (Corbetta \& Shulman, 2002) or experience-driven (e.g., affect-neutral pictures and words attract attention when they are relevant to current task-goals; Vogt, De Houwer, \& Crombez, 2011; Vogt, De Houwer, Crombez, \& Van Damme, 2013).
Another source of salience concerns the affective properties of encountered information. Affective significance can be conferred by: learned associations (e.g., repeated exposure to an object's rewarding properties; Gallagher \& Holland, 1994; Gottfried, O’Doherty, \& Dolan, 2003; Schoenbaum \& Roesch, 2005), evolutionarily transmitted predispositions, for instance speciesspecific survival threats (i.e., biological preparedness or "inherent goal states"; LeDoux, 2012; Mobbs, Hagan, Dalgleish, Silston, \& Prévost, 2015), as well as perceiver-based categorizations and appraisals (Barrett, 2006; Scherer, Dan, \& Flykt, 2006). These perceiver-based conceptual pathways have the potential to overwrite inherent or learned associations about a stimulus' affective impact (e.g., Ochsner, Bunge, Gross, \& Gabrieli, 2002). Salience attribution to affective properties is likely to have developed phylogenetically in humans as a function of threat/reward detection mechanisms (Dolan, 2002; LeDoux \& Brown, 2017) and more broadly as a heuristic for accelerating goal-directed behavior (AlShawaf, Conroy-Beam, Asao, \& Buss, 2016; Barrett, 2013).

Imagine the case of a fire alarm going off during dinner preparations which involve the maintenance of necessary cooking steps in WM. The fire alarm will immediately lead to reprioritization of the goal of cooking as entirely insignificant, while the new goal of exiting the building with kin becomes the dominant priority in the goal hierarchy. This reprioritization occurs because of the alarm's strong learned association with danger allied with the perceiver's appraisals of how events are likely to unfold if no action is taken (Amo et al., 2014; Gilmartin, Balderston, \& Helmstetter, 2014; Moscarello \& Maren, 2018).

Outside the rarefied setting of the laboratory, information processed in WM, then, is evaluated in terms of its relative facilitation versus interference of the pursuit of current goal-states (Barrett, 2005; Clore \& Huntsinger, 2007; Fox, 2008; Power \& Dalgleish, 2015), and the affective significance of encountered information has the potential to initiate the overriding of currently active goals in order to prioritize other goal-states (Barrett, 2013; Krieglmeyer, Deutsch, De Houwer, \& De Raedt, 2010) due to their salience to,

\footnotetext{
${ }^{1}$ There is a multitude of competing theories of WM, generating vibrant debate around definitions and underlying mechanisms (cf. Miyake \& Shah, 1999) which we acknowledge. An indebt discussion of these debates, however, is beyond the scope of this review.
} 
for example, survival (LeDoux, 2012) or self-identity (Kendzierski, Ritter, Stump, \& Anglin, 2015), or other domains central to the welfare of the organism.

\section{Theories About the Impact of Affective Properties on WM}

Despite this almost ubiquitous requirement for $\mathrm{WM}$ in the real world to operate in affective contexts, we currently lack a compelling unified theory of the different ways in which the processing of affective information can impact on WM. Instead, most theoretical work has focused on the role of acute or trait affective states on WM processing (for reviews, see: depression, Baddeley, 2013; mood, Mitchell \& Phillips, 2007; anxiety, Moran, 2016). Other theories have offered frameworks about the impact of affective information within other domains of cognition including attention (Mather \& Sutherland, 2011; Vuilleumier, 2005; Vuilleumier \& Huang, 2009; Wells \& Matthews, 2015) and memory (Hamann, 2001; Phelps, 2004, 2006; Talmi, 2013) and some of these theories make specific predictions regarding WM (e.g., Mather \& Sutherland, 2011). Common to these diverse models is the proposal that affective properties of encountered information modulate the strength of its resultant cognitive and neural representations. This can then facilitate or impair goal-directed behavior, depending on whether the affective information is relevant to the goal at-hand or to an alternative competing goal, respectively. A theoretical framework that enshrines this common component across models is Pessoa's dual competition framework (DCF; Pessoa, 2009). Specifically, the DCF proposes that affective properties of encountered information can compete for processing resources within the cognitive system either at the level of perceptual processing or at the level of executive control. Thus, at any one time, cognitive resources devoted to the processing of affective properties become temporarily unavailable to all other goal-relevant properties, thereby interfering with goal-directed behavior that depends on these other properties.

\section{Investigating the Impact of Affective Properties on WM in the Laboratory and the Brain Scanner}

How can we evaluate with some precision the impact of affective context on WM? Prototypically, the impact of affective properties on WM is tested by populating standard experimental tasks, administered in the laboratory, with affective stimuli. One way to do this is to solicit and use personally relevant affective information from participants. However, this tends to introduce sources of variance across participants regarding stimulus attributes that are unrelated to their affective properties (e.g., word length). Researchers therefore more commonly opt for "standardized" affective stimuli that pertain to prototypical affective goals presumed to be more or less relevant to all participants (e.g., survival motives). These can include words (Bradley \& Lang, 1999), faces (Tottenham et al., 2009), and other affective images (Lang, Bradley, \& Cuthbert, 2008). However, the potential downside of using such standardized stimuli is that their affective significance-their positive or negative value to a healthy research participant-will usually be relatively low (Pessoa, 2009). That is, while these generic stimuli are still likely to receive some preferential processing within the cognitive system, their modulating effect on current task performance is proposed to be limited - they are given what the DCF calls soft prioritization (Pessoa, 2009). At the behavioral level this relatively weak impact on prioritization is likely to be both difficult to detect and replicate, as well as being subject to strong influences from study-specific factors such as WM load. To translate this to our aforementioned real-world example of preparing dinner, imagine seeing news footage about a building on fire instead of hearing an alarm go off in your building. The footage may mildly interfere with the updating of the individual cooking steps in WM (e.g., forgetting to add salt), but is unlikely to have a fundamental effect on the priority of your goal to prepare dinner.

At the neural level, however, the effects of soft prioritization of standardized affective information should be easier to assess because the neural impact of the processing of affective information will be detectable even in situations where there has been no marked effect on overt behavior. Affective compared with neutral stimuli are proposed to have stronger perceptual representations in the brain's visual cortices (Vuilleumier, 2005) and other sensory cortices for nonvisual stimuli (Satpute et al., 2015). This increased strength of representation is in part proposed to be a function of amygdalergic projections to cortical sensory areas (Amaral, Behniea, \& Kelly, 2003; Sah, Faber, Lopez De Armentia, \& Power, 2003) and has the potential to modulate executive competition by prioritizing attention toward affective compared with neutral stimuli. A second neural route through which executive competition can be impacted as a function of a stimulus' affective significance is through the direct processing of affective information in the fronto-parietal control network (Okon-Singer et al., 2015; Pessoa, 2009). This would mean that executive resources are occupied by the processing of the affective information and thus no longer available for executive control- (here, WM-) demanding activities (Eysenck, Derakshan, Santos, \& Calvo, 2007). Specifically, processing of affective information includes a wide range of potential processes including but not limited to valuation/appraisal of affective material with neural substrates distributed across the prefrontal cortex including a hub in the orbitofrontal cortex (Dixon, Thiruchselvam, Todd, \& Christoff, 2017), and affect regulation involving multiple regions in the fronto-parietal control network including the lateral as well as the medial prefrontal and parietal cortices (Buhle et al., 2014; Etkin, Büchel, \& Gross, 2015). Moreover, affective distractors and targets are likely to engage both overlapping and separate components of the frontoparietal control network (Dolcos, Katsumi, Denkova, \& Dolcos, 2017). In sum, then, perceptual competition from affective (relative to neutral) material during the performance of a WM task should be associated with increased neural activation within the visual cortex (for affective visual stimuli) as well as within the brain's "salience network" (Seeley et al., 2007; cf. ventral attention; Corbetta \& Shulman, 2002), including the amygdala (Barrett \& Satpute, 2013). Executive competition should also be reflected in augmented activation of the salience network and additionally with enhanced recruitment of the fronto-parietal control network (Pessoa, 2008, 2009).

This analysis suggests then that the behavioral and neural effects of affective stimuli on WM may be "dissociable." It is hypothesized that there will small behavioral effects, because the stimuli prototypically used in the laboratory ultimately have low affective significance and only attract soft prioritization, allied to clear neural effects representing the analysis of the stimuli's affective 
significant in preparation for any prioritization in the domain of behavior. A growing body of literature suggests that the impact of affective material on WM performance vary depending on the stimuli's task-relevance (i.e., opposing effects of task-relevant material vs. task-irrelevant distractors) and in some cases the stimuli's affective valence (Dolcos et al., 2017; Okon-Singer et al., 2015; Pessoa, 2009).

\section{Task-Relevance}

Preferential allocation of perceptual and executive processing resources to task-relevant affective stimuli is proposed to improve behavioral performance on the task at hand. ${ }^{2}$ This affective enhancement effect is well-established in the long-term memory literature (for reviews of laboratory and neuroimaging studies, see Buchanan \& Adolphs, 2002; Hamann, 2001; LaBar \& Cabeza, 2006; Phelps, 2004) with individuals remembering affective information and events better compared with neutral information. Similarly, research on "emotional attention" shows reliable affective processing biases with individuals being faster to detect affective information in visual searches (Vuilleumier \& Huang, 2009). Evidence from behavioral research on WM in healthy individuals appears more mixed with some studies showing an enhancement of WM for affective compared with neutral information (e.g., Xie et al., 2017), others showing no effect (e.g., Grissmann, Faller, Scharinger, Spüler, \& Gerjets, 2017; M. Li et al., 2018; Nejati, Salehinejad, \& Sabayee, 2018), WM impairment (e.g., Garrison \& Schmeichel, 2018; Hur, Iordan, Dolcos, \& Berenbaum, 2017; Tamm, Kreegipuu, Harro, \& Cowan, 2017; Yoon, Kutz, LeMoult, \& Joormann, 2017), or complex interactions with task-design features (e.g., trial type; Levens, Armstrong, Orejuela-Dávila, \& Alverio, 2017; Quinlan, Yue, \& Cohen, 2017). Meta-analytic synthesis of the relevant evidence is therefore required to elucidate the potential impact(s) of affective memoranda on WM.

Greater perceptual- and executive-level prioritization of taskirrelevant (henceforth, distractors) affective, relative to neutral, stimuli is hypothesized to impair behavioral WM performance (e.g., Derakshan \& Eysenck, 2009; Okon-Singer et al., 2015; Pessoa, 2009). This is in line with evidence from tasks assessing executive control in processes other than WM (e.g., dichotic listening tasks, modified Stroop tasks or spatial attention tasks; Schupp, Flaisch, Stockburger, \& Junghöfer, 2006; Yiend, 2010). The literature on the impact of affective distractors on WM performance again is mixed, showing no effect (Jenness et al., 2018) or impaired behavioral (Ladouceur, Schlund, \& Segreti, 2018; Stout, Shackman, Pedersen, Miskovich, \& Larson, 2017; Tollenaar, Ruissen, Elzinga, \& de Bruijn, 2017; Wingert, Blais, Ball, \& Brewer, 2018) performance.

At the neural level, the inferior PFC is considered critical to selecting task-relevant targets and inhibiting responses and attention to task-irrelevant distractors (Aron, Robbins, \& Poldrack, 2004; Miller \& Cohen, 2001). However, recent reviews of the literature on the neural substrates of affect-cognition interactions suggest that the inhibition of attention and responses to, as well as the regulation of, affective distractors may recruit a wider network in the ventral stream of the fronto-parietal control network (Iordan \& Dolcos, 2017; Okon-Singer et al., 2015), this includes the inferior PFC but is not limited to it. WM tasks performed in the presence of affective distractors have similarly shown greater recruitment of the ventral PFC (e.g., Dolcos \& McCarthy, 2006), though some studies have also shown the involvement of more dorsal and medial parts of the frontoparietal control network (García-Pacios, Garcés, Del Río, \& Maestú, 2015, 2017). The current neuroimaging meta-analysis allows us to investigate the relative contributions of these different brain regions to the interference from affective compared with neutral distractors.

\section{Valence}

The vast majority of the experimental literature on WM in affective contexts, to-date, focuses on the impact of negatively valenced information (usually threat-related). However, comparable theoretical arguments to those articulated above can be made for the effects of positive stimuli, neutral stimuli with high-arousal associations (Mourão-Miranda et al., 2003), and novel stimuli. Except in some circumstances (e.g., erotic stimuli, see below) the positive stimuli prototypically used in laboratory studies are considered very low in affective significance (Pereira et al., 2006; Pessoa, 2009) and are thus unlikely to elicit robust behavioral effects let alone reprioritize current goals. Studies on the temporal course of peripheral physiological responses to affective information in laboratory contexts support this notion with responses to negative material being faster (N. K. Smith, Cacioppo, Larsen, \& Chartrand, 2003) ${ }^{3}$ and more protracted than for positive stimuli (Brosschot \& Thayer, 2003; Taylor, 1991). Similarly, while both pleasant and unpleasant stimuli engage overlapping parts of the brain's salience network, neural responses are nevertheless less reliable for pleasant than unpleasant stimuli in the amygdala and insula (Lindquist, Satpute, Wager, Weber, \& Barrett, 2016). Evidence from WM appears to show a comparable pattern, with positive stimuli having a lower impact on performance compared with negative stimuli, though the effect of valence may be stronger for WM reaction time (RT) data compared with accuracy data (e.g., Colligan \& Koven, 2015). Furthermore, there may be developmental differences with performance being more affected by rewarding stimuli in adolescence (Cromheeke \& Mueller, 2016). The reviewed work then suggests that the impact of affective material as evaluated in laboratory WM tasks will be greater for negative compared with positive material.

\section{The Impact of Affective Information on WM Beyond Young Psychologically Healthy Adults}

Theoretically, stimuli high in affective significance are proposed to have pronounced effects on behavioral performance through the recruitment of common executive control resources in the service of processing these affectively laden stimuli-consider our realworld fire alarm example. Pessoa (2009) terms this hard prioriti-

\footnotetext{
${ }^{2}$ It should be noted that the arousal-biased competition model (Mather \& Sutherland, 2011), qualifies as an exception to this enhancement. This theory suggests that WM performance for multiple task-relevant items will be impaired for affective compared with neutral targets. The rationale is that, while maintaining affective stimuli in WM, the prioritized attentiona processing afforded to the active affective item increases the costs for the competing stimuli more than for less arousing neutral items.

${ }^{3}$ However, see Brosch, Sander, Pourtois, and Scherer (2008) for highly similar patterns of attentional capture for both negative and positive pictures.
} 
zation. Such hard prioritization is difficult to investigate in the laboratory with psychologically healthy individuals as the standardized stimuli used in such studies, as discussed above, are low in affective significance. Indeed, to our knowledge, no study has systematically modulated stimuli's affective significance to investigate the nature of the relationship between affective significance and WM performance.

However, one way that prioritization can be investigated experimentally is to work with populations - such as samples characterized by mental health difficulties - for whom standardized stimuli are evaluated as relatively high in affective significance. Affective information, it is proposed, gains harder prioritization in individuals suffering from mental health problems because it is critical to the individual's perpetually activated affect-related concerns. That is, many mental health difficulties (including mood and anxiety disorders, schizophrenia, and attention deficit and hyperactivity disorder; Aleman \& Kahn, 2005; Bar-Haim, Lamy, Pergamin, Bakermans-Kranenburg, \& van IJzendoorn, 2007; Cubillo, Halari, Smith, Taylor, \& Rubia, 2012; Gotlib \& Joormann, 2010; Mathews \& MacLeod, 2005) are associated with: preferential processing of affective, particularly negative, information; slowed disengagement from affective information (e.g., depression; Koster, De Lissnyder, Derakshan, \& De Raedt, 2011); and maladaptive regulation of affective material (Aldao, Nolen-Hoeksema, \& Schweizer, 2010). The impact of affective material on WM then is likely to be increased in individuals suffering from mental health problems compared with healthy controls. This is also likely to be the case for affectively positive stimuli. For example, individuals with eating-related mental health (Wagner et al., 2015) and physiological weight-related problems (Boutelle et al., 2014) show increased activation of the amygdala in response to standardized food-related stimuli compared with healthy individuals.

Related to this, another possible moderator of perceived affective significance is age. There is a wealth of evidence that for older adults positive stimuli may carry greater affective significance due to the age-related positivity effect-the finding that in older-age individuals preferentially process positive information across a range of cognitive domains and stimulus types (Carstensen, 2006; Mather \& Carstensen, 2005). Comparing WM performance for affective information across age then may reveal dissociable effects for positive and negative stimuli.

To summarize, broadly speaking the effects of affective material on WM processing are hypothesized to vary as a function of the material's affective significance, valence, and task-relevance. Furthermore, the behavioral and neural levels of analysis are predicted to show dissociable effects for prototypical studies involving standardized stimuli with low-affective significance administered to unselected or psychologically healthy populations. In the sections that follow, we outline specific hypotheses within each of these sets of circumstances before reviewing the relevant data.

\section{The Present Reviews}

The primary aim of the current reviews was to evaluate both the behavioral impact of affective information on WM performance and the neural substrates of those putative effects, through a pair of meta-analyses of the extant literatures. To this end we reviewed behavioral and functional MRI (fMRI) studies published up until
February 28, 2017, that investigated the effect of affective material on WM functioning.

Guided by the definition of WM as comprising one or more storage components alongside an executive control component, the present meta-analytic work included studies employing three types of tasks as measures of WM (see Figure 1 for task schematics): (a) tasks that require continuous updating of WM content through the sequential presentation of memoranda-these include simple span tasks and $n$-back tasks (Figure 1A; Cohen et al., 1997; Owen et al., 2005); (b) delayed-match-to-sample tasks (Figure 1B) that require the recall of memoranda following a delay interval during which participants are either presented with distractors or some other form of secondary task-demand ${ }^{4}$ (Courtney, Petit, Maisog, Ungerleider, \& Haxby, 1998; Jiang, Haxby, Martin, Ungerleider, \& Parasuraman, 2000; Sawaguchi \& Goldman-Rakic, 1991); and (c) complex span tasks (Figure 1C) which comprise an operation task (e.g., solving a mathematical problem) and a storage task (e.g., remembering words; Conway et al., 2005). For a given study to be included in our analyses these tasks needed to present affective stimuli as either task-relevant memoranda (targets) or taskirrelevant distractors.

\section{Behavioral Meta-Analysis}

In line with the previous theoretical discussion, the behavioral meta-analysis examined the following hypotheses:

Hypothesis A: In the context of a proposed dissociation between behavioral and neural levels of analysis in psychologically healthy individuals (or unselected), for the behavioral meta-analysis we predicted at most small effects of affective, relative to neutral, material on WM performance due to affective stimuli' low affective significance and the predicted moderating and interacting effects of valence (A1) and task relevance (A2). Specifically, we hypothesized that:

Hypothesis A1: Positive stimuli have a smaller effect on WM performance compared with negative stimuli, and;

Hypothesis A2: Affective distractors and targets have opposing effects on WM performance, with affective distractors impairing WM performance relative to neutral distractors and affective targets enhancing WM performance relative to neutral targets.

Hypothesis B1: Affective stimuli have a greater impact on behavioral WM performance in individuals with mental health problems for whom it is proposed they have greater affective significance compared with healthy individuals.

Hypothesis B2: The impact of positive, but not negative, stimuli, relative to neutral stimuli, on WM performance increases as a function of age in line with the age-related positivity bias.

\footnotetext{
${ }^{4}$ Studies that simply presented a delay interval without distractors or a secondary task were not included as we consider them to be better conceptualized as perceptual, short-term or long-term memory tasks depending on the delay interval.
} 

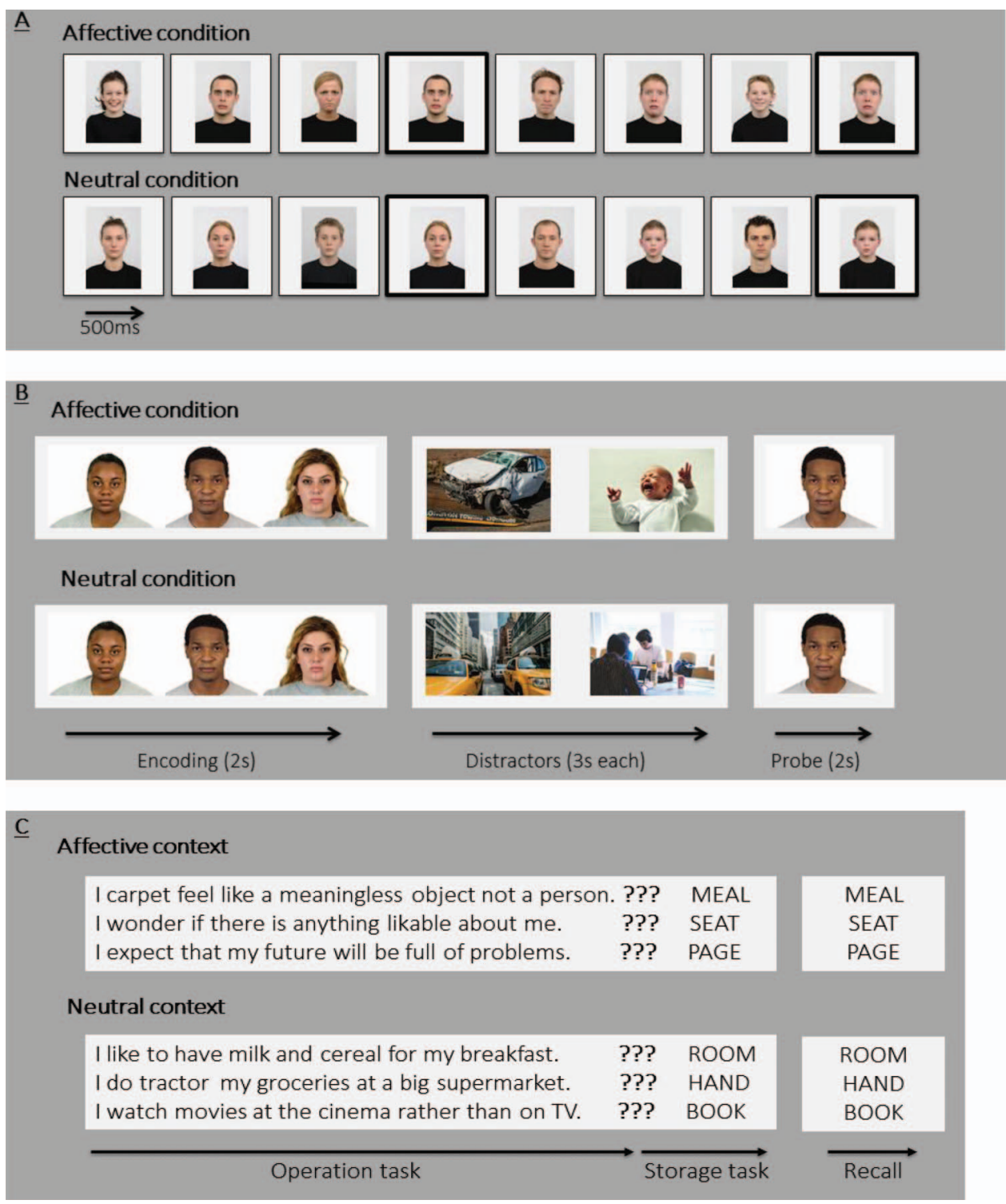

Figure 1. Schematics of three prototypical WM tasks, presented in affective and neutral contexts. The figure depicts three prototypical WM tasks capturing the range of paradigms included in the present meta-analyses. 1A shows an $n$-back task (where in this case $n=2$ ) that requires participants to continuously update the content of their active WM representations. In the figure, trials with a bold black border indicate target trials. In the affective context the images that have to be matched across trials are negative in valence and in the neutral context the target stimuli are neutral. 1B depicts an example of a delayed-match-tosample task. In this task, participants are required to match the emotional expression of a probe face with the expression in one of three presented memoranda. During the retention interval participants see either two negative distractor images (affective context) or two valence-neutral images (neutral context). 1C provides an illustration of a complex span task, which comprises an operation component and a storage component. The example depicts an affective reading span task where participants make judgments about the semantic accuracy of self-statements. In the affective context the first sentence requires a "no" response as it is semantically meaningless, while the other sentences are semantically correct. In the neutral context the second sentence is incorrect and the others are semantically meaningful. For the storage component participants have to recall the words in upper case that are presented at the end of each sentence. The recall happens at the end of each block, with block lengths typically varying between three and seven trials. See the online article for the color version of this figure. 


\section{Methods for the Behavioral Meta-Analysis}

\section{Identification of Studies for Inclusion ${ }^{5}$}

The literature search was conducted in accordance with the Preferred Reporting Items for Systematic Reviews and MetaAnalyses (PRISMA; Moher, Liberati, Tetzlaff, \& Altman, 2009) guidelines (for the PRISMA Checklist, see online supplementary materials). There was no review protocol. All searches were executed in the databases PubMed and PsycINFO with the following search parameter delimitations-publication language: English, human participants, publication date: 01.01.1900 (default in PubMed)-28.02.2017 (for the electronic search strategy please see the online supplementary materials). The search term combinations entered were: Combination $\mathrm{I}^{6}=$ "emotion" $\mathrm{OR}$ affective AND executive* function*; Combination II = "emoti* OR affective AND cogniti* function""; Combination III = "emoti* OR affective AND working memory"; Combination IV = "emoti" OR affective AND n-back"; and Combination V = "emoti* OR affective AND delayed-match-to-sample." In addition to the articles yielded by the database search we also checked the reference lists of those articles.

\section{Screening}

After removing all duplicates, review articles, and theoretical papers, articles generated in the identification stage were screened. Inclusion criteria in the screening phase were: Article titles needed to refer to two separate components: (a) the word "emotional" (or synonyms thereof) or a "mental health disorder," as well as (b) the word "cognitive" or terms referring to "executive functioning." Abstracts needed to mention the use of one or more memory tasks or refer to executive functioning tasks. This led to a set of full-text articles, which were assessed in the final step.

\section{Eligibility}

Eligibility was assessed by checking the full-text articles for the following components: (a) They needed to report at least one empirical study in humans. (b) The studies also had to report accuracy performance and/or RTs on a measure of WM, which required the recall of affective and neutral task-relevant memoranda in WM, or contained affective and neutral task-irrelevant distractors which had to be ignored. If these data were not reported in the paper authors were contacted with a request for these data (denoted with data request [DR] in Table 1; studies that met all inclusion criteria but for which no data was made available are reported in the relevant online supplementary materials section). Studies that used mood induction or naturally occurring mood states (e.g., mania) as an emotion manipulation were excluded as this was beyond the scope of the present reviews.

To ensure that the search was performed in accordance to the search strategy outlined above $30 \%$ of all hits at the screening stage were checked by $\mathrm{CH}$ and $\mathrm{MB}$ in addition to the first author who completed the search for all entries. Interrater agreement was $89 \%$. All conflicts for this stage were resolved in discussion between the first author and the two additional raters. Finally, all full text studies included in the final stage were checked by the twos additional raters. For this stage there was $100 \%$ independent interrater agreement.

\section{Analytic Approach}

\section{Behavioral analyses.}

Publication bias. The presence of publication biases (Rothstein, Sutton, \& Borenstein, 2005) was tested in two steps. An approximation for multilevel analyses of the standard regression test (Egger, Davey Smith, Schneider, \& Minder, 1997) examined whether the standard errors were significant predictors of the observed effect sizes. Considering that publication bias can vary as a function of study characteristics (Coburn \& Vevea, 2015) and that we investigated several such characteristics as moderators of interest the regression analysis was supplemented with a regression test for multilevel implementation, where study variance is included as a moderator before running the rank correlation test (thereby approximating the Egger test for multilevel data).

Effect sizes. Effect sizes (Cohen's $\hat{d}$ ) were calculated using the escalc function in the metafor (Version 1.9-5; Viechtbauer, 2010) software package in R (Version 2.15.0; R Core Team, 2013) by dividing the mean difference of WM performance/response time in an affective versus neutral context by the unbiased estimates of the sampling variance. Unbiased estimates of the sampling variance are computed by applying a correction to the pooled standard deviation to correct for a slight positive bias within the standard error function (for a detailed discussion of the positive bias see: Hedges, 1982, p. 492; 1989).

Hypothesis testing. To test our hypotheses investigating the effects of affective context on WM performance (accuracy and response time) we conducted a random effects model analysis on the effect sizes of studies that directly compared WM in affective versus neutral contexts. This analysis was based on the premise that differences in methods and samples across the studies included in the meta-analysis would introduce variance (heterogeneity) among the true effects, which could be incorporated into the study weights (Hedges \& Vevea, 1998).

The predicted moderating effects of task-relevance (target vs. distractor) and valence (positive vs. negative) were tested in the sample of healthy participants. Affective significance as a function of study population (healthy individuals vs. individuals suffering from psychopathology ${ }^{7}$ ) was investigated in the total sample. The association of WM and age was investigated with correlation analyses. All hypothesized moderator effects were investigated in a series of planned moderation analyses using multilevel models in which effect size (Level 1) is nested within the study (Level 2) estimated using the rma.mv() function in the metafor package (Version 1.9-5; Viechtbauer, 2010). This approach enabled the models to include multiple effect sizes from the same study.

\footnotetext{
${ }^{5}$ There is no published review protocol for the two meta-analyses reported in this article.

${ }^{6}$ The asterisks in the search term combinations denote so-called wild cards in the database search. That is, every permutation of the term is entered and searched within the database (e.g., emoti* performs searches including emotive, emotion, emotional, etc., ....).

${ }^{7}$ Some studies included neuropsychological populations. Data from these samples were excluded from the moderation analyses, as they were not part of the investigation of interest. The healthy control samples from those studies, however, were included in the moderation analyses.
} 


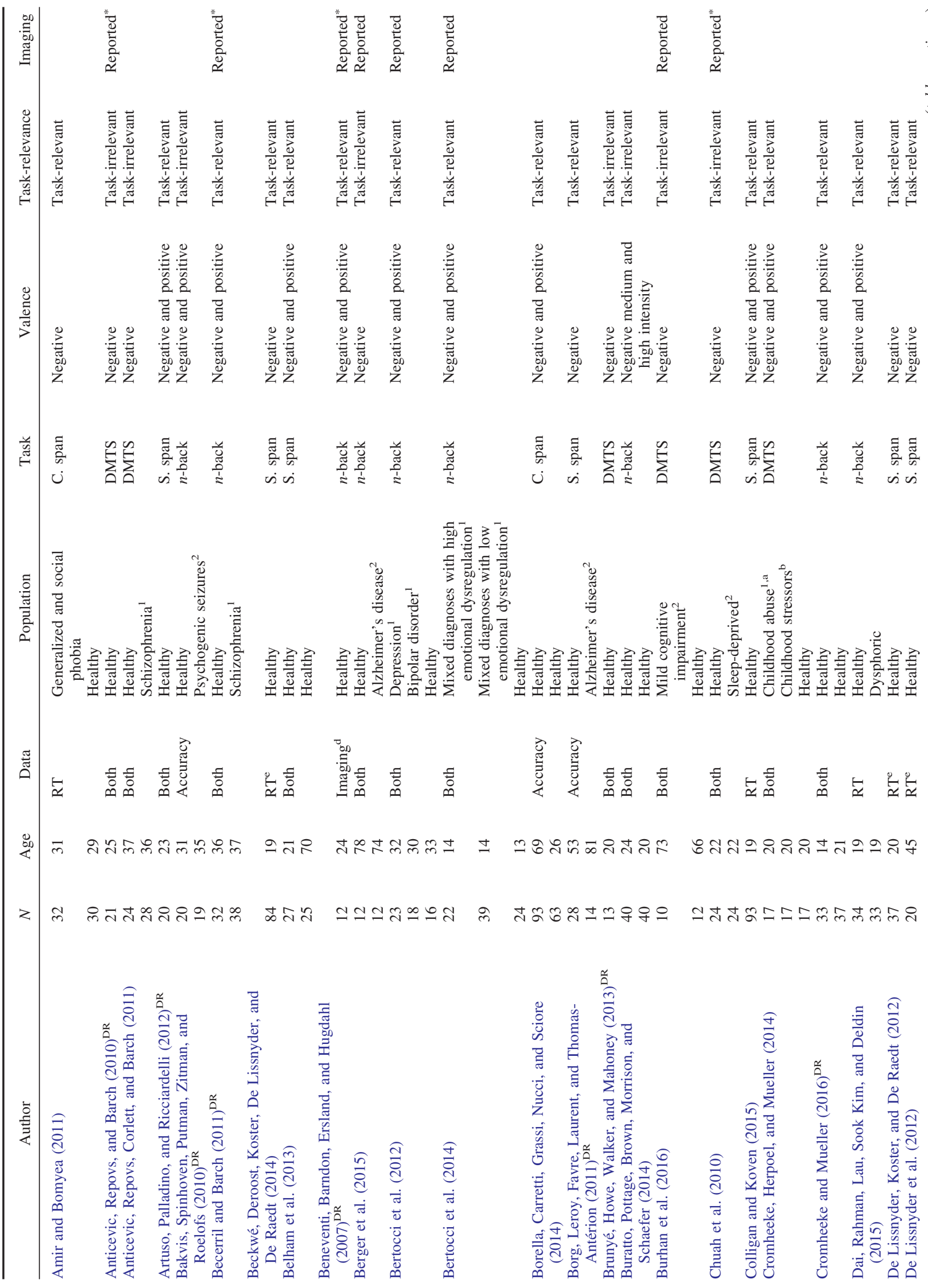




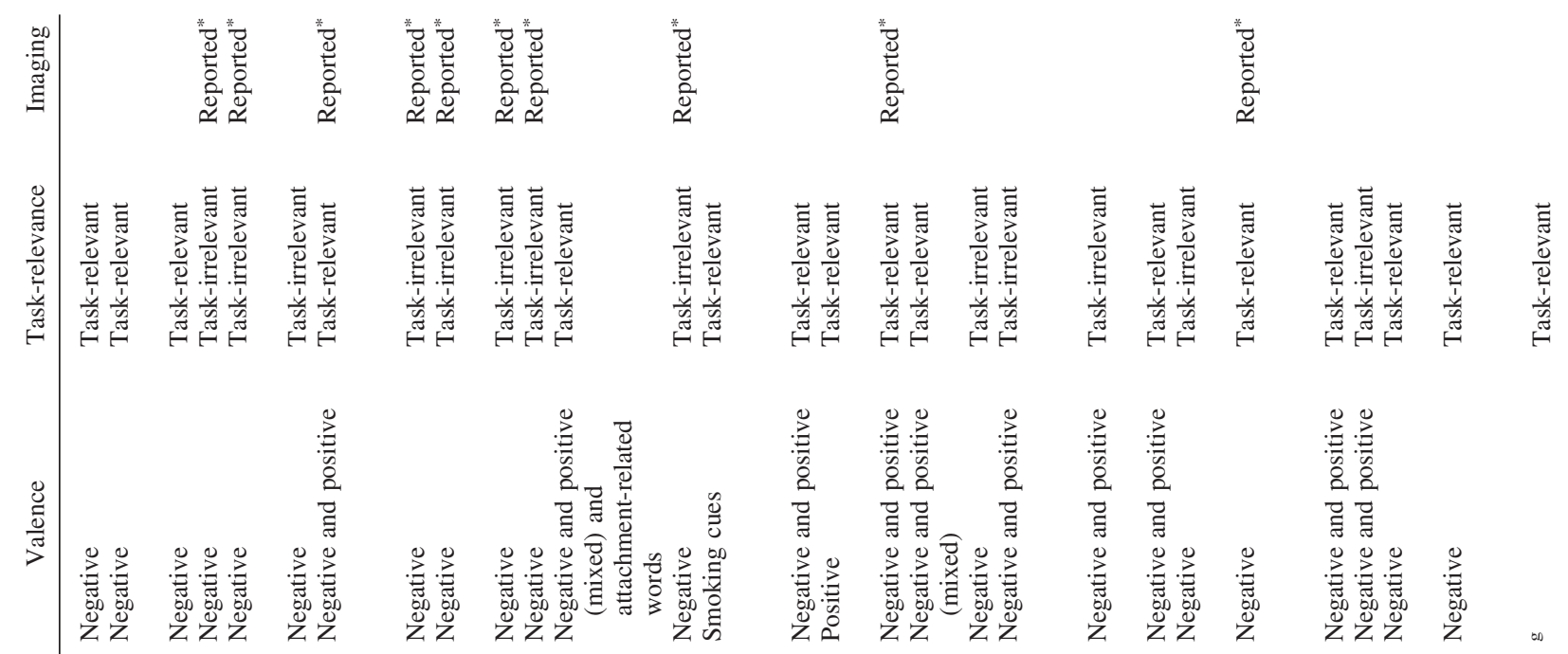

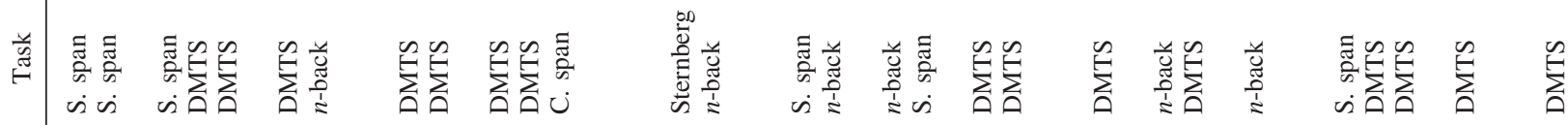

葛

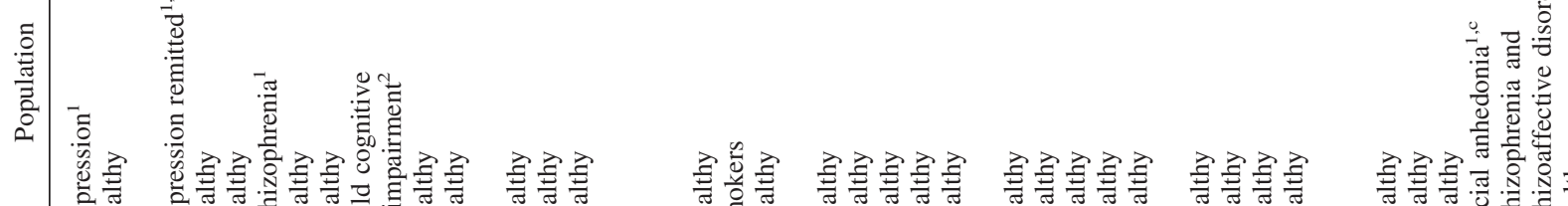

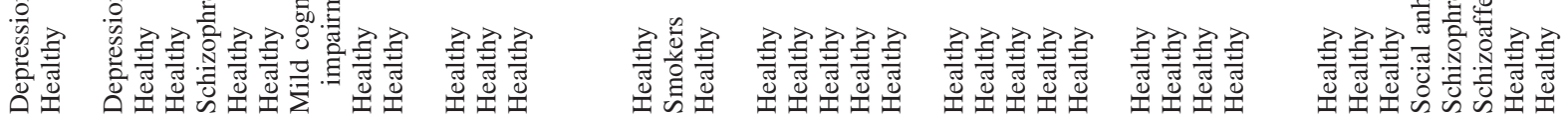

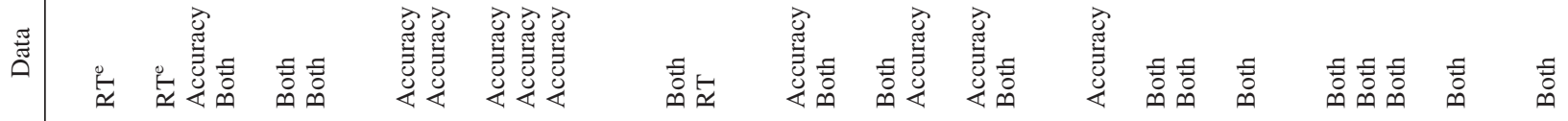

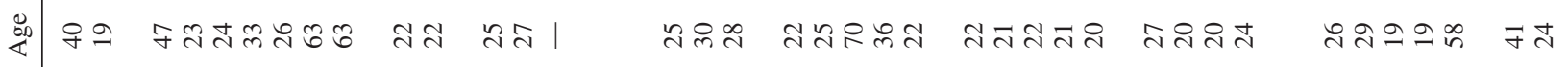

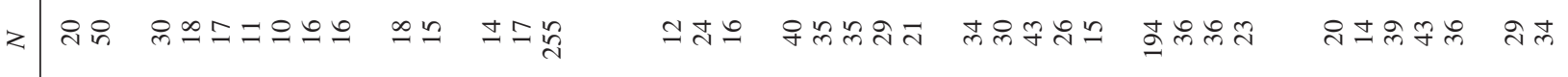

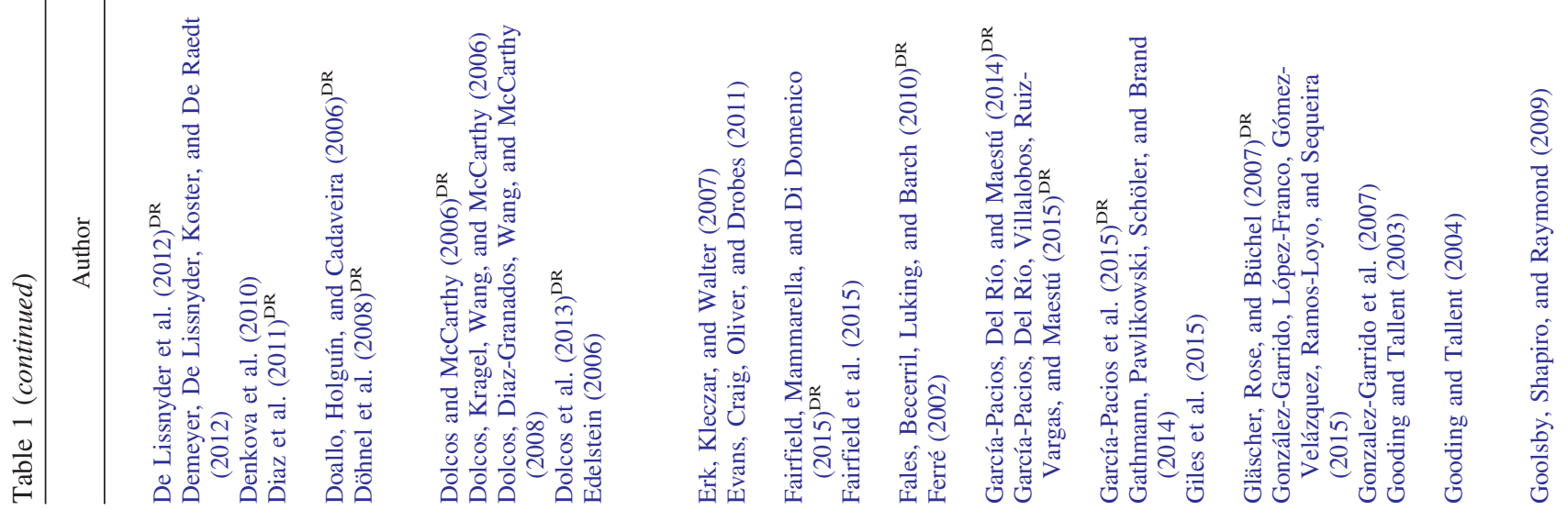




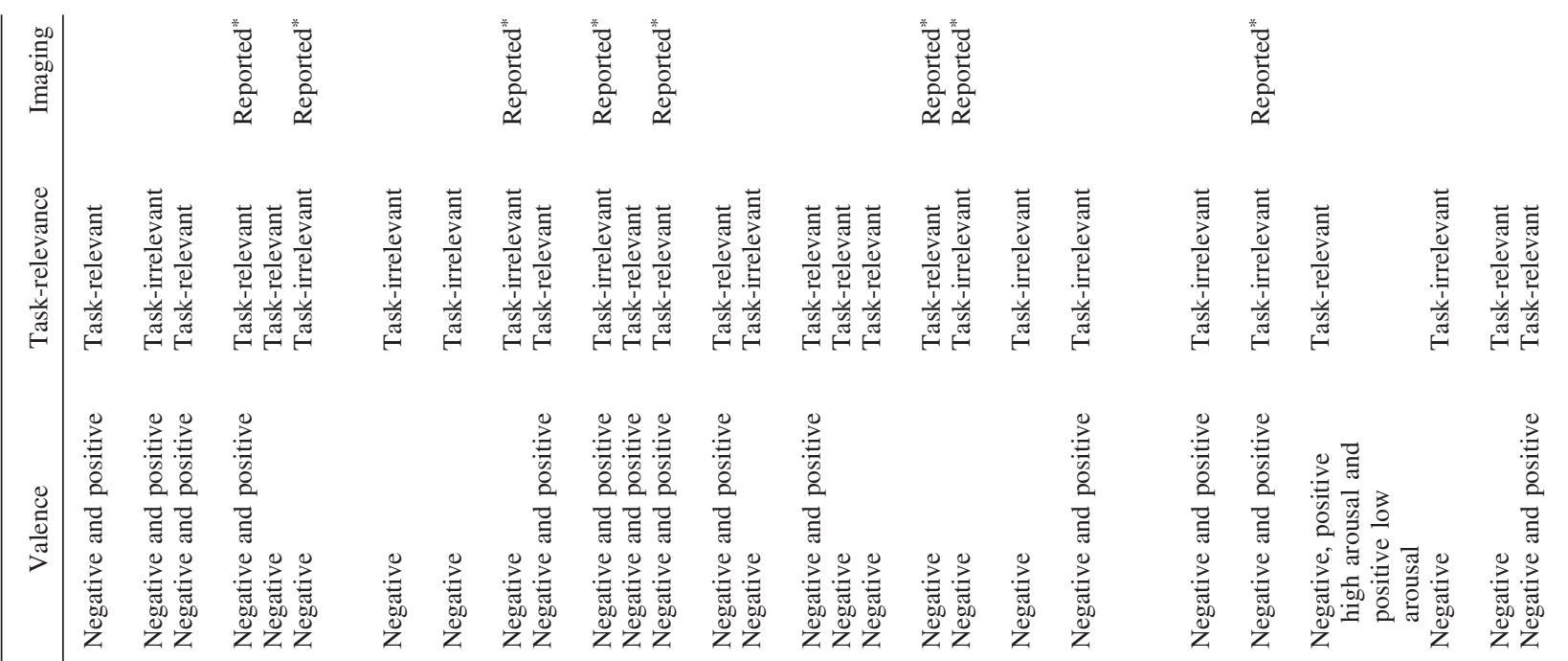

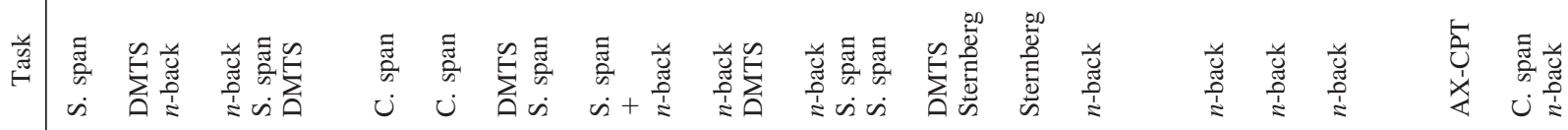

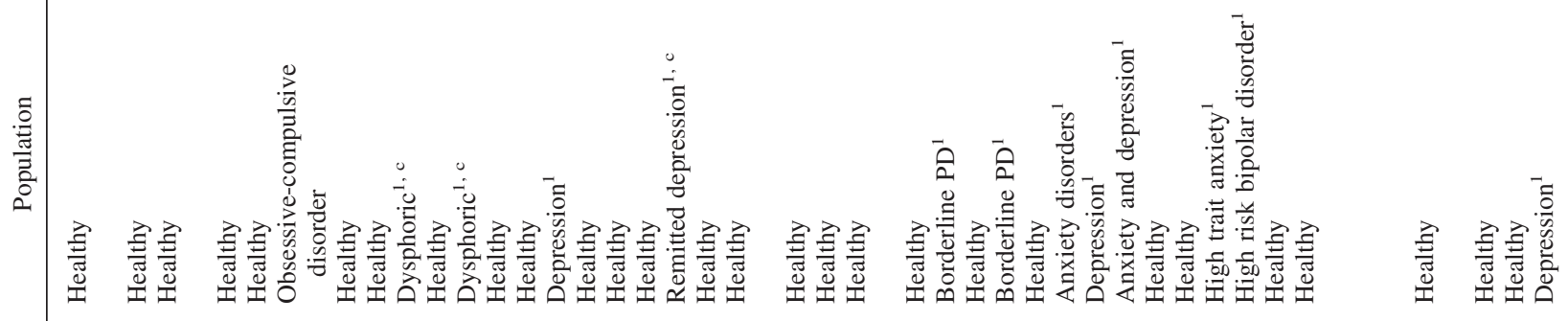

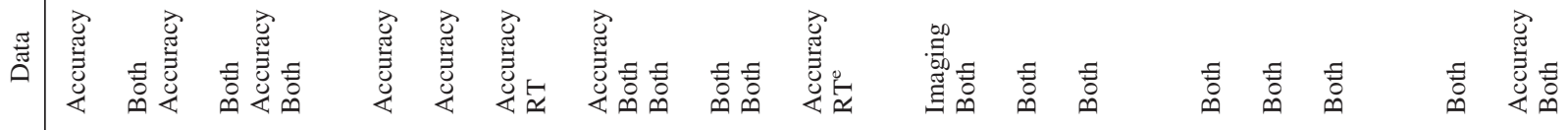

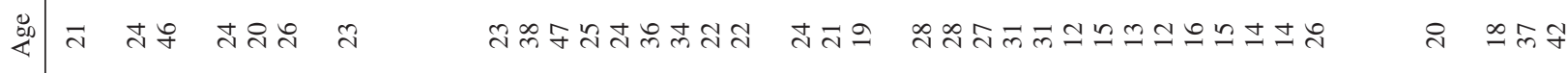

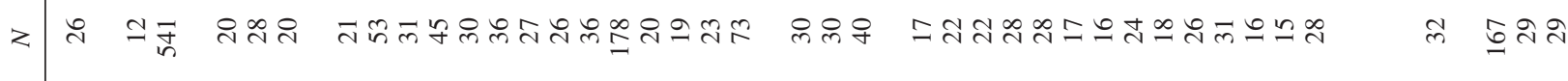

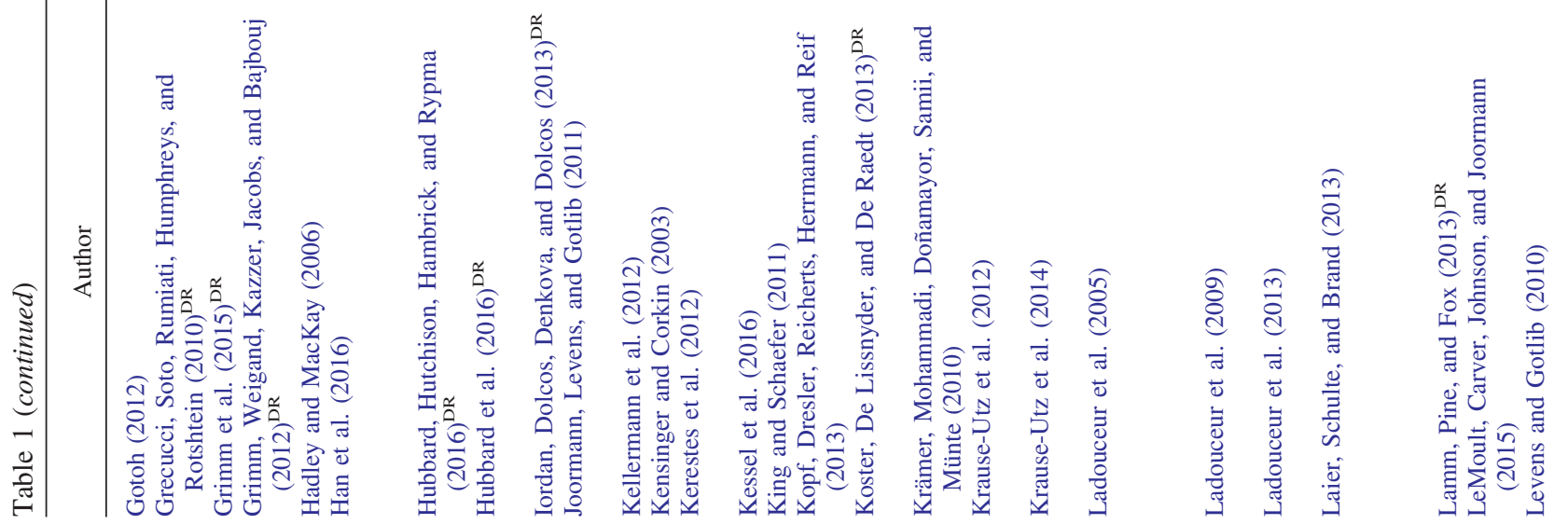




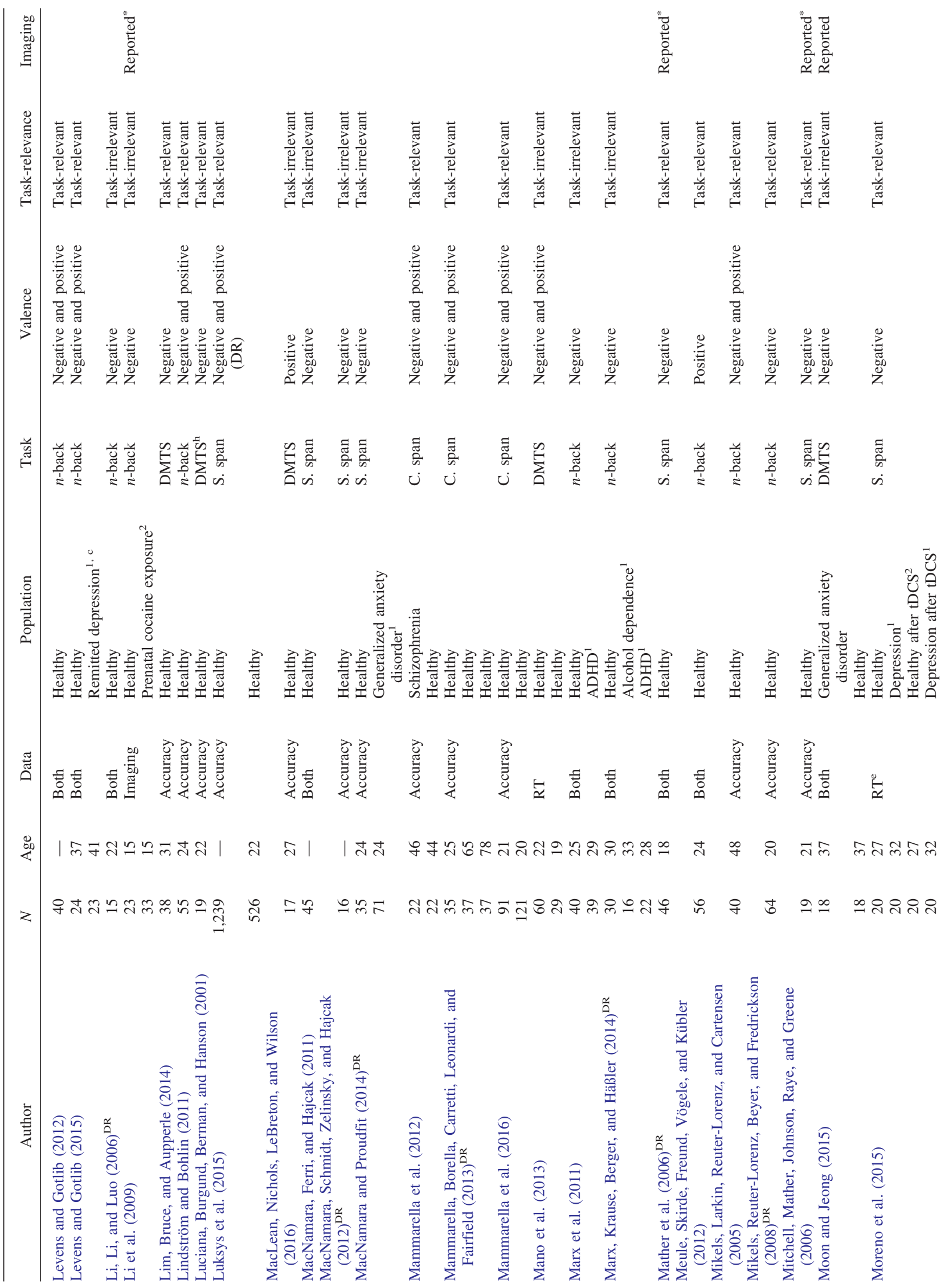




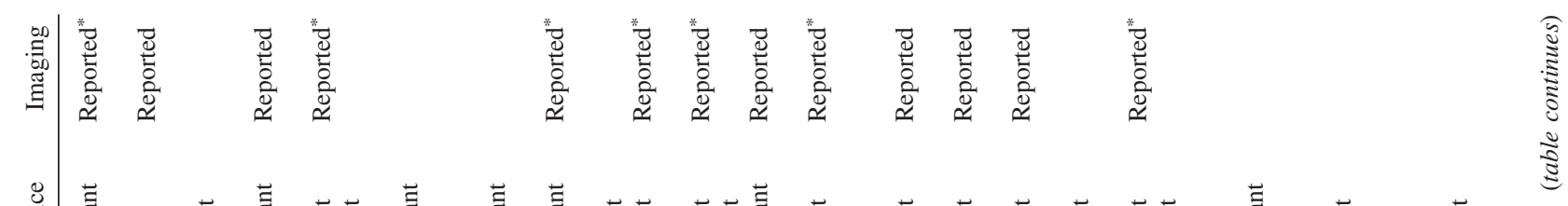

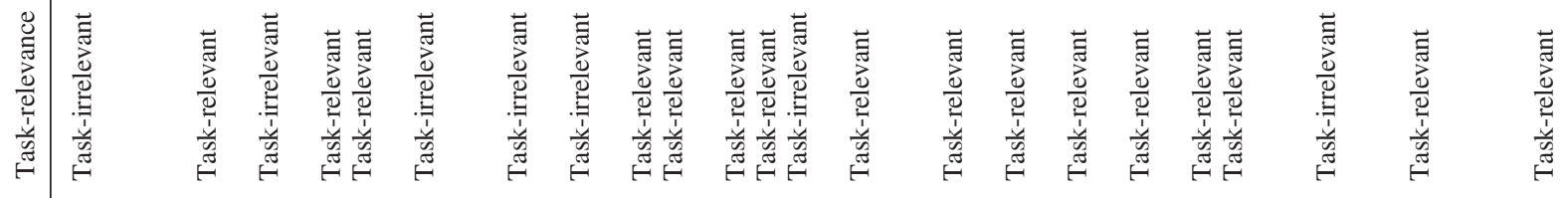

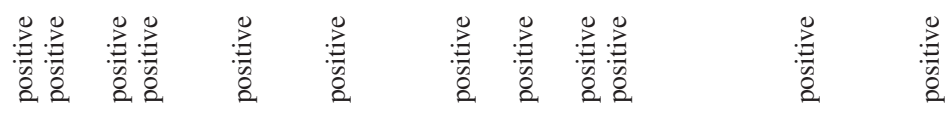

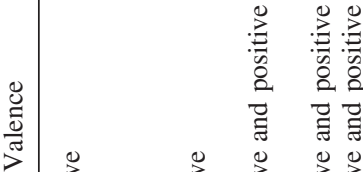

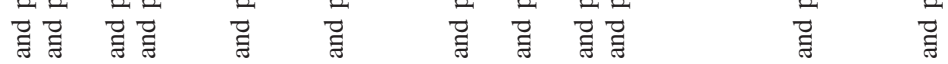

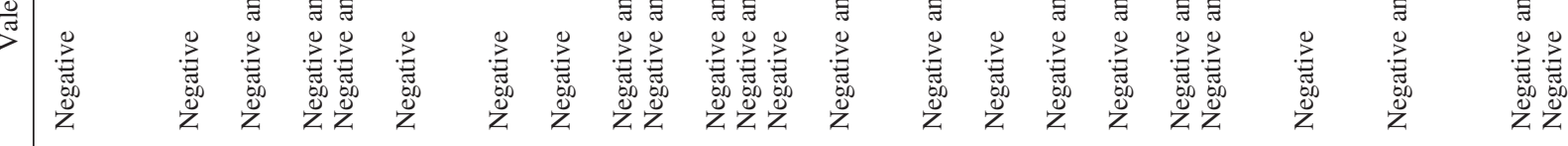

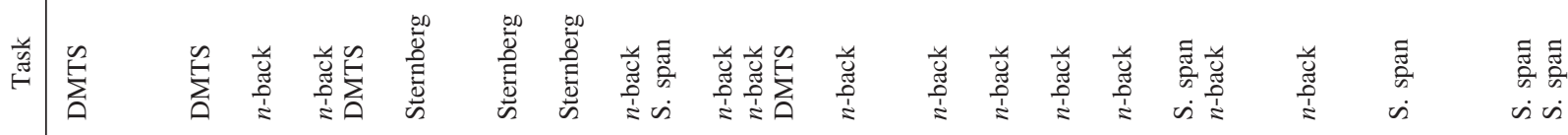

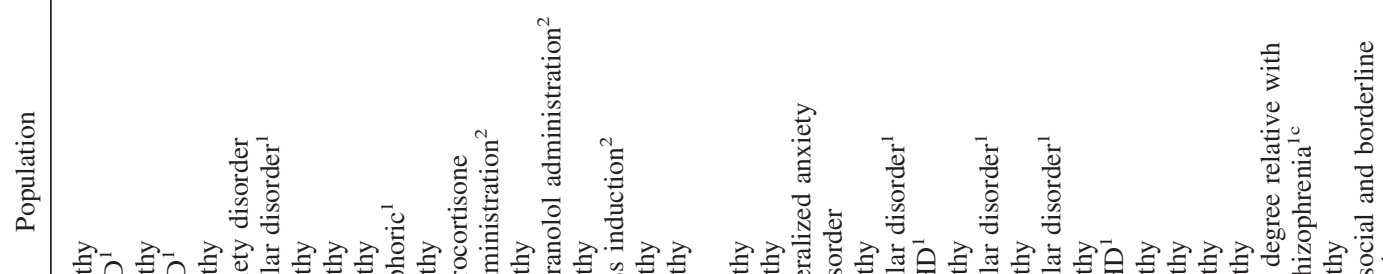

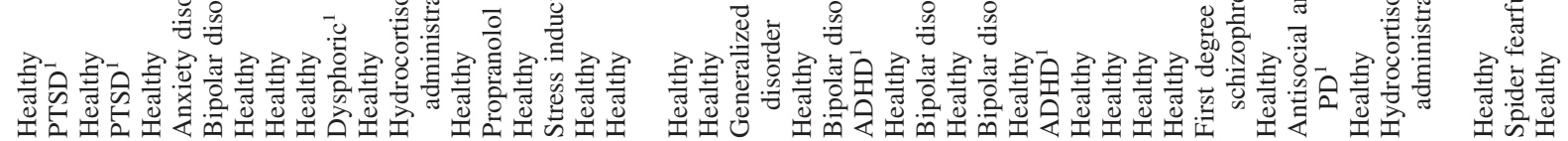

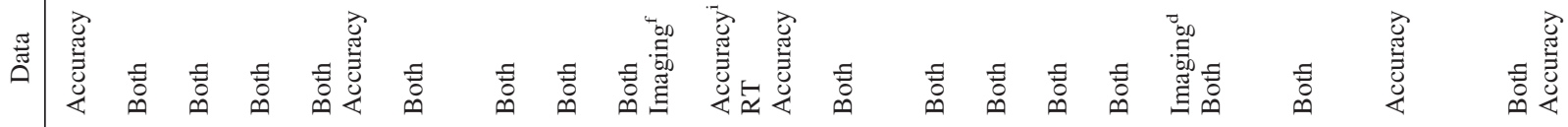

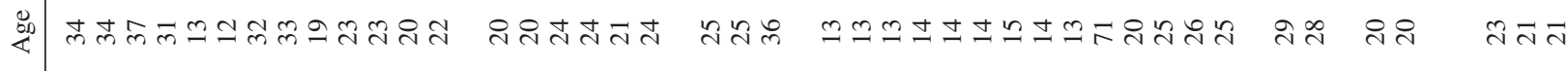

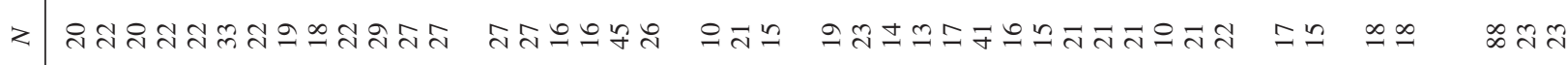

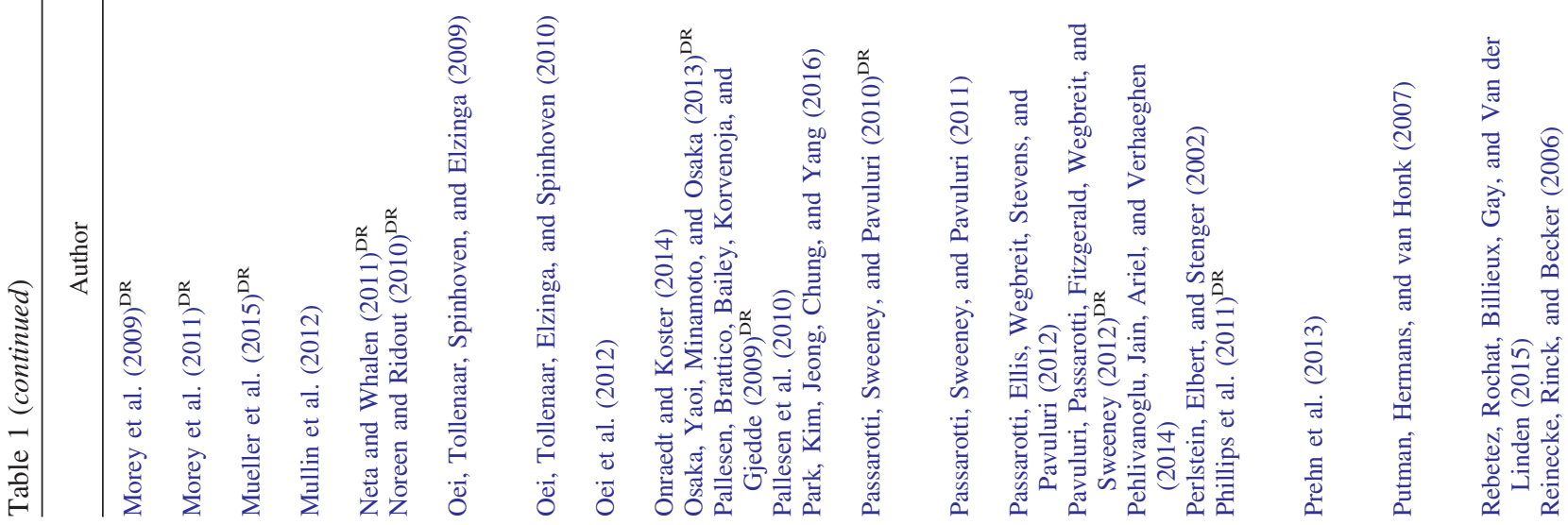




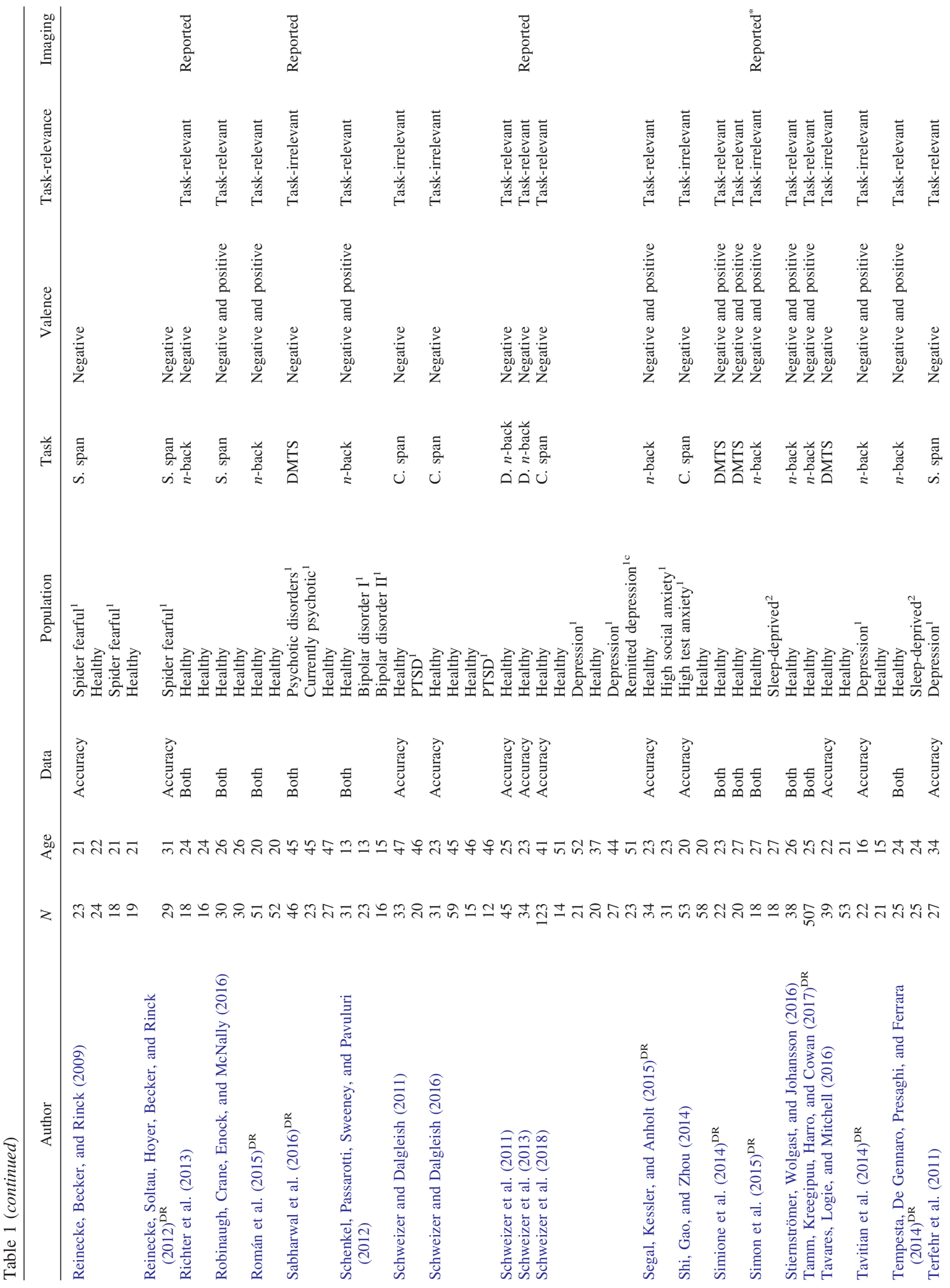




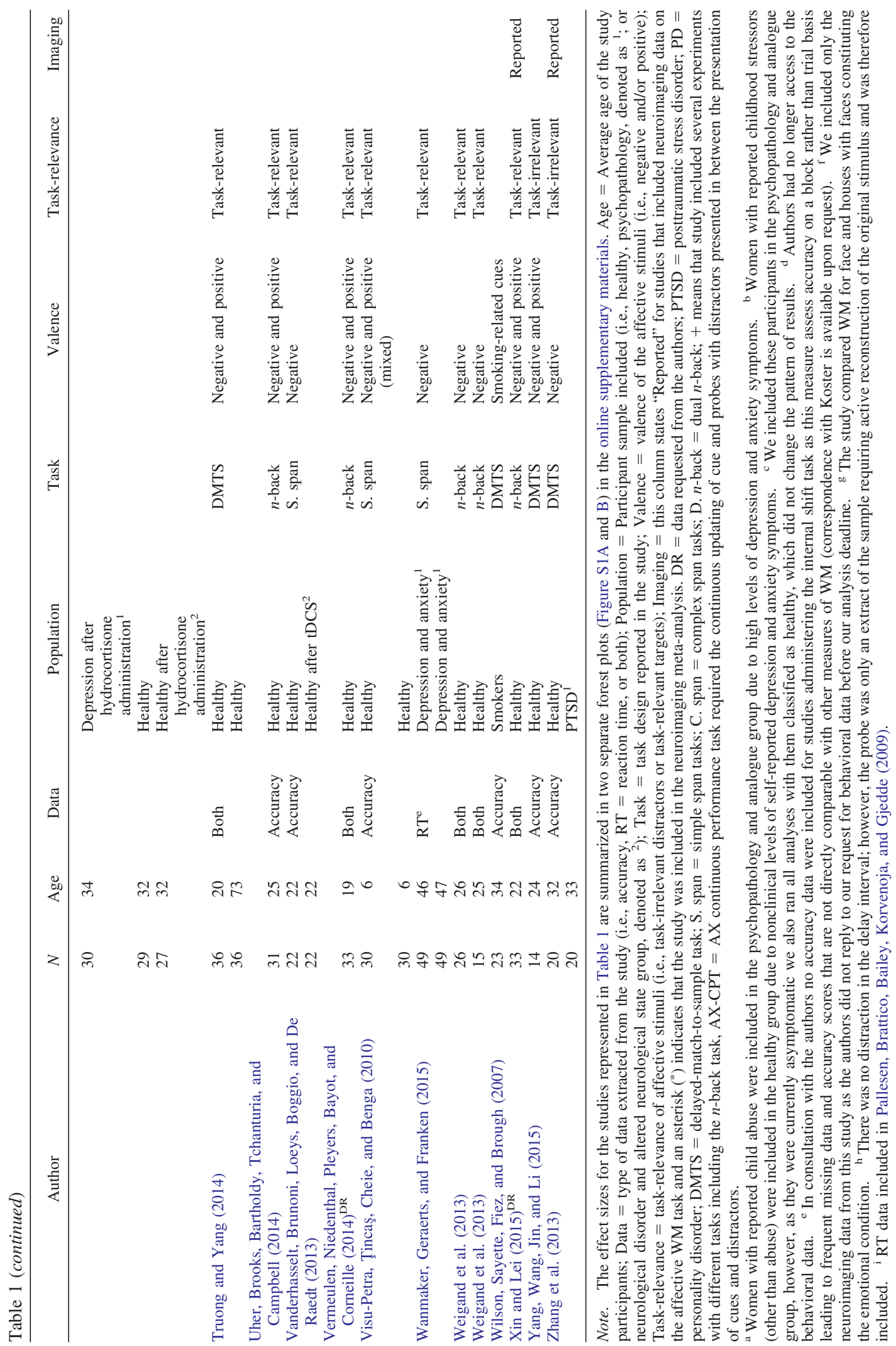


We fitted a random intercepts model, allowing effects sizes to be free to vary across studies. We chose to apply multivariate random- and mixed-effects models, because fixed-effects models have been shown to be too liberal, overestimating true effect sizes (Field, 2003; Hunter \& Schmidt, 2000), whereas random-effects models are thought to provide better estimates of the true effect investigated (Schmidt, Oh, \& Hayes, 2009). It should be noted, however, that random-effects models with relatively small sample sizes provide only approximations of the true effect (Schmidt et al., 2009).

All analyses were performed twice, once with WM accuracy as the outcome measure and once with WM RT.

\section{Results of the Behavioral Meta-Analysis}

Figure 2 provides a schematic overview of the search results for the behavioral meta-analysis (PRISMA flow diagram; Moher et al., 2009). One-hundred and 65 data sets were included in the present meta-analyses. Table 1 provides a list of the included studies together with an overview of their task designs, participant samples, task-relevance and valence of the included affective stimuli, and whether the studies reported functional neuroimaging data.

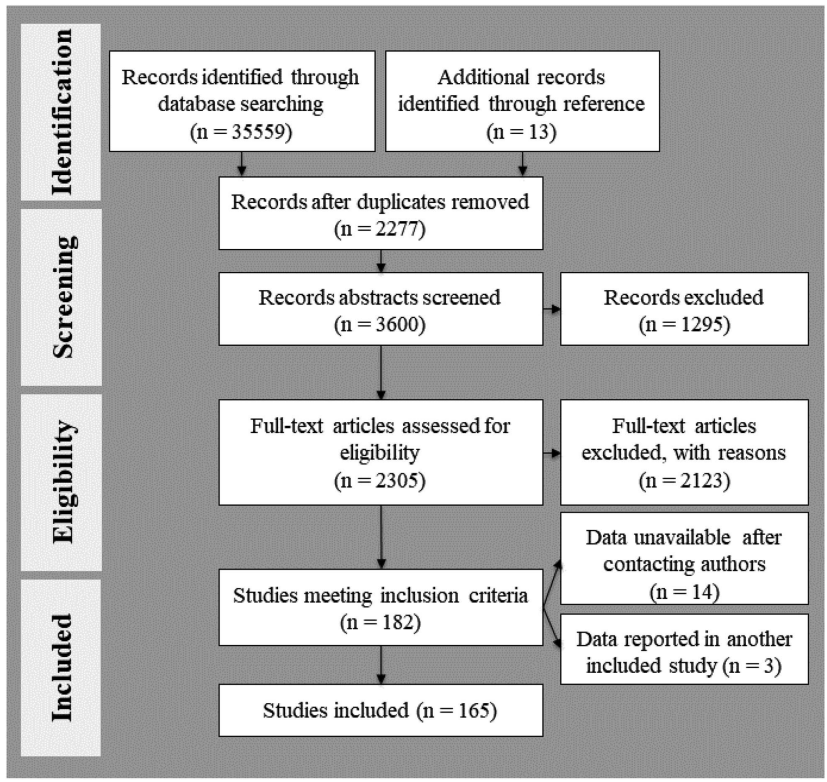

Figure 2. PRISMA flow-diagram for the behavioral meta-analysis. Reasons for exclusion are detailed in the online supplementary materials. For those meeting inclusion, data were unavailable due to departmental, personnel move, or data storage issues (de Almeida et al., 2012; DeYoung, Shamosh, Green, Braver, \& Gray, 2009; Lindström \& Bohlin, 2012; Maat et al., 2014; Mirabolfathi, Moradi, \& Bakhtiari, 2016) and we did not receive replies from the following authors (Chen, Feng, Wang, Su, \& Zhang, 2016; Diwadkar et al., 2012; Fan, Hsu, \& Cheng, 2013; Gotoh, 2008; Liu, Wang, Wang, \& Jiang, 2016; Luo et al., 2014; Mackay et al., 2004; Pecchinenda \& Heil, 2007; Shi, Gao, \& Zhou, 2015). The following publications were included as part of other citations included in the analysis (García-Pacios, Garcés, Del Río, \& Maestú, 2017; Krause-Utz, Elzinga, Oei, Paret et al., 2014; Luksys et al., 2014).

\section{Publication Bias}

The funnel plots (see Figure 3) for accuracy and RT show the distribution of the standardized mean difference (observed outcome) between accuracy and RT for affective compared with neutral WM across the standard error distribution. The regression test of the publication bias was nonsignificant for both accuracy $(z=-1.33, p=.184)$ and RT $(z=-1.64, p=.101)$. The regression test for multilevel implementation was also non-significant for both accuracy (Kendall's $\tau=-0.02, p=$ .523 ) and reaction time (Kendall's $\tau=-0.02, p=.518$ ), which suggests that there was no significant publication bias in the set of studies included in the meta-analytic review.

\section{Overall Effect of Affective Context on WM in Psychologically Healthy Individuals (Hypothesis A)}

Consistent with Hypothesis A, although the multivariate random effects analysis in healthy individuals showed that RTs for affective compared with neutral material in WM were significantly slowed, the effect size was of trivial magnitude $k=317, \hat{d}=0.07,95 \%$ CI [0.03, $.12], S E M=0.02, p=.002$. Furthermore, there was no significant effect of affective information on WM accuracy, $k=391, \hat{d}=0.03$, $95 \%$ CI $[-0.05,0.12], S E M=0.04, p=.438$. In addition to the effect sizes, we report the omnibus $Q$-tests of heterogeneity, because the statistic is less disposed to Type I errors than other tests of heterogeneity (Viechtbauer, 2007). The estimated heterogeneities in the overall effect sizes accounted for by the differential effect of affective compared with neutral material on both WM accuracy, $Q(390)=$ $2609.79, p \leq .0001, \sigma^{2}=0.21$; and RT, $Q(311)=529.19, p \leq .0001$, $\sigma^{2}=0.02$, were significant. That is, for both WM accuracy and RT a significant amount of variance is likely to be accounted for by variations in study-specific factors.

The moderating effects of valence (Hypothesis A1), task-relevance (Hypothesis A2), and mental health status (Hypothesis B1) and age (Hypothesis B2) are tested below. However, given the substantial amount of heterogeneity in the results we additionally explored the potentially moderating effects of emotion-type (fear, anger, sad, happy) and WM task load. Differential influences of emotion-type might partially account for the heterogeneity in the results because threat-related stimuli might be more arousing, and thus impact WM, more compared with sadness-related stimuli (Saxton, Myhre, Siyaguna, \& Rokke, 2018; Vuilleumier, 2002). The rationale for WM load as an additional moderator is that it has been shown to influence attentional control (Lavie, Hirst, de Fockert, \& Viding, 2004). The load theory of selective attention and cognitive control (Lavie et al., 2004) would suggest that the impact of affective relative to neutral material is greatest for lower levels of WM load. The results showed that WM RT, but not WM accuracy, was moderated by emotion type. For RT the moderating effect of emotion type reflected the valence effect (Hypothesis A1) reported below, with RTs being faster in the context of happiness-related versus neutral stimuli, whereas all negative emotions were associated with relatively slower RTs (see SM6 for a full set of statistics and results). For WM load there was no main effect of load on either WM accuracy or RT, $p$ 's > .648. WM load did, however, interact with task-relevance, indicating that WM accuracy (not RT) for task-relevant affective, relative to neutral, targets improved across load, $r(130)=.24,95 \%$ CI $[.07, .39], p=.006$ (see SM6 for a full set of statistics and results). 


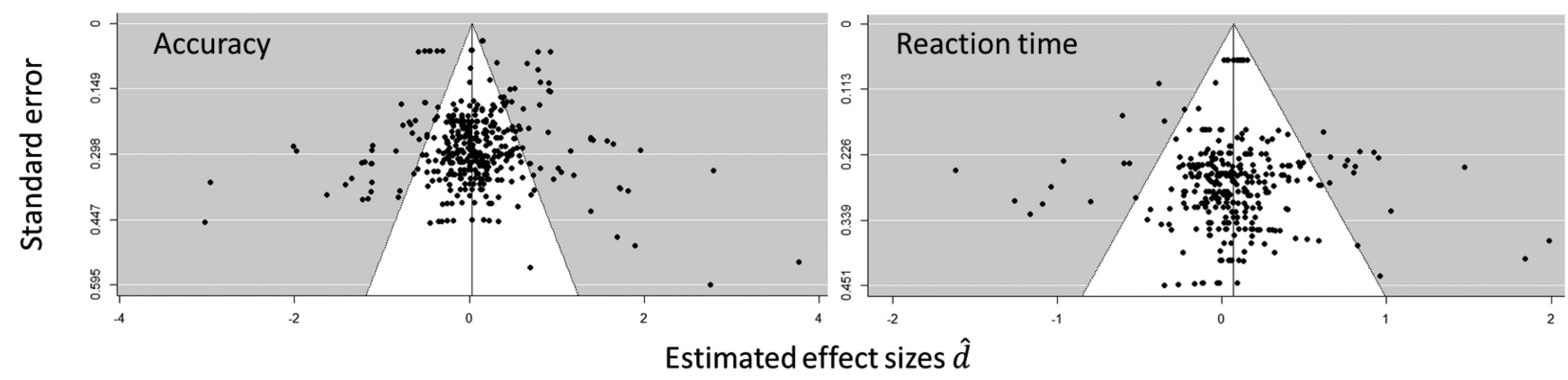

Figure 3. Funnel plots for studies reporting accuracy and RT for the behavioral meta-analysis. For WM accuracy the plot in the left box shows, from left to right on the $x$-axis, studies where WM performance is impaired by the presence of affective compared with neutral stimuli through to studies where WM is more accurate in the presence of affective relative to neutral stimuli. In the right-hand box the RT plot shows the distribution of effect sizes for studies showing faster response times for affective compared with neutral from left to the right of the middle line, from which point onward studies showed slowed RTs for affective compared with neutral stimuli.

\section{Effects of Task-Relevance and Valence on WM Performance in Psychologically Healthy Individuals (Hypotheses A1 and A2 and Their Interaction)}

For WM accuracy there were significant moderating effects of valence, $k=385, \hat{d}=0.14,95 \%$ CI [0.10, 0.19], SEM $=0.02, p \leq$ $.0001, Q_{M}(1)=38.29, p \leq .0001$; and task-relevance, $k=391$, $\hat{d}=-0.24,95 \%$ CI $[-0.40,-0.07], S E M=0.08, p=.004$, $Q_{M}(1)=8.15, p=.004$. The valence effect was due to positive stimuli, $k=117, \hat{d}=0.12, p=.02$, having a greater enhancement effect on WM accuracy compared with negative stimuli, $k=268, \hat{d}=$ $0.04, p=.38$ (see Table S2 for full statistics). The effect of taskrelevance was due to task-relevant affective targets, $k=257, \hat{d}=$ $0.08, p=.15$, improving WM performance and task-irrelevant affective distractors impairing performance, $k=134, \hat{d}=-0.04, p=.55$, though both effects considered alone were trivial in magnitude and neither was significant (Table S2).

These main effects on WM accuracy were qualified by a significant interaction of valence and task-relevance, $k=385$, $\hat{d}=-0.52,95 \%$ CI $[-0.70,-0.33], S E M=0.09, p \leq .0001$, $Q_{M}(3)=78.62, p \leq .0001$. Univariate analyses (see supplemental results, SM7, for the moderating effect of valence in task-relevant and task-irrelevant stimuli separately) revealed that task-relevant targets improved WM irrespective of valence (Table 2). In contrast, negative and positive task-irrelevant distractors had opposing effects with positive distractors improving, and negative distractors impairing, performance (Table 2). However, neither of these separate effects in the context task-irrelevant distractors was significant alone.

For RT neither main effects were significant, $p \geq .20$. Unlike WM accuracy there was no significant heterogeneity, $Q_{M}(3)=$ $6.80, p=.079$. However, there was a significant interaction of valence and task relevance, $k=309, \hat{d}=-0.16,95 \%$ CI $[-0.30$, $.03], S E M=0.07, p=.023$. Univariate analyses showed a significantly moderating effect of valence only for targets not task-irrelevant distractors (SM7). The significant effect in targets was due to significantly slowed WM RT for negative targets, which was not observed for positive targets, which showed a non-significant speeding effect (Table 2).

\section{Variations in Affective Significance as a Function of Mental Health Status (Hypothesis B1)}

As a test of affective significance-the difference between the predicted hard prioritization afforded highly significant material versus soft prioritization (Pessoa, 2009) - we hypothesized (Hypothesis B1) that, overall, affective information will have a greater behavioral impact on WM processing in individuals suffering from mental health problems compared with psychologically healthy individuals.

In line with Hypothesis B1, results showed that WM accuracy was significantly more impaired by affective material in those experiencing mental health problems compared with healthy individuals, $k=505, \hat{d}=-0.17,95 \%$ CI $[-0.26,-0.09]$, SEM $=$ $0.04, p \leq .0001, Q_{M}(1)=17.49, p \leq .0001$ (Figure 4A) with

Table 2

Effect Sizes for Each Type of Stimulus Across Task-Relevance (Task-Relevant and Irrelevant) and Valence (Positive and Negative) for WM Accuracy and WM Reaction Time

\begin{tabular}{|c|c|c|c|c|c|}
\hline Stimulus type & $k$ & $\hat{d}$ & $\begin{array}{c}95 \% \text { CI } \\
{[\mathrm{LB}, \mathrm{UB}]}\end{array}$ & SEM & $Q$ \\
\hline \multicolumn{6}{|l|}{ Accuracy } \\
\hline \multicolumn{6}{|c|}{ Task-irrelevant distractors } \\
\hline Positive & 22 & 0.11 & $-0.10,0.51$ & 0.16 & $85.23^{* * * *}$ \\
\hline Negative & 112 & -0.07 & $-0.22,0.07$ & 0.07 & $547.71^{* * * * *}$ \\
\hline \multicolumn{6}{|l|}{ Task-relevant targets } \\
\hline Positive & 95 & $0.09^{\dagger}$ & $-0.00,0.20$ & 0.05 & $454.76^{* * * *}$ \\
\hline Negative & 156 & $0.11^{*}$ & $0.00,0.23$ & 0.06 & $1350.91^{* * * *}$ \\
\hline \multicolumn{6}{|c|}{ Reaction time } \\
\hline \multicolumn{6}{|c|}{ Task-irrelevant distractors } \\
\hline Positive & 22 & $0.11^{*}$ & $0.01,0.21$ & 0.05 & $39.06^{* * * *}$ \\
\hline Negative & 81 & 0.05 & $-0.03,0.13$ & 0.04 & $123.26^{* * * *}$ \\
\hline \multicolumn{6}{|l|}{ Task-relevant targets } \\
\hline Positive & 86 & -0.04 & $-0.14,0.06$ & 0.05 & $172.03^{* * * *}$ \\
\hline Negative & 116 & $0.11^{* * *}$ & $0.03,0.18$ & 0.04 & $175.41^{\text {****** }}$ \\
\hline
\end{tabular}

Note. The table reports effect sizes on WM accuracy and reaction time of the comparison between affective stimuli of a certain task-relevance and valence and neutral stimuli of the same task-relevance.

${ }^{\dagger} \leq .10 .{ }^{*} p<.05$. $^{* * *} p<.01$. $^{* * * *} p \leq .001$. 
A

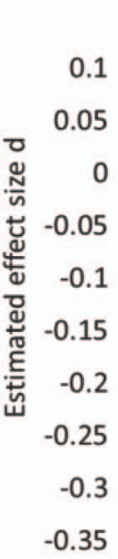

0.1
Mental Health WM accuracy

$\square$ Healthy $\square$ Mental health problems

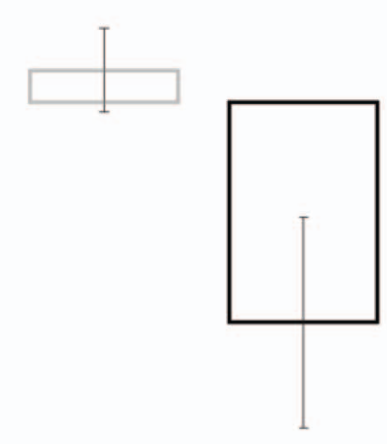

B Age WM reaction time for positive material

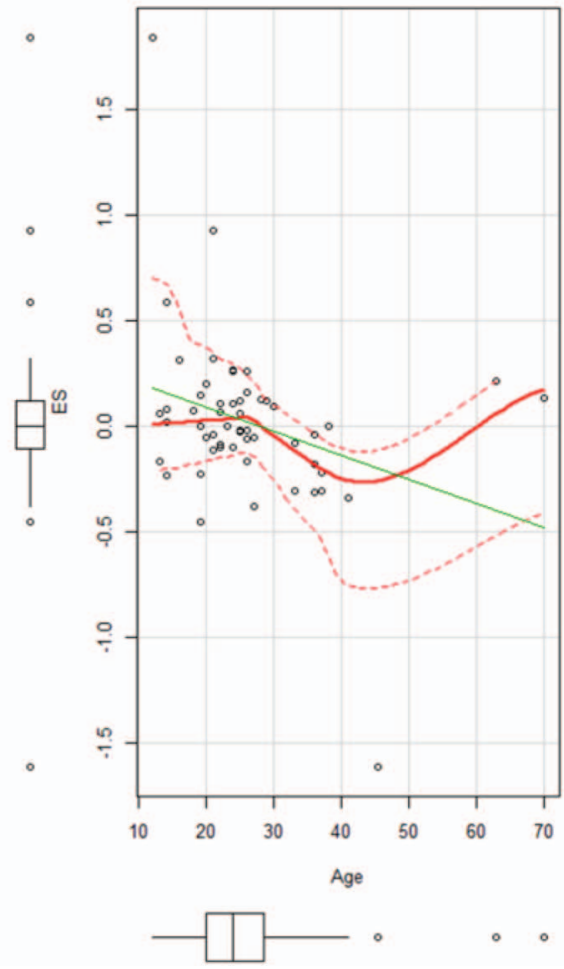

Figure 4. Affective significance across mental health status (A) and age (B). (A) The left panel depicts the effect sizes $(\hat{d})$ of the difference between WM accuracy for affective compared with neutral stimuli in healthy individuals (light gray) and those suffering from mental health problems (black). (B) The right panel illustrates the association between ES = the effects size of the difference in WM RT for positive relative to neutral stimuli and age. See the online article for the color version of this figure.

affective stimuli having the predicted larger effect on WM performance in individuals suffering from mental health difficulties, $k=$ $114, \hat{d}=-0.21,95 \%$ CI $[-0.42,-0.01], S E M=0.10, p=.041$, $Q_{M}(113)=790.96, p \leq .0001$, compared with healthy individuals (see results for Hypothesis A for a characterization of healthy performance).

As in the healthy individuals (see results for Hypotheses A1 and A2), the effect of affective material in those with mental health problems was moderated by main effects of valence, $k=114, \hat{d}=$ $0.21,95 \%$ CI [0.06, 0.36], SEM $=0.08, p=.006, Q_{M}(1)=7.71$, $p=.006$; and task-relevance, $k=114, \hat{d}=-0.59,95 \% \mathrm{CI}$ $[-0.92,-0.27], S E M=0.17, p=.0004, Q_{M}(1)=12.70, p=$ .0004. Univariate analyses showed impairing effects on WM accuracy of similar magnitude for negative $(\hat{d}=-0.20)$ and positive $(\hat{d}=-0.25)$ material, although only in the case of negative stimuli was this statistically significant (Table S3). In individuals with mental health problems, task-irrelevant distractors $(\hat{d}=-0.24)$ showed a greater impairing effect on WM accuracy compared with task-relevant targets $(\hat{d}=-0.05)$, which did not significantly impair WM accuracy (Table S3). There were insufficient studies including positive materials across the two conditions of taskrelevance to investigate the interacting effects between taskrelevance and valence.
There was no effect of mental health status for WM RT, $k=$ $409, \hat{d}=0.08,95 \%$ CI $[-0.06,0.08], S E M=0.04, p=.774$, $Q_{M}(1)=0.08, p=.774$ nor was there a moderating effect of valence or task relevance, $k=95, p$ 's $>.114$.

\section{Variations in Affective Significance Across Age (Hypothesis B2)}

A second source of variation in affective significance is age, with the age-related positivity effect in attention and memory (Scheibe \& Carstensen, 2010) leading to the prediction that with increasing age individuals become better at processing positive information in WM. WM accuracy showed small positive associations with age for both negative, $r(143)=.17,95 \%$ CI $[0.00$, $0.32], p=.045$; and positive stimuli, $r(73)=.15,95 \%$ CI $[-0.08$, $0.37], p=.186$, with older individuals remembering more affective relative to neutral material. For WM RT there was a small to moderate size significant association with RT for positive relative to neutral stimuli decreasing across age, $r(53)=-.31,95 \% \mathrm{CI}$ $[-0.53,-0.05], p=.023$. That is, older individuals were faster to respond to WM tasks when the tasks included positive relative to neutral stimuli. There was no significant association between WM 
RT and age for negative stimuli, $r(96)=.13,95 \%$ CI $[-0.07$, 0.32], $p=.202$.

\section{Interim Discussion: The Behavioral Meta-Analysis}

In line with our Hypothesis A, in psychologically healthy individuals, although WM RTs in the presence of affective, relative to neutral, stimuli were significantly slower, the effect size was trivial in magnitude $(\hat{d}=0.07)$. We also found no significant overall effect of affective material $(\hat{d}=0.03)$ on WM accuracy. These negligible effect sizes are in line with the DCF's assertion that the kinds of stimuli typically employed in laboratory experimentsaffective words and pictures-will be afforded low affective significance and only elicit a "soft prioritization" in the system. This will result in correspondingly minimal behavioral effects, that are modulated by other study-specific and individual-differences factors beyond affective significance such as WM load, age, and the nature of the affective stimuli (e.g., words, vs. images) and interactions between them (King \& Schaefer, 2011; Mano et al., 2013; Mikels, Larkin, Reuter-Lorenz, \& Cartensen, 2005; Rypma \& D'Esposito, 2000; Sander, Lindenberger, \& Werkle-Bergner, 2012; Scheibe \& Carstensen, 2010). Previous work showed opposing effects of affective distractors compared with task-relevant information on a range of cognitive processes (for a review, see Dolcos et al., 2017). In line with this work we predicted that study-specific sources of variation would be affective stimuli task-relevance and valence.

\section{Task-Relevance Interacts With the Valence of Affective Stimuli to Impact on WM Performance}

There were small significant effects of valence and taskrelevance on WM accuracy in line with our Hypotheses A1 and A2. The valence effect was due to positive stimuli enhancing WM accuracy compared with negative stimuli. The effect of taskrelevance was due to task-relevant affective targets improving WM performance while task-irrelevant affective distractors impaired WM performance. Importantly, there was also a moderate to large significant interaction between task-relevance and valence on WM accuracy, with task-irrelevant positive and negative distractors having no significant effects on WM accuracy (but in opposite directions), while task-relevant affective (irrespective of valence) targets significantly improved WM performance, although effects were small. Interestingly, in the absence of accuracy effects there was a trivial to small slowing effect of negative targets on WM RT. These facilitation effects suggest that relative to neutral targets, task-relevant affective targets may confer a small advantage in terms of perceptual competition. The neuroimaging meta-analysis may further elucidate this point if affective information does show a related activation increase within the brain's attention network.

The well-documented affective enhancement effect in long-term memory is proposed to be associated with enhanced early encoding of the affective memory trace, which is then consolidated over time (Murty, Ritchey, Adcock, \& LaBar, 2010). The mediation model of emotional memory (Talmi, Schimmack, Paterson, \& Moscovitch, 2007) argues that the mnemonic enhancement effect is the product of three types of interrelated and interacting processes: first, the above noted prioritizing of affective information within the context of limited attentional resources (Pourtois, Schettino, \& Vuilleumier, 2013; Vuilleumier, 2005); second distinctiveness, the notion that encoding of affective information is prioritized because affective relative to neutral information stands out (cf. the notion of "impact"; Ewbank, Barnard, Croucher, Ramponi, \& Calder, 2009); and finally, shared thematic links (organization), which Talmi, Schimmack, Paterson, and Moscovitch (2007) argue are more easily formed between affective compared with neutral information further assisting memory encoding. These processes could similarly account for the small affective advantage observed for task-relevant affective material here in WM and could usefully be systematically explored in future research.

The small, nonsignificant enhancing effect $(\hat{d}=0.20)$ of positive distractors and the negligible impairing effect of negative distractors (lower accuracy $\hat{d}=-0.07$, slowed WM RT $\hat{d}=0.11$ ) suggest that competition for perceptual or executive resources from affective distractors do not markedly affect WM performance over and above that of neutral distractors. However, the nonsignificant enhancement effect of positive distractors needs to be considered in the context of the small number of effect sizes $(k=$ 28) from 13 studies contributing to this effect. If this small enhancing effect does replicate across a larger number of future studies, it could arguably be interpreted as reflecting the motivational impact of positive information (H. Yang, Yang, \& Isen, 2013). Specifically, one could argue that positive stimuli related to reward and motivations of affiliation may focus executive processes due to the increased-relative to neutral-motivational salience of the context in which WM is engaged (Stussi, Pourtois, $\&$ Sander, 2018). To further explore the role of motivational salience in WM and executive control more broadly, careful consideration should be given to the nature of the positive and negative stimuli used in research. The type of stimuli should be theorydriven and tap into affective concerns relevant to the study population under investigation (e.g., social stimuli in adolescence; Mueller, Cromheeke, Siugzdaite, \& Boehler, 2017; or negative self-referential processing in depression Schweizer et al., 2018) and the construct under investigation (e.g., survival relevance; Lindström \& Bohlin, 2012).

\section{Affective Significance}

We hypothesized that the effect of affective stimuli on WM performance would vary as a function of their affective significance. Affective significance was proposed to vary as a function of both mental health status (Hypothesis B1) and age (Hypothesis B2).

Mental health status. Supporting Hypothesis B1, we found a significantly greater effect of affective relative to neutral material on WM accuracy in individuals suffering from mental health problems $(\hat{d}=-0.21)$ compared with healthy individuals $(\hat{d}=$ 0.03). In individuals suffering from mental health problems performance was impaired relative to neutral by both negative $(\hat{d}=-0.20)$ and positive stimuli $(\hat{d}=-0.25)$. Though the effect was significant only for negative stimuli. The lack of significance for positive material may reflect a power issue as only 26 effect sizes were included. Showing that both positive and negative information have an effect of similar magnitude highlights the importance of recent developments toward the investigation of hedonic processing and reward learning in individuals with psy- 
chopathology (e.g., Admon \& Pizzagalli, 2015; Husain \& Roiser, 2018) to complement research into the processing of negative information. The relatively greater impairment in WM performance for affective relative to neutral material is remarkable considering that this is over and above the substantial impairments in performance on affectively neutral task measures of executive functions (including WM) found in most types of mental health problems. For example, compared with healthy individuals those with depression $(\hat{d}=0.32-0.97$; Snyder, 2013), attention-deficit and hyperactivity disorder $(\hat{d}=0.60-0.89$; Boonstra, Oosterlaan, Sergeant, \& Buitelaar, 2005), and posttraumatic stress disorder $(\hat{d}=0.46-0.62$; Scott et al., 2015) show moderate to large impairments in executive functioning in tasks populated with neutral material.

In individuals suffering from mental health problems there was a significant effect of task-relevance, with task-irrelevant distractors having a greater impairing impact $(\hat{d}=-0.24)$ compared with task-relevant targets $(\hat{d}=-0.05)$. This effect of task relevance in those with mental health difficulties is in line with theories emphasizing the importance of attentional control with respect to cognitive vulnerabilities to mental health problems. Reduced inhibition of negative, especially threat-related, information in anxiety is likely to account for increased attentional resources drawn to the affective distractors that become unavailable to task-relevant processing (Bar-Haim et al., 2007; Derakshan \& Eysenck, 2009; Reinholdt-Dunne, Mogg, \& Bradley, 2013). In depression, the inability to disengage attention from affective distractors may similarly limit the attentional resources available to processing task-relevant information in WM (De Raedt \& Koster, 2010; Everaert, Koster, \& Derakshan, 2012). Affective WM tasks then may be sensitive transdiagnostically to individual differences in mental health status. While attentional control capacity has been shown to be predictive of the onset of depressive and anxiety symptoms prospectively (Kertz, Belden, Tillman, \& Luby, 2016), little is known about the development of attentional control over affective information specifically (Peterson \& Welsh, 2014; Prencipe et al., 2011), which may identify those at risk for mental health problems across a range of disorders.

Disorder-specific variation. A cautionary note is warranted when interpreting these findings of course because, as with psychologically healthy individuals, tests of heterogeneity for all of these effects in individuals with mental health problems were significant. It is worth rehearsing two caveats related to using mental health status as a proxy for affective significance that may partly account for this heterogeneity. First, the status "mental health" here included a wide range of mental health problems (including schizophrenia, attention deficit and hyperactivity disorder, depression, and posttraumatic stress disorder). Second, the impact of affective material is potentially and likely not uniform across this diversity of mental health conditions or across other syndrome-specific sources of variation such as phase of the syndrome (e.g., acute vs. remitted), although these remain empirical questions.

Age. The effects discussed above were limited to WM accuracy. The moderating effect of age, however, was strongest on WM RTs with effects on accuracy being trivial-to-small and unreliable. The RT results showed that, with increasing age, individuals respond more quickly on WM tasks in the context of positive information $(r=-.31)$ with this effect being nonsignificant in the reverse direction in the context of negative information $(r=.15)$. This is in line with the positivity effect that characterizes socioemotional selectivity theory (Carstensen, 2006), whereby older adults preferentially process positive information due to age-related motivational shifts (Mather, 2016; Mather \& Carstensen, 2005). Kensinger (2008) interestingly showed that the age-related positivity effect may be particularly marked for low arousing material, whereas items high in arousal hijack attentional resources irrespective of valence. This argument is also in line with Labouvie-Vief, Grühn, and Studer's (2010) equilibrium model, which argues that with increasing age the spectrum of acceptable emotions shrinks, in particular for negative emotions. As noted above, with one exception, all of the positive stimuli included in the current meta-analysis are arguably low in arousal and may therefore be particularly sensitive to the age-related positivity effect.

We turn next to the neuroimaging review and revisit the results of this behavioral meta-analysis in the General Discussion in light of the results of imaging data synthesis.

\section{Neuroimaging Meta-Analysis}

Functional neuroimaging studies and research in lesion patients have provided good evidence for the involvement of a fronto-parietal control network (Figure 5) in WM and other higher-order cognitive functions such as fluid intelligence (for reviews, see Duncan, 2006, 2010; Nee et al., 2013). Specifically, neural models of WM capacity have implicated this network in the active maintenance of representations and goal-states in WM, and in the control of task-related attention (Constantinidis \& Klingberg, 2016; Duncan \& Owen, 2000; Miller, 2000; Miller \& Cohen, 2001; Nee et al., 2013; Nee, Wager, \& Jonides, 2007; Owen et al., 2005; Postle, 2016). The major nodes of the frontoparietal control network include the bilateral dorsolateral prefrontal cortex (dIPFC) and the inferior parietal lobe.

In addition to the fronto-parietal network (e.g., Coull, Frith, Frackowiak, \& Grasby, 1996; Vincent, Kahn, Snyder, Raichle, \& Buckner, 2008), WM, especially in the presence of affective information, may recruit portions of the so-called salience network and ventral attention network (Barrett \& Satpute, 2013; Corbetta, Patel, \& Shulman, 2008; Eckert et al., 2009; Seeley et al., 2007; see Figure 5), which include nodes in the anterior cingulate cortex (ACC), anterior insula, and amygdala (Seeley et al., 2007; Wilson-Mendenhall, Barrett, \& Bar-

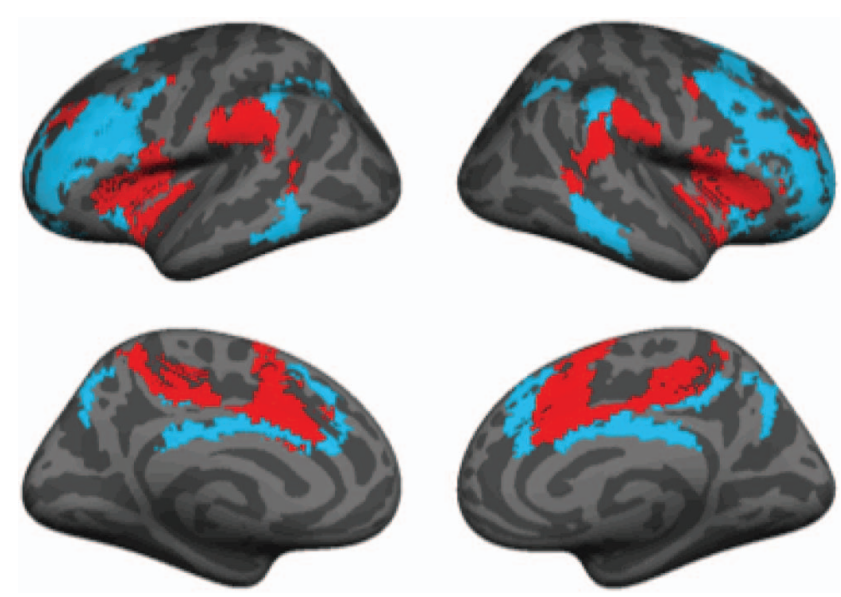

Figure 5. Fronto-parietal control network (blue) and salience network (red). See the online article for the color version of this figure. 
salou, 2013). Both of these networks are predicted by the theories reviewed above to be sensitive to the perceptual and executive competition created by affective (relative to neutral) stimuli in WM tasks (e.g., Pessoa, 2008, 2009).

\section{Neural Substrates of Affective WM Processing}

The hypothesized involvement of the amygdala during affective WM is in line with research showing that attentional capture from affective information (e.g., Pessoa \& Ungerleider, 2004) is associated with increased activation of the amygdala (LeDoux, 2012; Öhman, Flykt, \& Esteves, 2001; Vuilleumier, 2005; Vuilleumier \& Huang, 2009). The interactive connections of the amygdala with sensory processing regions show that these effects appear early in processing and implicate the amygdala in the biasing of processing toward affective salience at a preconscious stage (Pessoa, 2005; Phelps, 2006; Whalen \& Phelps, 2009).

This prioritized processing of affective information reliably shows greater recruitment of visual brain areas for affective compared with neutral stimuli (Sabatinelli et al., 2011; Satpute et al., 2015), irrespective of whether the stimuli are attended or unattended (for reviews, see Tamietto \& de Gelder, 2010; Vuilleumier, 2005; Vuilleumier \& Huang, 2009).

The elicited affective experience in turn may engender affectregulatory processes that recruit components from the fronto-parietal control network (for reviews, see Buhle et al., 2014; Kalisch, 2009). Models of affect regulation have implicated the ventrolateral node (i.e., inferior frontal gyrus) of the fronto-parietal control network in the regulation of affective responses as the neural substrate of processes involved in the selection of alternative semantic interpretations of the affective material, as well as of more generic inhibitory processes (Dillon \& Pizzagalli, 2007; Elliott \& Deakin, 2005; Ochsner, Silvers, \& Buhle, 2012). Cognitive control models of emotion regulation also implicate dorsal nodes of the fronto-parietal control network, including the dIPFC, posterior PFC and inferior parietal regions, because of their likely role underpinning the directing of selective attention and the updating of WM (Ochsner et al., 2012). Given these regions' involvement in WM per se, however, it seems unlikely that they will be more activated during the processing of affective material relative to neutral information. Indeed, we suggest below that the opposite (greater involvement for neutral over affective) may be the case.

\section{Neural Substrates of WM Processing of Affectively Neutral Information Relative to Affective Information}

At the neural level, the theories of emotion-cognition interactions do not offer a specific prediction regarding this "reverse contrast"the neural substrates that are recruited more frequently during WM tasks in the presence of neutral versus affective information. The DCF does however predict that, through perceptual and executive competition, affective information draws resources away from task-related processing. Consequently, it seems plausible that task-relevant brain regions should be recruited more frequently in the absence of affective material. In the case of WM, these task-related regions include the more dorsal regions of the fronto-parietal network, especially the dlPFC (Nee et al., 2013). This putative dissociation between the ventral and the dorsal streams of the fronto-parietal control network is supported by recent reviews of the neuroimaging literature showing greater involvement of the dorsal stream of the network for neutral compared with affective distractor material presented in executive functioning tasks, including WM tasks (Iordan \& Dolcos, 2017; Okon-Singer et al., 2015). In contrast, and in line with our hypotheses derived from the DCF, affective distractors are associated with more frequent recruitment of the ventral stream of the network (Iordan \& Dolcos, 2017; Okon-Singer et al., 2015).

To summarize, we hypothesized that:

Hypothesis $C$ : Compared with the processing of neutral stimuli, the processing of affective stimuli would be associated with more frequent activation within the visual cortices, portions of the salience network, including the amygdala, and the ventrolateral prefrontal node within the fronto-parietal control network.

Hypothesis D: And that the reverse contrast-differential activation when processing neutral compared with affective stimuli (neutral $>$ affective) — would be associated with more frequent neural activation within task-related regions in the dorsal components of the fronto-parietal control network.

In line with the behavioral analyses, we explored the neural correlates of affective versus neutral stimuli's task-relevance. ${ }^{8}$ However, we were unable to explore the effects of valence or interactions between valence and task-relevance within the fMRI data because insufficient neuroimaging studies included these contrasts. Moreover, it was not possible to explore the neural correlates of the effects of affective significance because the few studies which reported neuroimaging data for individuals with mental health problems ranged across various disorders that arguably present with both overlapping and distinct anatomical and functional anomalies (Davidson et al., 2002; Dickstein, Bannon, Castellanos, \& Milham, 2006; Elzinga \& Bremner, 2002; Menon, 2011; Shenton, Dickey, Frumin, \& McCarley, 2001), thus precluding useful data synthesis at this stage.

\section{Methods for the Imaging Meta-Analysis}

\section{Identification and Screening of Studies}

The identification and screening stages were conducted in tandem with the behavioral meta-analysis according to PRISMA guidelines.

\section{Eligibility}

We checked the full-texts of the identified studies to ascertain whether they reported fMRI data associated with the effects of affective material on WM in healthy individuals (Table 1). To be included, studies had to report functional imaging contrasts comparing neutral and affective information. Specifically, we included the contrasts examining regions showing greater activation for neutral versus affective stimuli during WM task performance and the reverse contrast identifying regions that reported greater activation for affective versus neutral stimuli during a WM task (for reasons for exclusion see SM8). The studies had to report BOLD response data on these contrasts

\footnotetext{
${ }^{8}$ It was not possible to look at the comparisons between neutral and affective target stimuli, because there were insufficient studies reporting the contrast neutral $>$ affective.
} 
either across the whole brain or in specified regions of interest using normalized stereotactic spaces (i.e., Montreal Neurological Institute and Hospital [MNI] or Talairach space). For each contrast, peak activations were included that were reported in the individual studies. It should be noted here that while we tested specific anatomical hypotheses (Hypotheses C and D) about the correlates of WM tasks including affective versus neutral information, the imaging metaanalytic approach we adopted was agnostic to these hypotheses and conducted across the whole brain.

\section{Analytic Approach}

We coded contrasts based on the affective qualities of the stimuli (e.g., affective vs. neutral, neutral vs. affective) and on the taskrelevance (i.e., task-relevant targets vs. task-irrelevant distractors). Based on these codes, we computed multikernel density maps (procedures described below) that corresponded with the behavioral analysis. First, we examined the brain regions that were frequently engaged during affective versus neutral stimulus conditions (28 contrasts), and neutral versus affective stimulus conditions (19 contrasts). To investigate differential effects of affective material depending on task-relevance of the affective stimuli, multikernel density analysis (MKDA) maps were calculated separately for task-relevant affective targets (10 contrasts) and task-irrelevant affective distractors (18 contrasts).

Multikernel density analysis (MDKA). The contrast maps were submitted to a MKDA, as described in detail and validated by Wager, Lindquist, and Kaplan (2007; see Kober et al., 2008; Lindquist, Wager, Kober, Bliss-Moreau, \& Barrett, 2012) and implemented in Matlab software using the NeuroElf toolbox (www .neuroelf.net). A MKDA nests activation points within contrast maps and thereby limits the undue influence of studies that report many more activation points than others. Coordinates reported in Talairach space were transformed to MNI space using the "mni2tal" estimation procedure provided by M. Brett (http://imaging .mrc-cbu.cam.ac.uk/imaging/CbuImaging). An indicator map was generated for each study contrast by setting voxels in a $10-\mathrm{mm}$ sphere surrounding each reported peak activation point to 1 . Contrasts were weighted by the square root of the sample size. For each voxel, a point estimate of the probability of contrasts that activated the voxel was computed. To determine significance, for each comparison a Monte Carlo simulation (5,000 iterations) was performed that preserved the number of contrasts and coordinates within contrasts, but randomly assigned the coordinate locations to gray matter regions of the brain, and for a voxel-level threshold of $p<.01$, a $k$-extent cluster-level threshold was obtained to meet a whole-brain family wise error rate (FWER) statistical correction of $p<.05$.

\section{Results of the Neuroimaging Meta-Analysis}

\section{Included Studies}

Of the 165 studies identified in the behavioral meta-analysis, 52 studies included fMRI data. Of these, 19 were excluded from the neuroimaging meta-analysis (see supplementary results for reasons for exclusion and the PRISMA diagram in Figure S2). The final sample included 683 participants, 456 coordinates, and 63 contrasts from 33 studies (denoted with an asterisk in the column titled
"Imaging" in Table 1). See Table S5 for an overview of the specific contrasts and number of peak activation points (i.e., coordinates) included across studies. The tasks included in the analyses are described in Table 1 with the most frequently used tasks in the neuroimaging studies reviewed being $n$-back $(n=13)$ and delayed-match-to-sample $(n=12)$ tasks.

\section{Brain Regions Consistently Engaged During Affective Compared With Neutral Stimulus Conditions in WM Tasks (Hypotheses C and D)}

The neuroimaging meta-analytic results supported our first neural hypothesis (Hypothesis C) that the processing of affective stimuli during WM tasks, relative to neutral stimuli, would be associated with more frequent activation across the brain's salience network, specifically the bilateral amygdalae, and also within the ventrolateral prefrontal cortex (Figure 6A). We also found support for our second neural hypothesis (Hypothesis D), with the contrast comparing neutral with affective stimulus material being associated with more frequent activation in brain regions commonly associated with WM task performance in the dorsal stream of the fronto-parietal control network-a large node in the right $\mathrm{dlPFC}$ - as well as the precuneus in the inferior parietal cortex (Figure 6B). For a full list of significant clusters comparing affective with neutral stimuli, see Table S6. Given the proposed greater affective significance of negative compared with positive stimuli (Hypothesis A1) we explored the corresponding neural effects for negative and positive stimuli separately. The contrast comparing negative with neutral stimuli (Figure 6C-D; Table 3) showed the same pattern of results as the overall affective effect. In contrast, no brain regions were significantly more recruited when comparing positive with neutral stimuli.

\section{Task-Relevance: An Exploratory Analysis of Brain Regions More Consistently Engaged When the Affective Information Is the Task-Relevant Target Versus the Task-Irrelevant Distractor'}

Next, we computed differences in MKDA maps to explore which neural regions were more frequently engaged during the processing of affective relative to neutral information, separately for task-relevant targets and task-irrelevant distractors. Interestingly, given the behavioral results which showed a significant effect of affective material only for task-relevant targets, the neuroimaging effects were driven by the taskirrelevant distractors. Relative to neutral distractors affective distractors more frequently activated the bilateral vlPFC, amygdalo-hippocampal complex, and left temporo-occipital lobe (including the fusiform gyrus; see Figure 6C). The reverse contrast showed greater activation in the dlPFC for neutral compared with affective distractors. For a full list of the clusters and peak activations see Table S7. There were no significant differences in MKDA maps between contrasts that included affective compared with neutral targets.

\footnotetext{
${ }^{9}$ There were insufficient contrasts including neutral memoranda to look at the effects of affective versus neutral stimuli across task-relevant and task-irrelevant material.
} 
A Affective $>$ Neutral

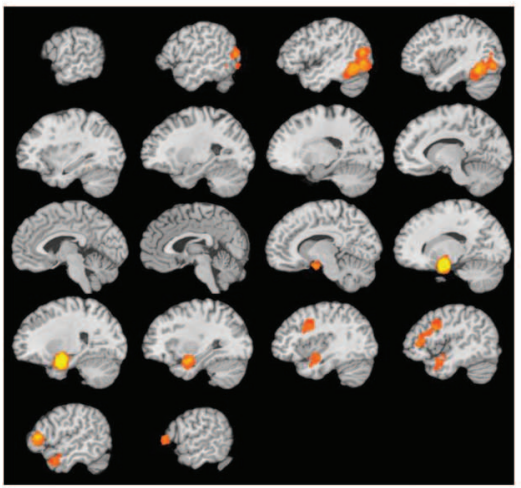

C Negative $>$ Neutral

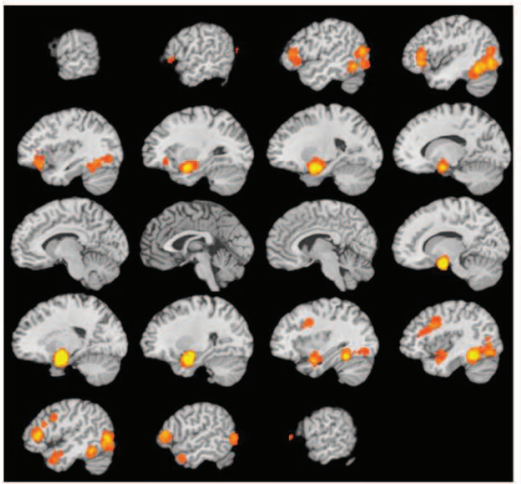

E Irrelevant $>$ Relevant

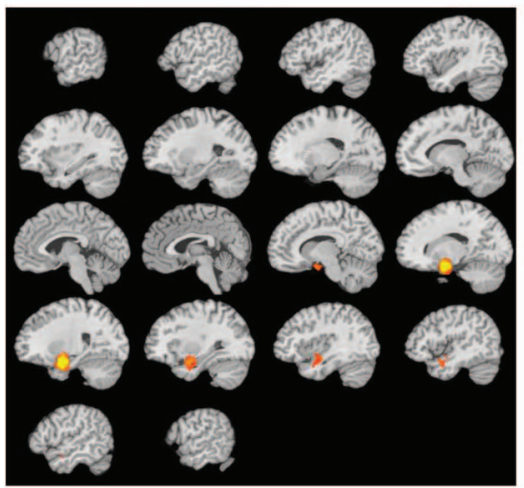

B Neutral > Affective

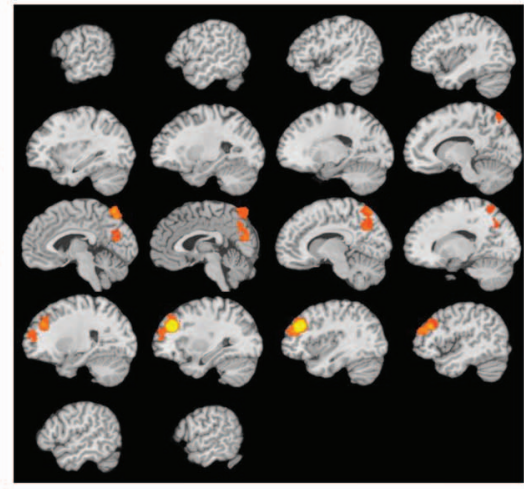

D Neutral > Negative

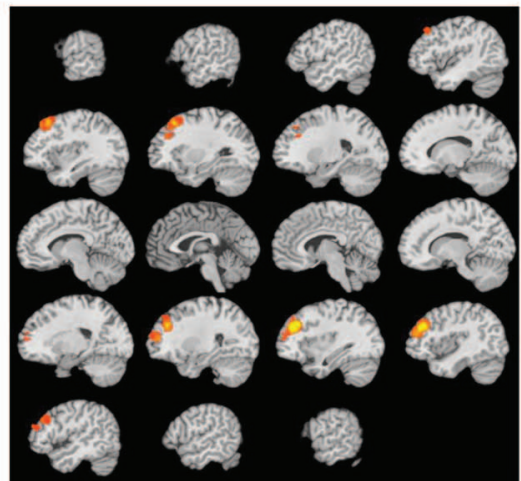

F $\quad$ Relevant $>$ Irrelevant

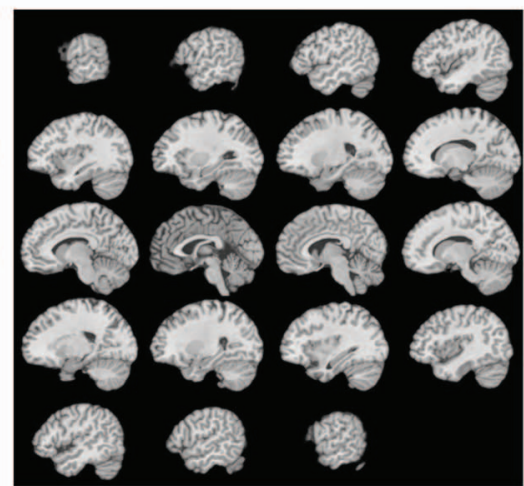

Figure 6. Affective stimuli as distractors or targets in WM tasks. Each panel shows brain regions that were more frequently engaged for WM contrasts comparing: (A) affective $>$ neutral stimuli; (B) neutral $>$ affective stimuli; (C) negative > neutral stimuli; (D) neutral $>$ negative stimuli; (E) affective task-irrelevant distractor $>$ affective task-relevant targets in WM tasks; and (F) task-relevant compared with irrelevant affective stimuli, for which there were no reliable activations. The color gradation in the figure indicates the frequency of recruitment of a specific region. That is, the lighter the yellow, the more frequently the region was recruited during the contrast of interest. Colored areas represent activation frequencies at $p<.05$, FWER corrected. See the online article for the color version of this figure.

Finally, looking at only the affective conditions comparing MKDA maps for affective task-irrelevant distractors with affective taskrelevant targets revealed more frequent activation of a cluster in the right temporal lobe and subcortical regions including the amygdalo- hippocampal complex, $k=476$, maxima $=.71$, peak coordinate $=$ 24/0/-24 (see Figure 6E) for task-irrelevant distractors. The reverse contrast showed no brain regions to be more significantly activated for task relevant affective target compared with irrelevant distractors. 
Table 3

Brain Regions Consistently Engaged During Affective Compared With Neutral Stimulus Conditions in WM Tasks

\begin{tabular}{|c|c|c|c|c|c|}
\hline Region & $\mathrm{L} / \mathrm{R}$ & $\begin{array}{l}\text { Cluster size } \\
\text { (voxels) }\end{array}$ & $\begin{array}{l}\text { Subcluster size } \\
\quad \text { (voxels) }\end{array}$ & Maximum & $\mathrm{x} / \mathrm{y} / \mathrm{z}$ \\
\hline \multicolumn{6}{|l|}{ Negative $>$ Neutral Stimuli } \\
\hline \multirow[t]{2}{*}{ vlPFC/OFC } & $\mathrm{L}$ & 228 & \multirow[b]{2}{*}{71} & .31 & $-39 / 33 /-6$ \\
\hline & & \multirow{5}{*}{338} & & & $-39 / 36 / 3$ \\
\hline \multirow[t]{4}{*}{ Amygdala } & \multirow[t]{4}{*}{$\mathrm{L}$} & & & .35 & $-27 /-3 /-18$ \\
\hline & & & 103 & & $-24 /-12 /-18$ \\
\hline & & & 80 & & $-18 / 0 /-18$ \\
\hline & & & 46 & & $-21 /-6 /-6$ \\
\hline \multirow[t]{3}{*}{ Temporal lobe (including amygdalo-hippocampal complex) } & \multirow[t]{3}{*}{$\mathrm{R}$} & \multirow[t]{3}{*}{419} & & .50 & $21 /-6 /-18$ \\
\hline & & & 48 & & $36 / 0 /-24$ \\
\hline & & & 51 & & $39 /-3 /-15$ \\
\hline \multirow[t]{6}{*}{ Temporo-occipital lobe (including fusiform gyrus) } & \multirow[t]{6}{*}{$\mathrm{L}$} & \multirow[t]{6}{*}{648} & & .29 & $-39 /-57 /-12$ \\
\hline & & & 192 & & $-42 /-78 / 0$ \\
\hline & & & 93 & & $-45 /-75 / 12$ \\
\hline & & & 110 & & $-36 /-51 /-21$ \\
\hline & & & 36 & & $-51 /-63 / 6$ \\
\hline & & & 34 & & $-48 /-51 / 3$ \\
\hline \multirow[t]{7}{*}{ Temporo-occipital lobe (including fusiform gyrus) } & \multirow[t]{7}{*}{$\mathrm{R}$} & \multirow[t]{7}{*}{512} & & .33 & $42 /-54 /-18$ \\
\hline & & & 110 & & $39 /-75 /-12$ \\
\hline & & & 87 & & $42 /-45 /-12$ \\
\hline & & & 70 & & $42 /-72 / 0$ \\
\hline & & & 45 & & $48 /-69 /-12$ \\
\hline & & & 33 & & $42 /-54 /-6$ \\
\hline & & & 60 & & $54 /-69 / 6$ \\
\hline \multirow{7}{*}{$\begin{array}{l}\text { Neutral > Negative stimuli } \\
\text { dlPFC }\end{array}$} & \multirow{7}{*}{$\mathrm{R}$} & \multirow{7}{*}{505} & & & \\
\hline & & & & .49 & $36 / 42 / 30$ \\
\hline & & & 180 & & $36 / 33 / 33$ \\
\hline & & & 34 & & $27 / 51 / 12$ \\
\hline & & & 51 & & $33 / 54 / 18$ \\
\hline & & & 44 & & $33 / 39 / 42$ \\
\hline & & & 21 & & $27 / 30 / 51$ \\
\hline
\end{tabular}

Note. Table 3 reports brain regions that were significantly more frequently activated in response to one condition compared with another. Peak activations for each (sub)cluster are reported as well as the maximum statistic, which reflects the analysis of the distribution of maximum values corrected for multiple comparisons at a FWER of .05 (Salimi-Khorshidi, Smith, Keltner, Wager, and Nichols, 2009; Wager, Lindquist, and Kaplan, 2007). dl = dorsolateral; vl = ventrolateral; $\mathrm{PFC}=$ prefrontal cortex; $\mathrm{OFC}=$ orbitofrontal cortex; $\mathrm{L}=$ left; $\mathrm{R}=$ right; Maximum $=$ maximum of the $z$-field. The negative $>$ neutral comparison was based on 211 coordinates from 24 contrasts; the neutral > negative comparison was based on 144 coordinates from 20 contrasts.

\section{Interim Discussion of the Neuroimaging Meta-Analysis}

The meta-analysis of the brain regions recruited during WM performance in the presence of affective compared with neutral stimuli confirmed our hypothesis (Hypothesis C) that affective stimuli would recruit regions from both the larger salience network (including the amygdalo-hippocampal complex) as well as ventral components of the fronto-parietal control network (i.e., vlPFC), in addition to regions in the temporooccipital lobe, in particular the fusiform gyrus, a brain region involved in the processing of faces (Bressler \& Menon, 2010; Ishai, 2008). In line with our second neural prediction (Hypothesis D), the MKDA map for brain regions that were more frequently activated for WM tasks performed with neutral (relative to affective) stimuli revealed two clusters in dorsal components of the fronto-parietal control network: one in the right dIPFC and a second cluster in the precuneus. Our exploratory analyses showed that contrasting regions activated more frequently in the presence of affective distractors compared with task-relevant targets yielded more frequent activation in the right amygdalo-hippocampal complex.

\section{Neural Substrates of Affective WM and the Dual Competition Framework}

Before discussing the meta-analytic findings, a note of caution is warranted. Any interpretations of findings from neuroimaging at the level of cognitive theory are subject to the concerns surrounding reverse inference (Poldrack, 2011). In the present case, a particular contrast, for example the presence of affective compared with neutral stimulus material in WM tasks, may be associated with more frequent activation of a given brain region. At the same time, in the wider literature, a particular cognitive process (e.g., attentional capture through salience) may have been previously putatively linked to that same region in other studies. Through a process of reverse inference, evidence supporting activation of that region in the present meta-analysis could be taken to mean that that particular cognitive process is also engaged by this contrast (Poldrack, 2006). However, of course, most brain regions and networks support a multitude of cognitive functions and so any such assumptions that the implicated processes across studies or sets of studies are the same, and specific, must only be tentative. That said, it would be remiss not to interpret the present findings within the 
context of the wider extant literature and so we have sought an appropriate balance of informed discussion and inferential caution.

Affective versus neutral material. Interestingly in light of negligible behavioral effects of affective information on WM performance in psychologically healthy individuals, the neuroimaging data shows that robust effects exist at the neural level of processing. The more frequent activation evident within the amygdala and the temporo-occipital lobe including the fusiform gyrus, arguably reflect the allocation of greater processing resources toward these affective, often facial, stimuli within the included studies. The more frequent activation of the amygdala is in line with the well-documented role of the amygdala in salience processing (Adolphs, 2010; Pessoa \& Adolphs, 2010; Whalen \& Phelps, 2009). The involvement of the inferior temporal gyrus, which has reliably been implicated in emotion regulation (for a review, see Buhle et al., 2014) may be indicative of individuals' affect regulatory efforts in response to affective stimuli.

Increased activation frequency observed in the vlPFC has been implicated in inhibitory processing (D'Esposito, Postle, Ballard, \& Lease, 1999; E. E. Smith \& Jonides, 1999; Jonides, Smith, Marshuetz, Koeppe, \& Reuter-Lorenz, 1998) and has been proposed to reflect individuals capacity to cope with the greater affective responses elicited by affective relative to neutral stimuli (Denkova et al., 2010; Dolcos, Kragel, Wang, \& McCarthy, 2006). Indeed, Dolcos and McCarthy (2006) showed a clear association $(r=-.74)$ between vlPFC activation and individuals' ratings of affective stimuli's distractibility during a WM task, but not for neutral distractors $r=.13$. The vlPFC's role in cognitive control over affective responses has also been related to the deployment of cognitively engaging affect regulatory strategies such as reappraisal (Buhle et al., 2014; Ochsner et al., 2009, 2012). The present finding may therefore also in part reflect the implicit emotion regulation of affective material that participants likely engage in when performing tasks that contain such material. These regulatory processes may be enacted more specifically through the retrieval and/or selection of relevant semantic (Badre \& Wagner, 2005, 2007) or social (Satpute, Badre, \& Ochsner, 2014) information.

Task-relevance. Our exploration of the neural substrates of a stimulus' task-relevance revealed that task-irrelevant distractors showed greater activation frequency, relative to task-relevant targets in the vlPFC, amygdalo-hippocampal complex, and temporooccipital complex, whereas neutral distractors recruited the dlPFC more reliably. This dissociation has been observed in reviews of the neural substrates of affective distractors included in cognitive paradigms beyond WM (Dolcos \& Denkova, 2014; Iordan, Dolcos, \& Dolcos, 2013) and indeed has been proposed by Dolcos and colleagues across a series of studies on the impact of affective distractors on WM (e.g., Dolcos, Diaz-Granados, Wang, \& McCarthy, 2008; Dolcos \& McCarthy, 2006; Iordan \& Dolcos, 2017). Specifically, the review by Iordan, Dolcos, Denkova, and Dolcos (2013) noted a dissociation between what they termed a 'cold' dorsal executive system (including the dIPFC reported in the present meta-analysis) that was recruited for neutral over affective distractors and the "hot" ventral system that includes all the areas that showed greater activation during WM tasks, including affective compared with neutral distractors, in the present meta-analysis (i.e., vlPFC, amygdala, fusiform gyrus, and visual cortex).
More recently, Dolcos and colleagues' dorsal executive and ventral attention systems have been linked to specific functional networks to offer a systems-level dissociation between the two (e.g., Dolcos \& McCarthy, 2006; Iordan \& Dolcos, 2017). In particular they highlight the dorsal executive system's integration within the wider fronto-parietal network and the ventral attention system's overlap with the salience network for the vlPFC and amygdala (Iordan \& Dolcos, 2017). As Iordan and Dolcos (2017) note, this functional dissociation extends beyond a simplistic attribution of bottom-up processes to a ventral system and top-down executive functions to a dorsal system (cf., Pfeifer \& Allen, 2012), instead emphasizing the contribution of both systems in emotion processing (e.g., showing valence specific effects in the lateral parietal cortex of the fronto-parietal network/dorsal executive system; Iordan \& Dolcos, 2017; Iordan, Dolcos, \& Dolcos, 2018) and control.

Finally, of the neuroimaging studies investigating the effects of task-irrelevant distractors, $60 \%$ (nine of 15) were studies including variants of the delayed-match-to-sample task (e.g., Dolcos \& McCarthy, 2006). These tasks introduce a temporal latency between the distractors and memoranda (Daniel, Katz, \& Robinson, 2016), which might place greater demands on executive compared with perceptual competition.

\section{General Discussion}

Our aim with these two meta-analytic reviews was to help advance understanding of how human cognition operates in affectively laden environments, by synthesizing data on the impact of affective information on WM and the neural correlates of this effect. WM is implicated in virtually all day-to-day cognition (Barrett et al., 2004; Engle \& Kane, 2004; Miyake \& Shah, 1999) and much of its operation takes place in affective contexts, ranging from the overt manipulation of affective information to the performance of relatively neutral tasks in the context of affectively laden goals and plans. The studies reviewed here have tried to measure these forms of interplay by looking at WM in affective versus comparatively affect-neutral contexts within the laboratory and scanner using carefully controlled tasks. ${ }^{10}$ The challenge inherent in these tasks is to pursue the relatively neutral task goals while dealing with affectively laden contexts of different types as a proxy for the challenges faced in day-to-day cognition.

Our findings show that neural and behavioral data reviews and syntheses can complement each other; in this case with evidence for widespread neural engagement that arguably reflects broader cognitive engagement than the resultant behavioral data reveal (Barrett, 2009). This is a vindication of models such as Pessoa's (2009) DCF and others (e.g., the conceptual act theory, Barrett, 2014; the model of the cognitive control of emotions, Ochsner et al., 2012) that seek to generate and integrate sets of both behavioral and neural predictions. These complementary insights from the current set of reviews further highlight the importance for future data synthesis endeavors of including, where possible, mea-

\footnotetext{
${ }^{10}$ It should be noted here that theorists have argued that there is no affect-free cognition (Barrett, 2006, 2009; Lindquist, 2013) and seemingly well-validated "neutral" stimuli elicit significant amounts of ambivalence, which is related to arousal (Schneider, Veenstra, van Harreveld, Schwarz, \& Koole, 2016)
} 
sures of behavioral performance as well as functional neuroimaging data. While this conclusion appears self-evident there is a surprising lack of meta-analytic reviews that integrate findings in this manner.

\section{Dissociable Behavioral and Neural Effects of Affective Information Across Task-Relevance}

The dissociation between behavioral and neural findings in healthy individuals was strongest for the moderating effect of task-relevance. Interestingly, across the behavioral studies affective targets had a negligible-to-small enhancing effect on WM accuracy, whereas the effect of affective distractors was small and dependent on valence. The neuroimaging meta-analysis, however, showed that affective distractors led to more frequent recruitment of the predicted brain regions (including, amygdala, vlPFC) whereas affective targets did not. Moreover, task-irrelevant affective distractors had a greater impairing effect on WM accuracy compared with affective targets in individuals with mental health issues.

The differential behavioral and neural effects of affective stimuli on WM in healthy individuals arguably evidence the efficiency of the cognitive control system in mitigating any impact of affective information on performance. The increased recruitment of the vlPFC may reflect the organism's effort to inhibit attention and responses toward these distractors and regulate any affective experience elicited by the distractor. This is particularly adaptive in our contemporary environments that are populated with myriads of affective distractors (e.g., phone alerts). This dissociation of behavioral and neural results observed in healthy individuals is in line with research into the interaction between affect and other types of cognition including long-term memory (Erk, von Kalckreuth, \& Walter, 2010). This dissociation appears to be maintained across time (Erk et al., 2010), with behavioral memory performance for affective material being unaffected by whether individuals had been instructed to regulate their affective responses to the memoranda at encoding 12 months prior (in line with Dolcos, Labar, \& Cabeza, 2005). At the neural level, however, amygdala activation during encoding of affective items that were viewed without attempts to downregulate affective experiences was stronger than amygdala activation to items encoded 12 months prior while individuals were attempting to regulate their affective responses. The reviewed evidence further suggests that it is in particular the connectivity between this vlPFC node and the amygdalo-hippocampal complex that reflects the efficacy of healthy individuals in controlling any potential interference from affective information in WM (Krause-Utz, Elzinga, Oei, Paret et al., 2014; Ladouceur et al., 2013; Ziaei, Salami, \& Persson, 2017). Interestingly, Ladouceur et al. (2013) showed reduced downregulation of amygdala reactivity by the vlPFC in response to negative and positive distractors in young people with a parent suffering from bipolar disorder compared with a healthy age-matched sample. This differential pattern of neural activation across groups was observed in the absence of behavioral performance differences. Altered functional connectivity during WM performance in the presence of affective compared with neutral material may therefore constitute a sensitive marker for mental health problems before the behavioral differences that were observed in the current behavioral meta-analysis emerge. To- gether the studies lend support to the argument that competition for resources from affective information is being routinely resolved in the vIPFC.

In mental ill health, however, maladaptive behavioral responses and involuntary attentional engagement with affective distractors are characteristic of many disorders (e.g., anxiety disorders; BarHaim et al., 2007). WM performance and its neural substrates in the presence of affective distractors may therefore constitute a source of individual differences associated with mental health problems. In line with this argument, Menon's (2011) triple neural network model of mental health proposes that weak mapping from the salience network is involved (among other things) in "[. . .] aberrant bottom-up detection of salient events, [and] aberrant control signals to other large-scale networks that facilitate access to attention and working memory resources, [. . .]" (Menon, 2011, p. 501). That is, mental health problems may be associated with particularly impaired WM performance in the presence of affective distractors due to both aberrant salience attribution to affective information at the perceptual level of competition as well as impaired control at the executive level of competition.

\section{Affective Significance in Mental Health and Across the Life Span}

A critical prediction, although somewhat underresearched in the literature, is the impact of stimuli's degree of affective significance on executive performance. Here we used age and mental health status as proxies for affective significance. In line with our predictions older people were faster to respond to positive material and WM performance in individuals with mental health problems was significantly impaired by affective information.

The changing impact of affective information on WM performance across the life span. The age results were in line with the age-related positivity effect shown in the attention and memory literature (for a meta-analytic review, see Reed, Chan, \& Mikels, 2014). However, little is known about the development of WM in affective contexts from childhood through into adulthood. Of the included studies fewer than $10 \%(n=14)$ were conducted in children and/or adolescents (Bertocci et al., 2014; Cromheeke \& Mueller, 2016; Ladouceur et al., 2005, 2013, 2009; Mueller et al., 2015; Passarotti, Ellis, Wegbreit, Stevens, \& Pavuluri, 2012, 2010, 2011; Pavuluri, Passarotti, Fitzgerald, Wegbreit, \& Sweeney, 2012; Schenkel, Passarotti, Sweeney, \& Pavuluri, 2012; Tavitian et al., 2014; Visu-Petra, Tुincaş, Cheie, \& Benga, 2010; Z. Li et al., 2009) and there was no study of the typical development of affective WM. This is particularly surprising given that affective WM in developmental samples may provide evidence for those at risk for emotional disorders by virtue of problems with affective control capacity. Moreover, interventions that augment executive control in affective contexts may constitute efficient forms of prevention, especially when administered early in development (Wass, Porayska-Pomsta, \& Johnson, 2011).

Pathways to competition from affective information in individuals with mental health problems. There are likely to be variations in the pathways through which the effects of affective significance create perceptual and executive competition across different mental health disorders. Arguably, differences in affective significance may exert their impact on perceptual competition in a similar way across diverse forms of psychopathology, whereas 
the intersection of affective significance and executive competition may rely upon different mechanisms across disorders. For example, engaging in cognitively costly emotion regulation strategies (including rumination in depression, or suppression in anxiety disorders; Aldao et al., 2010) in response to affective stimuli versus increased executive competition due to resources deployed to disambiguate affective information in schizophrenia (Kohler, Walker, Martin, Healey, \& Moberg, 2010). Similarly, there are likely to be variances in the relative affective significance of the stimuli included in standard experimental paradigms across disorders. Despite these potential differences, all of the mental health disorders included in the current behavioral meta-analysis have been shown to be associated with affective dysregulation: alcohol dependence (Cheetham, Allen, Yücel, \& Lubman, 2010); anxiety disorders (Cisler, Olatunji, Feldner, \& Forsyth, 2010); attentiondeficit and hyperactivity disorder (Graziano \& Garcia, 2016; Shaw, Stringaris, Nigg, \& Leibenluft, 2014); borderline personality disorder (Carpenter \& Trull, 2013); mood disorders (Hofmann, Sawyer, Fang, \& Asnaani, 2012; Townsend \& Altshuler, 2012); obsessive-compulsive disorder (Calkins, Berman, \& Wilhelm, 2013); PTSD (Frewen \& Lanius, 2006); and schizophrenia (Horan, Kring, \& Blanchard, 2006; Trémeau, 2006). Poor WM performance in the presence of affective material then may be a transdiagnostic marker of dysregulated affect across these disorders.

At the neural level the paucity of available studies means that the current analysis cannot speak to finer-grained questions concerning the neural substrates of the effects of affective significance across disorders. As and when further evidence emerges on affective WM from each disorder, future meta-analyses should investigate the interaction between behavioral and neuroimaging findings in these clinical populations. We currently know little about the neural substrates associated with individual differences in affective WM and potentially different pathways to interference from affective information across mental health problems. As with the posited cognitive-level pathways, the neural signatures are argued to be both overlapping and distinct across different types of mental health problems. Interestingly, the networks proposed in Menon's (2011) triple neural network model of mental health overlap with the neural networks shown in the current metaanalysis to be associated with the effects of affective stimuli on WM performance (i.e., the salience and fronto-parietal control networks). Future research is warranted to explore the neural substrates of affective WM both within and across disorders.

\section{Future Directions}

These behavioral and neural reviews focus on the interplay and integration between affective and cognitive processing. Here we offer some suggestions for potential next steps in this endeavor. A primary aim, we submit, should be to refine and provide empirical evaluation of neurobehavioral models of cognitive functioning in both intrinsic (e.g., affective states) and/or extrinsic (e.g., facial expression) affective contexts. Empirical support of, or challenges to, these models are currently typically offered by experimental tasks performed in laboratory settings, such as the affective WM tasks reviewed here. Empirical evidence for the influence of affective material in the real world, however, is scarce. That said, preliminary, yet critical, attempts have recently been made to embed and relate the findings from these laboratory measures to exerting affective control in everyday environments (Pe, Brose, Gotlib, \& Kuppens, 2016; Pe, Raes, Koval et al., 2013; Pe, Raes, \& Kuppens, 2013; Quinn \& Joormann, 2015a, 2015b). For example, in an experience sampling study $(N=95)$, Pe, Koval, and Kuppens (2013) showed that affective WM updating ability predicted individuals' ability to down-regulate high-arousal negative affective states (e.g., experiencing anger), but not low-arousal negative affective states (e.g., dysphoria). The study further showed differential associations between WM updating ability and self-reported tendencies to use rumination and reappraisal as emotion regulation strategies. These types of studies provide important insights into how executive control, as measured on laboratory tasks, may be sensitive to some but not all types of executive control over affective input in daily life. Similarly, the current analyses were limited in exploring only the impact of externally presented affective material. In daily life, however, executive control is often taxed and arguably impacted on by internally generated affective information (e.g., thoughts, memories). In a recent study, Iordan, Dolcos, and Dolcos (2018) show that autobiographical memories processed with an emotion-focus, compared with a context-focus, impair WM performance.

Inherently linked to the notion of embedding findings from tasks assessing executive control over affective information in our understanding of quotidian human cognition is the construct of emotion regulation. WM in affective contexts has been posited as central to contemporary models of emotion regulation (Etkin, Büchel, \& Gross, 2015). A recent example stems from a metaanalysis, which showed that repetitive negative thinking, a maladaptive emotion regulation strategy (Ehring \& Watkins, 2008; McEvoy, Mahoney, \& Moulds, 2010) commonly observed in mood and anxiety disorders (Klemanski, Curtiss, McLaughlin, \& Nolen-Hoeksema, 2017; Spinhoven, Drost, van Hemert, \& Pen$\operatorname{ninx}, 2015)$, is selectively associated with difficulties in discarding task-irrelevant material from WM (Zetsche, Bürkner, \& Schulze, 2018). Similarly, the current study showed that task-irrelevant distractors impair WM performance $(\hat{d}=-0.24)$, unlike taskrelevant information $(\hat{d}=-0.05)$, in individuals with mental health problems.

Investigating the association between emotion regulation at diverse levels of analysis (from self-report to experience sampling in everyday life) and performance on affective WM tasks could advance our understanding of the role of higher-order cognitive control in emotion regulation and open new avenues for intervention (Engen \& Kanske, 2013; Schweizer \& Dalgleish, 2013). Preliminary studies have shown that training affective WM can improve individuals' executive control over affective stimuli across executive functions (e.g., on an affective Stroop task; Schweizer, Hampshire, \& Dalgleish, 2011) as well as their emotion regulation capacity (Schweizer et al., 2013). However, to optimize the success of such endeavors, we require mechanistic accounts of the role of cognitive control in mental health, beyond merely showing deficits in specific processes (Grahek, Everaert, Krebs, \& Koster, 2018). In their important opinion article Grahek, Everaert, Krebs, and Koster (2018) propose that, in order to advance our understanding of the role of cognitive control in mental health, we require a multifaceted approach integrating the affective, cognitive and motivational domain rather than viewing them as separate processes merely interacting with each other. 
Finally, all analyses showed considerable remaining heterogeneity. That is, the moderators included (i.e., valence, taskrelevance, mental health status, age, emotion type, and WM load) accounted for only part of the variance in the effect of affective relative to neutral information on WM performance. Understanding the effects of other individual difference variables (e.g., factors that influence affective processing including gender and personality; Fischer, Kret, \& Broekens, 2018; Hamann \& Canli, 2004; Kret \& De Gelder, 2012; Speed et al., 2015) not modeled in the current analyses will therefore constitute an important next step in elucidating the impact of affective information on WM performance. Characterizing the relation between these individual differences and the impact of affective information on cognition is especially relevant in the context of recent findings showing that self-relevant information may particularly tax executive resources (Dai, Rahman, Lau, Sook Kim, \& Deldin, 2015; Hubbard, Hutchison, Hambrick et al., 2016; Hubbard, Hutchison, Turner et al., 2016; Iordan et al., 2018; though see Schweizer et al., 2018, Experiment 3).

\section{Conclusions}

The present meta-analyses support theoretical proposals concerning the complex interplay between affective information and WM performance. Based on the current state of science, affective information has only a negligible effect on behavioral measures of WM in healthy individuals. At the neural level, however, processing affective versus neutral material during WM is associated with more frequent recruitment of the vlPFC, the amygdala, and the temporo-occipital cortex. The behavioral impact of affective information appears to be augmented in individuals for whom affective stimuli carry greater affective significance. Compared with healthy individuals, those suffering from mental health problems show a small and reliable impairment of WM accuracy in the presence of affective material and older adults show faster RTs in WM tasks including positive material. These findings suggest that investigating the impact of affective information on executive performance can provide an important window into the understanding of individuals' cognitive functioning in affectively valenced everyday environments.

\section{References}

Admon, R., \& Pizzagalli, D. A. (2015). Dysfunctional reward processing in depression. Current Opinion in Psychology, 4, 114-118. http://dx.doi .org/10.1016/j.copsyc.2014.12.011

Adolphs, R. (2010). What does the amygdala contribute to social cognition? Annals of the New York Academy of Sciences, 1191, 42-61. http://dx.doi.org/10.1111/j.1749-6632.2010.05445.x

Aldao, A., Nolen-Hoeksema, S., \& Schweizer, S. (2010). Emotionregulation strategies across psychopathology: A meta-analytic review. Clinical Psychology Review, 30, 217-237. http://dx.doi.org/10.1016/j .cpr.2009.11.004

Aleman, A., \& Kahn, R. S. (2005). Strange feelings: Do amygdala abnormalities dysregulate the emotional brain in schizophrenia? Progress in Neurobiology, 77, 283-298. http://dx.doi.org/10.1016/j.pneurobio.2005 .11 .005

Allen, R. J., Schaefer, A., \& Falcon, T. (2014). Recollecting positive and negative autobiographical memories disrupts working memory. Acta Psychologica, 151, 237-243. http://dx.doi.org/10.1016/j.actpsy.2014.07 .003

Alonso-Recio, L., Martín-Plasencia, P., Loeches-Alonso, Á., \& SerranoRodríguez, J. M. (2014). Working memory and facial expression recog- nition in patients with Parkinson's disease. Journal of the International Neuropsychological Society, 20, 496-505. http://dx.doi.org/10.1017/ S1355617714000265

Al-Shawaf, L., Conroy-Beam, D., Asao, K., \& Buss, D. M. (2016). Human emotions: An evolutionary psychological perspective. Emotion Review, 8, 173-186. http://dx.doi.org/10.1177/1754073914565518

Amaral, D. G., Behniea, H., \& Kelly, J. L. (2003). Topographic organization of projections from the amygdala to the visual cortex in the macaque monkey. Neuroscience, 118, 1099-1120. http://dx.doi.org/10.1016/ S0306-4522(02)01001-1

Amir, N., \& Bomyea, J. (2011). Working memory capacity in generalized social phobia. Journal of Abnormal Psychology, 120, 504-509. http:// dx.doi.org/10.1037/a0022849

Amo, R., Fredes, F., Kinoshita, M., Aoki, R., Aizawa, H., Agetsuma, M., . . . Okamoto, H. (2014). The habenulo-raphe serotonergic circuit encodes an aversive expectation value essential for adaptive active avoidance of danger. Neuron, 84, 1034-1048. http://dx.doi.org/10.1016/j .neuron.2014.10.035

Anticevic, A., Repovs, G., \& Barch, D. M. (2010). Resisting emotional interference: Brain regions facilitating working memory performance during negative distraction. Cognitive, Affective \& Behavioral Neuroscience, 10, 159-173. http://dx.doi.org/10.3758/CABN.10.2.159

Anticevic, A., Repovs, G., Corlett, P. R., \& Barch, D. M. (2011). Negative and nonemotional interference with visual working memory in schizophrenia. Biological Psychiatry, 70, 1159-1168. http://dx.doi.org/10 .1016/j.biopsych.2011.07.010

Aron, A. R., Robbins, T. W., \& Poldrack, R. A. (2004). Inhibition and the right inferior frontal cortex. Trends in Cognitive Sciences, 8, 170-177. http://dx.doi.org/10.1016/j.tics.2004.02.010

Aronen, E. T., Vuontela, V., Steenari, M. R., Salmi, J., \& Carlson, S. (2005). Working memory, psychiatric symptoms, and academic performance at school. Neurobiology of Learning and Memory, 83, 33-42. http://dx.doi.org/10.1016/j.nlm.2004.06.010

Artuso, C., Palladino, P., \& Ricciardelli, P. (2012). How do we update faces? Effects of gaze direction and facial expressions on working memory updating. Frontiers in Psychology, 3, 362. http://dx.doi.org/10 .3389/fpsyg.2012.00362

Augusti, E.-M., Torheim, H. K., \& Melinder, A. (2014). The effect of emotional facial expressions on children's working memory: Associations with age and behavior. Child Neuropsychology, 20, 86-105. http:// dx.doi.org/10.1080/09297049.2012.749225

Avery, R. E., Smillie, L. D., \& de Fockert, J. W. (2013). The role of working memory in achievement goal pursuit. Acta Psychologica, 144, 361-372. http://dx.doi.org/10.1016/j.actpsy.2013.07.012

Baddeley, A. (2003). Working memory: Looking back and looking forward. Nature Reviews Neuroscience, 4, 829-839. http://dx.doi.org/10 $.1038 / \mathrm{nrn} 1201$

Baddeley, A. D. (2013). Working memory and emotion: Ruminations on a theory of depression. Review of General Psychology, 17, 20-27. http:// dx.doi.org/10.1037/a0030029

Badre, D., \& Wagner, A. D. (2005). Frontal lobe mechanisms that resolve proactive interference. Cerebral Cortex, 15, 2003-2012. http://dx.doi .org/10.1093/cercor/bhi075

Badre, D., \& Wagner, A. D. (2007). Left ventrolateral prefrontal cortex and the cognitive control of memory. Neuropsychologia, 45, 2883-2901. http://dx.doi.org/10.1016/j.neuropsychologia.2007.06.015

Bakvis, P., Spinhoven, P., Putman, P., Zitman, F. G., \& Roelofs, K. (2010). The effect of stress induction on working memory in patients with psychogenic nonepileptic seizures. Epilepsy \& Behavior, 19, 448-454. http://dx.doi.org/10.1016/j.yebeh.2010.08.026

Balodis, I. M., Johnsrude, I. S., \& Olmstead, M. C. (2007). Intact preference conditioning in acute intoxication despite deficient declarative knowledge and working memory. Alcoholism, Clinical and Experimen- 
tal Research, 31, 1800-1810. http://dx.doi.org/10.1111/j.1530-0277 .2007.00482.x

Banks, J. B., Tartar, J. L., \& Tamayo, B. A. (2015). Examining factors involved in stress-related working memory impairments: Independent or conditional effects? Emotion, 15, 827-836. http://dx.doi.org/10.1037/ emo0000096

Bar-Haim, Y., Lamy, D., Pergamin, L., Bakermans-Kranenburg, M. J., \& van IJzendoorn, M. H. (2007). Threat-related attentional bias in anxious and nonanxious individuals: A meta-analytic study. Psychological Bulletin, 133, 1-24. http://dx.doi.org/10.1037/0033-2909.133.1.1

Barrett, L. F. (2005). Feeling is perceiving: Core affect and conceptualization in the experience of emotion. In L. F. Barrett, P. M. Niedenthal, \& P. Winkielman (Eds.), Emotion and consciousness (pp. 255-284). New York, NY: Guilford Press.

Barrett, L. F. (2006). Valence is a basic building block of emotional life. Journal of Research in Personality, 40, 35-55. http://dx.doi.org/10 .1016/j.jrp.2005.08.006

Barrett, L. F. (2009). The future of psychology: Connecting mind to brain. Perspectives on Psychological Science, 4, 326-339. http://dx.doi.org/10 $.1111 / \mathrm{j} .1745-6924.2009 .01134 . x$

Barrett, L. F. (2013). Psychological construction: The Darwinian approach to the science of emotion. Emotion Review, 5, 379-389. http://dx.doi .org/10.1177/1754073913489753

Barrett, L. F. (2014). The conceptual act theory: A précis. Emotion Review, 6, 292-297. http://dx.doi.org/10.1177/1754073914534479

Barrett, L. F., \& Satpute, A. B. (2013). Large-scale brain networks in affective and social neuroscience: Towards an integrative functional architecture of the brain. Current Opinion in Neurobiology, 23, 361372. http://dx.doi.org/10.1016/j.conb.2012.12.012

Barrett, L. F., Tugade, M. M., \& Engle, R. W. (2004). Individual differences in working memory capacity and dual-process theories of the mind. Psychological Bulletin, 130, 553-573. http://dx.doi.org/10.1037/ 0033-2909.130.4.553

Bauer, I. E., Jordan, G., Soares, J. C., \& Meyer, T. D. (2015). The role of negative mood induction on working memory capacity in individuals putatively at risk for bipolar disorder: A pilot study. Journal of Affective Disorders, 185, 60-66. http://dx.doi.org/10.1016/j.jad.2015.05.068

Becerril, K., \& Barch, D. (2011). Influence of emotional processing on working memory in schizophrenia. Schizophrenia Bulletin, 37, 10271038. http://dx.doi.org/10.1093/schbul/sbq009

Beckwé, M., Deroost, N., Koster, E. H. W., De Lissnyder, E., \& De Raedt, R. (2014). Worrying and rumination are both associated with reduced cognitive control. Psychological Research, 78, 651-660. http://dx.doi org/10.1007/s00426-013-0517-5

Belham, F. S., Satler, C., Garcia, A., Tomaz, C., Gasbarri, A., Rego, A., \& Tavares, M. C. (2013). Age-related differences in cortical activity during a visuo-spatial working memory task with facial stimuli. PLoS ONE, 8, e75778. http://dx.doi.org/10.1371/journal.pone.0075778

Beneventi, H., Barndon, R., Ersland, L., \& Hugdahl, K. (2007). An fMRI study of working memory for schematic facial expressions. Scandinavian Journal of Psychology, 48, 81-86. http://dx.doi.org/10.1111/j 1467-9450.2007.00536.x

Bennett, D. S., Mohamed, F. B., Carmody, D. P., Malik, M., Faro, S. H., \& Lewis, M. (2013). Prenatal tobacco exposure predicts differential brain function during working memory in early adolescence: A preliminary investigation. Brain Imaging and Behavior, 7, 49-59. http://dx.doi .org/10.1007/s11682-012-9192-1

Berger, C., Erbe, A.-K., Ehlers, I., Marx, I., Hauenstein, K., \& Teipel, S. (2015). Effects of task-irrelevant emotional stimuli on working memory processes in mild cognitive impairment. JAD, 44, 439-453. http://dx .doi.org/10.3233/JAD-141848

Bergmann, H. C., Rijpkema, M., Fernández, G., \& Kessels, R. P. (2012). The effects of valence and arousal on associative working memory and long-term memory. PLoS ONE, 7, e52616. http://dx.doi.org/10.1371/ journal.pone.0052616

Berman, M. G., Nee, D. E., Casement, M., Kim, H. S., Deldin, P., Kross, E., . . Jonides, J. (2011). Neural and behavioral effects of interference resolution in depression and rumination. Cognitive, Affective \& Behavioral Neuroscience, 11, 85-96. http://dx.doi.org/10.3758/s13415-0100014-x

Bertocci, M. A., Bebko, G. M., Mullin, B. C., Langenecker, S. A., Ladouceur, C. D., Almeida, J. R. C., \& Phillips, M. L. (2012). Abnormal anterior cingulate cortical activity during emotional n-back task performance distinguishes bipolar from unipolar depressed females. Psychological Medicine, 42, 1417-1428. http://dx.doi.org/10.1017/ S003329171100242X

Bertocci, M. A., Bebko, G., Olino, T., Fournier, J., Hinze, A. K., Bonar, L., . . . Phillips, M. L. (2014). Behavioral and emotional dysregulation trajectories marked by prefrontal-amygdala function in symptomatic youth. Psychological Medicine, 44, 2603-2615. http://dx.doi.org/10 .1017/S0033291714000087

Boonstra, A. M., Oosterlaan, J., Sergeant, J. A., \& Buitelaar, J. K. (2005) Executive functioning in adult ADHD: A meta-analytic review. Psychological Medicine, 35, 1097-1108. http://dx.doi.org/10.1017/ S003329170500499X

Borella, E., Carretti, B., Grassi, M., Nucci, M., \& Sciore, R. (2014). Are age-related differences between young and older adults in an affective working memory test sensitive to the music effects? Frontiers in Aging Neuroscience, 6, 298. http://dx.doi.org/10.3389/fnagi.2014.00298

Borg, C., Leroy, N., Favre, E., Laurent, B., \& Thomas-Antérion, C. (2011). How emotional pictures influence visuospatial binding in short-term memory in ageing and Alzheimer's disease? Brain and Cognition, 76, 20-25. http://dx.doi.org/10.1016/j.bandc.2011.03.008

Boutelle, K. N., Wierenga, C. E., Bischoff-Grethe, A., Melrose, A. J. Grenesko-Stevens, E., Paulus, M. P., \& Kaye, W. H. (2014). Increased brain response to appetitive tastes in the insula and amygdala in obese compared with healthy weight children when sated. International Journal of Obesity, 39, 620-628.

Bradley, B. P., \& Lang, P. J. (1999). Affective Norms for English Words (ANEW): Instruction manual and affective ratings. Gainesville, FL: The Center for Research Psychophysiology, University of Florida.

Bressler, S. L., \& Menon, V. (2010). Large-scale brain networks in cognition: Emerging methods and principles. Trends in Cognitive Sciences, 14, 277-290. http://dx.doi.org/10.1016/j.tics.2010.04.004

Brosch, T., Sander, D., Pourtois, G., \& Scherer, K. R. (2008). Beyond fear: Rapid spatial orienting toward positive emotional stimuli. Psychological Science, 19, 362-370. http://dx.doi.org/10.1111/j.1467-9280.2008 .02094.x

Brose, A., Lövdén, M., \& Schmiedek, F. (2014). Daily fluctuations in positive affect positively co-vary with working memory performance. Emotion, 14, 1-6. http://dx.doi.org/10.1037/a0035210

Brose, A., Schmiedek, F., Lövdén, M., \& Lindenberger, U. (2012). Daily variability in working memory is coupled with negative affect: The role of attention and motivation. Emotion, 12, 605-617. http://dx.doi.org/10 1037/a0024436

Brosschot, J. F., \& Thayer, J. F. (2003). Heart rate response is longer after negative emotions than after positive emotions. International Journal of Psychophysiology, 50, 181-187. http://dx.doi.org/10.1016/S01678760(03)00146-6

Brunyé, T. T., Howe, J. L., Walker, L. A., \& Mahoney, C. R. (2013). Acute bouts of endurance exercise increase distractibility to emotional stimuli. International Journal of Sport Psychology, 44, 471-492.

Buchanan, T. W., \& Adolphs, R. (2002). The role of the human amygdala in emotional modulation of long-term declarative memory. Advances in Consciousness Research, 44, 9-34. http://dx.doi.org/10.1075/aicr.44 .02 buc 
Buckert, M., Kudielka, B. M., Reuter, M., \& Fiebach, C. J. (2012). The COMT Val158Met polymorphism modulates working memory performance under acute stress. Psychoneuroendocrinology, 37, 1810-1821. http://dx.doi.org/10.1016/j.psyneuen.2012.03.014

Buhle, J. T., Silvers, J. A., Wager, T. D., Lopez, R., Onyemekwu, C., Kober, H., . . O Ochsner, K. N. (2014). Cognitive reappraisal of emotion: A meta-analysis of human neuroimaging studies. Cerebral Cortex, 24, 2981-2990. http://dx.doi.org/10.1093/cercor/bht154

Buratto, L. G., Pottage, C. L., Brown, C., Morrison, C. M., \& Schaefer, A. (2014). The effects of a distracting N-back task on recognition memory are reduced by negative emotional intensity. PLOS ONE, 9, e110211. http://dx.doi.org/10.1371/journal.pone.0110211

Burhan, A. M., Anazodo, U. C., Chung, J. K., Arena, A., Graff-Guerrero, A., \& Mitchell, D. G. (2016). The effect of task-irrelevant fearful-face distractor on working memory processing in mild cognitive impairment versus healthy controls: An exploratory fMRI study in female participants. Behavioural Neurology. Advance online publication. http://dx.doi .org/10.1155/2016/1637392

Calkins, A. W., Berman, N. C., \& Wilhelm, S. (2013). Recent advances in research on cognition and emotion in OCD: A review. Current Psychiatry Reports, 15, 357. http://dx.doi.org/10.1007/s11920-013-0357-4

Cao, H., Plichta, M. M., Schäfer, A., Haddad, L., Grimm, O., Schneider, M., . . . Tost, H. (2014). Test-retest reliability of fMRI-based graph theoretical properties during working memory, emotion processing, and resting state. NeuroImage, 84, 888-900. http://dx.doi.org/10.1016/j .neuroimage.2013.09.013

Carpenter, R. W., \& Trull, T. J. (2013). Components of emotion dysregulation in borderline personality disorder: A review. Current Psychiatry Reports, 15, 335. http://dx.doi.org/10.1007/s11920-012-0335-2

Carstensen, L. L. (2006). The influence of a sense of time on human development. Science, 312, 1913-1915. http://dx.doi.org/10.1126/ science. 1127488

Cheetham, A., Allen, N. B., Yücel, M., \& Lubman, D. I. (2010). The role of affective dysregulation in drug addiction. Clinical Psychology Review, 30, 621-634. http://dx.doi.org/10.1016/j.cpr.2010.04.005

Chen, X., Feng, Z., Wang, T., Su, H., \& Zhang, L. (2016). Internal switching and backward inhibition in depression and rumination. Psychiatry Research, 243, 342-348. http://dx.doi.org/10.1016/j.psychres .2016.06.014

Chen, Y., Norton, D., McBain, R., Ongur, D., \& Heckers, S. (2009). Visual and cognitive processing of face information in schizophrenia: Detection, discrimination and working memory. Schizophrenia Research, 107, 92-98. http://dx.doi.org/10.1016/j.schres.2008.09.010

Chuah, L. Y. M., Dolcos, F., Chen, A. K., Zheng, H., Parimal, S., \& Chee, M. W. L. (2010). Sleep deprivation and interference by emotional distracters. Sleep, 33, 1305-1313. http://dx.doi.org/10.1093/sleep/33.10 .1305

Cisler, J. M., Olatunji, B. O., Feldner, M. T., \& Forsyth, J. P. (2010). Emotion regulation and the anxiety disorders: An integrative review. Journal of Psychopathology and Behavioral Assessment, 32, 68-82. http://dx.doi.org/10.1007/s10862-009-9161-1

Clore, G. L., \& Huntsinger, J. R. (2007). How emotions inform judgment and regulate thought. Trends in Cognitive Sciences, 11, 393-399. http:// dx.doi.org/10.1016/j.tics.2007.08.005

Coburn, K. M., \& Vevea, J. L. (2015). Publication bias as a function of study characteristics. Psychological Methods, 20, 310-330. http://dx.doi .org/10.1037/met0000046

Cohen, J. D., Perlstein, W. M., Braver, T. S., Nystrom, L. E., Noll, D. C., Jonides, J., \& Smith, E. E. (1997). Temporal dynamics of brain activation during a working memory task. Nature, 386, 604-608. http://dx .doi.org/10.1038/386604a0

Colligan, S. M., \& Koven, N. S. (2015). Interference resolution in emotional working memory as a function of alexithymia. The American
Journal of Psychology, 128, 337-345. http://dx.doi.org/10.5406/ amerjpsyc.128.3.0337

Constantinidis, C., \& Klingberg, T. (2016). The neuroscience of working memory capacity and training. Nature Reviews Neuroscience, 17, 438 449. http://dx.doi.org/10.1038/nrn.2016.43

Conway, A. R. A., Kane, M. J., Bunting, M. F., Hambrick, D. Z., Wilhelm, O., \& Engle, R. W. (2005). Working memory span tasks: A methodological review and user's guide. Psychonomic Bulletin \& Review, 12, 769-786. http://dx.doi.org/10.3758/BF03196772

Cook, I. A., Bookheimer, S. Y., Mickes, L., Leuchter, A. F., \& Kumar, A. (2007). Aging and brain activation with working memory tasks: An fMRI study of connectivity. International Journal of Geriatric Psychiatry, 22, 332-342. http://dx.doi.org/10.1002/gps.1678

Corbetta, M., Patel, G., \& Shulman, G. L. (2008). The reorienting system of the human brain: From environment to theory of mind. Neuron, 58, 306-324. http://dx.doi.org/10.1016/j.neuron.2008.04.017

Corbetta, M., \& Shulman, G. L. (2002). Control of goal-directed and stimulus-driven attention in the brain. Nature Reviews Neuroscience, 3, 201-215. http://dx.doi.org/10.1038/nrn755

Coull, J. T., Frith, C. D., Frackowiak, R. S. J., \& Grasby, P. M. (1996). A fronto-parietal network for rapid visual information processing: A PET study of sustained attention and working memory. Neuropsychologia, 34, 1085-1095. http://dx.doi.org/10.1016/0028-3932(96)00029-2

Courtney, S. M., Petit, L., Maisog, J. M., Ungerleider, L. G., \& Haxby, J. V. (1998). An area specialized for spatial working memory in human frontal cortex. Science, 279, 1347-1351. http://dx.doi.org/10.1126/ science.279.5355.1347

Cromheeke, S., Herpoel, L.-A., \& Mueller, S. C. (2014). Childhood abuse is related to working memory impairment for positive emotion in female university students. Child Maltreatment, 19, 38-48. http://dx.doi.org/10 $.1177 / 1077559513511522$

Cromheeke, S., \& Mueller, S. C. (2016). The power of a smile: Stronger working memory effects for happy faces in adolescents compared to adults. Cognition and Emotion, 30, 288-301. http://dx.doi.org/10.1080/ 02699931.2014 .997196

Cubillo, A., Halari, R., Smith, A., Taylor, E., \& Rubia, K. (2012). A review of fronto-striatal and fronto-cortical brain abnormalities in children and adults with attention deficit hyperactivity disorder (ADHD) and new evidence for dysfunction in adults with ADHD during motivation and attention. Cortex, 48, 194-215. http://dx.doi.org/10.1016/j.cortex.2011 .04 .007

Curci, A., Lanciano, T., Soleti, E., \& Rimé, B. (2013). Negative emotional experiences arouse rumination and affect working memory capacity. Emotion, 13, 867-880. http://dx.doi.org/10.1037/a0032492

Dai, Q., Rahman, S., Lau, B., Sook Kim, H., \& Deldin, P. (2015). The influence of self-relevant materials on working memory in dysphoric undergraduates. Psychiatry Research, 229, 858-866. http://dx.doi.org/ 10.1016/j.psychres.2015.07.068

Daniel, T. A., Katz, J. S., \& Robinson, J. L. (2016). Delayed match-tosample in working memory: A BrainMap meta-analysis. Biological Psychology, 120, 10-20. http://dx.doi.org/10.1016/j.biopsycho.2016.07 .015

Davidson, R. J., Lewis, D. A., Alloy, L. B., Amaral, D. G., Bush, G., Cohen, J. D., . . Peterson, B. S. (2002). Neural and behavioral substrates of mood and mood regulation. Biological Psychiatry, 52, 478-502. http://dx.doi.org/10.1016/S0006-3223(02)01458-0

Deckersbach, T., Rauch, S. L., Buhlmann, U., Ostacher, M. J., Beucke, J.-C., Nierenberg, A. A., . . . Dougherty, D. D. (2008). An fMRI investigation of working memory and sadness in females with bipolar disorder: A brief report. Bipolar Disorders, 10, 928-942. http://dx.doi .org/10.1111/j.1399-5618.2008.00633.x

De Lissnyder, E., Koster, E. H. W., \& De Raedt, R. (2012). Emotional interference in working memory is related to rumination. Cognitive 
Therapy and Research, 36, 348-357. http://dx.doi.org/10.1007/s10608011-9352-4

De Lissnyder, E., Koster, E. H. W., Everaert, J., Schacht, R., Van den Abeele, D., \& De Raedt, R. (2012). Internal cognitive control in clinical depression: General but no emotion-specific impairments. Psychiatry Research, 199, 124-130. http://dx.doi.org/10.1016/j.psychres.2012.04 .019

De Lissnyder, E., Koster, E. H. W., Goubert, L., Onraedt, T., Vanderhasselt, M. A., \& De Raedt, R. (2012). Cognitive control moderates the association between stress and rumination. Journal of Behavior Therapy and Experimental Psychiatry, 43, 519-525. http://dx.doi.org/10.1016/j .jbtep.2011.07.004

Demeyer, I., De Lissnyder, E., Koster, E. H. W., \& De Raedt, R. (2012). Rumination mediates the relationship between impaired cognitive control for emotional information and depressive symptoms: A prospective study in remitted depressed adults. Behaviour Research and Therapy, 50, 292-297. http://dx.doi.org/10.1016/j.brat.2012.02.012

Denkova, E., Wong, G., Dolcos, S., Sung, K., Wang, L., Coupland, N., \& Dolcos, F. (2010). The impact of anxiety-inducing distraction on cognitive performance: A combined brain imaging and personality investigation. PLOS ONE, 5, e14150. http://dx.doi.org/10.1371/journal.pone .0014150

De Raedt, R., \& Koster, E. H. W. (2010). Understanding vulnerability for depression from a cognitive neuroscience perspective: A reappraisal of attentional factors and a new conceptual framework. Cognitive, Affective \& Behavioral Neuroscience, 10, 50-70. http://dx.doi.org/10.3758/ CABN.10.1.50

Derakshan, N., \& Eysenck, M. W. (2009). Anxiety, processing efficiency, and cognitive performance: New developments from attentional control theory. European Psychologist, 14, 168-176. http://dx.doi.org/10.1027/ 1016-9040.14.2.168

D’Esposito, M., Postle, B. R., Ballard, D., \& Lease, J. (1999). Maintenance versus manipulation of information held in working memory: An eventrelated fMRI study. Brain and Cognition, 41, 66-86. http://dx.doi.org/ 10.1006/brcg.1999.1096

DeYoung, C. G., Shamosh, N. A., Green, A. E., Braver, T. S., \& Gray, J. R. (2009). Intellect as distinct from Openness: Differences revealed by fMRI of working memory. Journal of Personality and Social Psychology, 97, 883-892. http://dx.doi.org/10.1037/a0016615

Diaz, M. T., He, G., Gadde, S., Bellion, C., Belger, A., Voyvodic, J. T., \& McCarthy, G. (2011). The influence of emotional distraction on verbal working memory: An fMRI investigation comparing individuals with schizophrenia and healthy adults. Journal of Psychiatric Research, 45, 1184-1193. http://dx.doi.org/10.1016/j.jpsychires.2011.02.008

Dickstein, S. G., Bannon, K., Castellanos, F. X., \& Milham, M. P. (2006). The neural correlates of attention deficit hyperactivity disorder: An ALE meta-analysis. Journal of Child Psychology and Psychiatry, 47, 10511062. http://dx.doi.org/10.1111/j.1469-7610.2006.01671.x

Dillon, D. G., \& Pizzagalli, D. A. (2007). Inhibition of action, thought, and emotion: A selective neurobiological review. Applied \& Preventive Psychology, 12, 99-114. http://dx.doi.org/10.1016/j.appsy.2007.09.004

Dilworth-Bart, J., Poehlmann, J., Hilgendorf, A. E., Miller, K., \& Lambert, H. (2010). Maternal scaffolding and preterm toddlers' visual-spatial processing and emerging working memory. Journal of Pediatric Psychology, 35, 209-220. http://dx.doi.org/10.1093/jpepsy/jsp048

Diwadkar, V. A., Pruitt, P., Zhang, A., Radwan, J., Keshavan, M. S., Murphy, E., . . Z Zajac-Benitez, C. (2012). The neural correlates of performance in adolescents at risk for schizophrenia: Inefficiently increased cortico-striatal responses measured with fMRI. Journal of Psychiatric Research, 46, 12-21. http://dx.doi.org/10.1016/j.jpsychires .2011.09.016

Dixon, M. L., Thiruchselvam, R., Todd, R., \& Christoff, K. (2017). Emotion and the prefrontal cortex: An integrative review. Psychological Bulletin, 143, 1033-1081. http://dx.doi.org/10.1037/bul0000096
Doallo, S., Holguín, S. R., \& Cadaveira, F. (2006). Attentional load affects automatic emotional processing: Evidence from event-related potentials. NeuroReport, 17, 1797-1801. http://dx.doi.org/10.1097/01.wnr .0000246325 .51191 .39

Döhnel, K., Sommer, M., Ibach, B., Rothmayr, C., Meinhardt, J., \& Hajak, G. (2008). Neural correlates of emotional working memory in patients with mild cognitive impairment. Neuropsychologia, 46, 37-48. http:// dx.doi.org/10.1016/j.neuropsychologia.2007.08.012

Dolan, R. J. (2002). Emotion, cognition, and behavior. Science, 298 1191-1194. http://dx.doi.org/10.1126/science.1076358

Dolcos, F., \& Denkova, E. (2014). Current emotion research in cognitive neuroscience: Linking enhancing and impairing effects of emotion on cognition. Emotion Review, 6, 362-375. http://dx.doi.org/10.1177/ 1754073914536449

Dolcos, F., Diaz-Granados, P., Wang, L., \& McCarthy, G. (2008). Opposing influences of emotional and non-emotional distracters upon sustained prefrontal cortex activity during a delayed-response working memory task. Neuropsychologia, 46, 326-335. http://dx.doi.org/10 .1016/j.neuropsychologia.2007.07.010

Dolcos, F., Iordan, A. D., Kragel, J., Stokes, J., Campbell, R., McCarthy, G., \& Cabeza, R. (2013). Neural correlates of opposing effects of emotional distraction on working memory and episodic memory: An event-related FMRI investigation. Frontiers in Psychology, 4, 293. http://dx.doi.org/10.3389/fpsyg.2013.00293

Dolcos, F., Katsumi, Y., Denkova, E., \& Dolcos, S. (2017). Factors influencing opposing effects of emotion on cognition: A review of evidence from research on perception and memory. In I. Opris \& M. F. Casanova (Eds.), The physics of the mind and brain disorders: Integrated neural circuits supporting the emergence of mind (pp. 297-341). Cham, Switzerland: Springer International Publishing. http://dx.doi.org/ 10.1007/978-3-319-29674-6_14

Dolcos, F., Kragel, P., Wang, L., \& McCarthy, G. (2006). Role of the inferior frontal cortex in coping with distracting emotions. NeuroReport, 17, 1591-1594. http://dx.doi.org/10.1097/01.wnr.0000236860.24081.be

Dolcos, F., LaBar, K. S., \& Cabeza, R. (2005). Remembering one year later: Role of the amygdala and the medial temporal lobe memory system in retrieving emotional memories. Proceedings of the National Academy of Sciences of the United States of America, 102, 2626-2631. http://dx.doi.org/10.1073/pnas.0409848102

Dolcos, F., \& McCarthy, G. (2006). Brain systems mediating cognitive interference by emotional distraction. The Journal of Neuroscience, 26 , 2072-2079. http://dx.doi.org/10.1523/JNEUROSCI.5042-05.2006

Dorahy, M. J., Irwin, H. J., \& Middleton, W. (2004). Assessing markers of working memory function in dissociative identity disorder using neutral stimuli: A comparison with clinical and general population samples. The Australian and New Zealand Journal of Psychiatry, 38, 47-55. http:// dx.doi.org/10.1177/000486740403800101

Dowson, J. H., Blackwell, A. D., Turner, D. C., Harvey, E., Malhotra, T., Robbins, T. W., \& Sahakian, B. J. (2007). Questionnaire ratings of attention-deficit/hyperactivity disorder (ADHD) in adults are associated with spatial working memory. European Psychiatry, 22, 256-263. http://dx.doi.org/10.1016/j.eurpsy.2006.08.005

Drapier, D., Surguladze, S., Marshall, N., Schulze, K., Fern, A., Hall, M. H., . . McDonald, C. (2008). Genetic liability for bipolar disorder is characterized by excess frontal activation in response to a working memory task. Biological Psychiatry, 64, 513-520. http://dx.doi.org/10 .1016/j.biopsych.2008.04.038

Dretsch, M. N., \& Tipples, J. (2008). Working memory involved in predicting future outcomes based on past experiences. Brain and Cog nition, 66, 83-90. http://dx.doi.org/10.1016/j.bandc.2007.05.006

Duncan, J. (2006). EPS Mid-Career Award 2004: Brain mechanisms of attention. Quarterly Journal of Experimental Psychology: Human Experimental Psychology, 59, 2-27. http://dx.doi.org/10.1080/ 17470210500260674 
Duncan, J. (2010). The multiple-demand (MD) system of the primate brain: Mental programs for intelligent behaviour. Trends in Cognitive Sciences, 14, 172-179. http://dx.doi.org/10.1016/j.tics.2010.01.004

Duncan, J., \& Owen, A. M. (2000). Common regions of the human frontal lobe recruited by diverse cognitive demands. Trends in Neurosciences, 23, 475-483. http://dx.doi.org/10.1016/S0166-2236(00)01633-7

Eckert, M. A., Menon, V., Walczak, A., Ahlstrom, J., Denslow, S., Horwitz, A., \& Dubno, J. R. (2009). At the heart of the ventral attention system: The right anterior insula. Human Brain Mapping, 30, 25302541. http://dx.doi.org/10.1002/hbm.20688

Edelstein, R. S. (2006). Attachment and emotional memory: Investigating the source and extent of avoidant memory impairments. Emotion, 6, 340-345. http://dx.doi.org/10.1037/1528-3542.6.2.340

Egger, M., Davey Smith, G., Schneider, M., \& Minder, C. (1997). Bias in meta-analysis detected by a simple, graphical test. British Journal of Medicine, 315, 629-634. http://dx.doi.org/10.1136/bmj.315.7109.629

Ehring, T., \& Watkins, E. R. (2008). Repetitive negative thinking as a transdiagnostic process. International Journal of Cognitive Therapy, 1, 192-205. http://dx.doi.org/10.1521/ijct.2008.1.3.192

El-Hage, W., Gaillard, P., Isingrini, M., \& Belzung, C. (2006). Traumarelated deficits in working memory. Cognitive Neuropsychiatry, 11, 33-46. http://dx.doi.org/10.1080/13546800444000164

Elliott, R., \& Deakin, B. (2005). Role of the orbitofrontal cortex in reinforcement processing and inhibitory control: Evidence from functional magnetic resonance imaging studies in healthy human subjects. International Review of Neurobiology, 65, 89-116. http://dx.doi.org/10 .1016/S0074-7742(04)65004-5

Elzinga, B. M., \& Bremner, J. D. (2002). Are the neural substrates of memory the final common pathway in posttraumatic stress disorder (PTSD)? Journal of Affective Disorders, 70, 1-17. http://dx.doi.org/10 .1016/S0165-0327(01)00351-2

Engelhard, I. M., van den Hout, M. A., \& Smeets, M. A. M. (2011). Taxing working memory reduces vividness and emotional intensity of images about the Queen's Day tragedy. Journal of Behavior Therapy and Experimental Psychiatry, 42, 32-37. http://dx.doi.org/10.1016/j.jbtep .2010 .09 .004

Engen, H., \& Kanske, P. (2013). How working memory training improves emotion regulation: Neural efficiency, effort, and transfer effects. The Journal of Neuroscience, 33, 12152-12153. http://dx.doi.org/10.1523/ JNEUROSCI.2115-13.2013

Engle, R. W., \& Kane, M. J. (2004). Executive attention, working memory capacity, and a two-factor theory of cognitive control. Psychology of Learning and Motivation, 44, 145-200. http://dx.doi.org/10.1016/ S0079-7421(03)44005-X

Epperson, C. N., Amin, Z., Ruparel, K., Gur, R., \& Loughead, J. (2012). Interactive effects of estrogen and serotonin on brain activation during working memory and affective processing in menopausal women. Psychoneuroendocrinology, 37, 372-382. http://dx.doi.org/10.1016/j .psyneuen.2011.07.007

Erk, S., Kleczar, A., \& Walter, H. (2007). Valence-specific regulation effects in a working memory task with emotional context. NeuroImage, 37, 623-632. http://dx.doi.org/10.1016/j.neuroimage.2007.05.006

Erk, S., von Kalckreuth, A., \& Walter, H. (2010). Neural long-term effects of emotion regulation on episodic memory processes. Neuropsychologia, 48, 989-996. http://dx.doi.org/10.1016/j.neuropsychologia.2009.11 .022

Etkin, A., Büchel, C., \& Gross, J. J. (2015). The neural bases of emotion regulation. Nature Reviews Neuroscience, 16, 693-700. http://dx.doi .org/10.1038/nrn4044

Evans, D. E., Craig, C., Oliver, J. A., \& Drobes, D. J. (2011). The smoking N-back: A measure of biased cue processing at varying levels of cognitive load. Nicotine \& Tobacco Research, 13, 88-93. http://dx.doi.org/ $10.1093 /$ ntr/ntq214
Everaert, J., Koster, E. H. W., \& Derakshan, N. (2012). The combined cognitive bias hypothesis in depression. Clinical Psychology Review, 32, 413-424. http://dx.doi.org/10.1016/j.cpr.2012.04.003

Ewbank, M. P., Barnard, P. J., Croucher, C. J., Ramponi, C., \& Calder, A. J. (2009). The amygdala response to images with impact. Social Cognitive and Affective Neuroscience, 4, 127-133. http://dx.doi.org/10 .1093/scan/nsn048

Eysenck, M. W., Derakshan, N., Santos, R., \& Calvo, M. G. (2007) Anxiety and cognitive performance: Attentional control theory. Emotion, 7, 336-353. http://dx.doi.org/10.1037/1528-3542.7.2.336

Fairfield, B., Mammarella, N., \& Di Domenico, A. (2015). Motivated goal pursuit and working memory: Are there age-related differences? Motivation and Emotion, 39, 201-215. http://dx.doi.org/10.1007/s11031014-9428-z

Fairfield, B., Mammarella, N., Di Domenico, A., \& Palumbo, R. (2015). Running with emotion: When affective content hampers working memory performance. International Journal of Psychology, 50, 161-164. http://dx.doi.org/10.1002/ijop.12101

Fales, C. L., Becerril, K. E., Luking, K. R., \& Barch, D. M. (2010). Emotional-stimulus processing in trait anxiety is modulated by stimulus valence during neuroimaging of a working-memory task. Cognition and Emotion, 24, 200-222. http://dx.doi.org/10.1080/02699930903384691

Fan, Y.-T., Hsu, Y.-Y., \& Cheng, Y. (2013). Sex matters: N-back modulates emotional mismatch negativity. NeuroReport, 24, 457-463. http:// dx.doi.org/10.1097/WNR.0b013e32836169b9

Faridi, N., Karama, S., Burgaleta, M., White, M. T., Evans, A. C., Fonov, V., . . Waber, D. P. (2015). Neuroanatomical correlates of behavioral rating versus performance measures of working memory in typically developing children and adolescents. Neuropsychology, 29, 82-91. http://dx.doi.org/10.1037/neu0000079

Ferré, P. (2002). Advantage for emotional words in immediate and delayed memory tasks: Could it be explained in terms of processing capacity? The Spanish Journal of Psychology, 5, 78-89. http://dx.doi.org/10.1017/ S1138741600005850

Field, A. P. (2003). The problems in using fixed-effects models of metaanalysis on real-world data. Understanding Statistics: Statistical Issues in Psychology, Education, and the Social Sciences, 2, 105-124.

Fischer, A. H., Kret, M. E., \& Broekens, J. (2018). Gender differences in emotion perception and self-reported emotional intelligence: A test of the emotion sensitivity hypothesis. PLOS ONE, 13, e0190712. http://dx .doi.org/10.1371/journal.pone.0190712

Fox, E. (2008). Emotion science: Cognitive and neuroscientific approaches to understanding human emotions. New York, NY: Palgrave Macmillan. http://dx.doi.org/10.1007/978-1-137-07946-6

Freeman, D., Startup, H., Dunn, G., Černis, E., Wingham, G., Pugh, K., . . . Kingdon, D. (2013). The interaction of affective with psychotic processes: A test of the effects of worrying on working memory, jumping to conclusions, and anomalies of experience in patients with persecutory delusions. Journal of Psychiatric Research, 47, 1837-1842. http://dx.doi .org/10.1016/j.jpsychires.2013.06.016

Frewen, P. A., \& Lanius, R. A. (2006). Toward a psychobiology of posttraumatic self-dysregulation: Reexperiencing, hyperarousal, dissociation, and emotional numbing. Annals of the New York Academy of Sciences, 1071, 110-124. http://dx.doi.org/10.1196/annals.1364.010

Fuge, P., Aust, S., Fan, Y., Weigand, A., Gärtner, M., Feeser, M., . . . Grimm, S. (2014). Interaction of early life stress and corticotropinreleasing hormone receptor gene: Effects on working memory. Biological Psychiatry, 76, 888-894. http://dx.doi.org/10.1016/j.biopsych.2014 .04 .016

Gallagher, M., \& Holland, P. C. (1994). The amygdala complex: Multiple roles in associative learning and attention. Proceedings of the National Academy of Sciences of the United States of America, 91, 11771-11776. http://dx.doi.org/10.1073/pnas.91.25.11771 
García-Pacios, J., Del Río, D., \& Maestú, F. (2014). State anxiety in healthy people can increase their vulnerability to neutral but not to unpleasant distraction in working memory. Cliníca y Salud, 25, 181185. http://dx.doi.org/10.1016/j.clysa.2014.10.002

García-Pacios, J., Del Río, D., Villalobos, D., Ruiz-Vargas, J. M., \& Maestú, F. (2015). Emotional interference-based forgetting in short-term memory. Cognitive inhibition of pleasant but not unpleasant biologically relevant distractors. Frontiers in Psychology, 6, 582.

García-Pacios, J., Garcés, P., Del Río, D., \& Maestú, F. (2015). Early detection and late cognitive control of emotional distraction by the prefrontal cortex. Scientific Reports, 5, 10046. http://dx.doi.org/10.1038/ srep 10046

García-Pacios, J., Garcés, P., Del Río, D., \& Maestú, F. (2017). Tracking the effect of emotional distraction in working memory brain networks: Evidence from an MEG study. Psychophysiology, 54, 1726-1740. http:// dx.doi.org/10.1111/psyp.12912

Garrison, K. E., \& Schmeichel, B. J. (2018). Effects of emotional content on working memory capacity. Cognition and Emotion, 0, 1-8. http://dx doi.org/10.1080/02699931.2018.1438989

Gärtner, M., Rohde-Liebenau, L., Grimm, S., \& Bajbouj, M. (2014). Working memory-related frontal theta activity is decreased under acute stress. Psychoneuroendocrinology, 43, 105-113. http://dx.doi.org/10 .1016/j.psyneuen.2014.02.009

Gathmann, B., Pawlikowski, M., Schöler, T., \& Brand, M. (2014). Performing a secondary executive task with affective stimuli interferes with decision making under risk conditions. Cognitive Processing, 15, 113126. http://dx.doi.org/10.1007/s10339-013-0584-y

Giles, G. E., Mahoney, C. R., Urry, H. L., Brunyé, T. T., Taylor, H. A., \& Kanarek, R. B. (2015). Omega-3 fatty acids and stress-induced changes to mood and cognition in healthy individuals. Pharmacology, Biochemistry, and Behavior, 132, 10-19. http://dx.doi.org/10.1016/j.pbb.2015.02 .018

Gilmartin, M. R., Balderston, N. L., \& Helmstetter, F. J. (2014). Prefrontal cortical regulation of fear learning. Trends in Neurosciences, 37, 455464. http://dx.doi.org/10.1016/j.tins.2014.05.004

Gläscher, J., Rose, M., \& Büchel, C. (2007). Independent effects of emotion and working memory load on visual activation in the lateral occipital complex. The Journal of Neuroscience, 27, 4366-4373. http:// dx.doi.org/10.1523/JNEUROSCI.3310-06.2007

Gohier, B., Ferracci, L., Surguladze, S. A., Lawrence, E., El Hage, W., Kefi, M. Z., . . . Le Gall, D. (2009). Cognitive inhibition and working memory in unipolar depression. Journal of Affective Disorders, 116, 100-105. http://dx.doi.org/10.1016/j.jad.2008.10.028

Gokcen, S., Bora, E., Erermis, S., Kesikci, H., \& Aydin, C. (2009). Theory of mind and verbal working memory deficits in parents of autistic children. Psychiatry Research, 166, 46-53. http://dx.doi.org/10.1016/j .psychres.2007.11.016

González-Garrido, A. A., López-Franco, A. L., Gómez-Velázquez, F. R., Ramos-Loyo, J., \& Sequeira, H. (2015). Emotional content of stimuli improves visuospatial working memory. Neuroscience Letters, 585, 43-47. http://dx.doi.org/10.1016/j.neulet.2014.11.014

Gonzalez-Garrido, A. A., Ramos-Loyo, J., Gomez-Velazquez, F. R., Alvelais Alarcón, M., \& Moises de la Serna Tuya, J. (2007). Visual verbal working memory processing may be interfered by previously seen faces. International Journal of Psychophysiology, 65, 141-151. http://dx.doi .org/10.1016/j.ijpsycho.2007.04.005

Gooding, D. C., \& Tallent, K. A. (2003). Spatial, object, and affective working memory in social anhedonia: An exploratory study. Schizophrenia Research, 63, 247-260. http://dx.doi.org/10.1016/S09209964(02)00326-2

Gooding, D. C., \& Tallent, K. A. (2004). Nonverbal working memory deficits in schizophrenia patients: Evidence of a supramodal executive processing deficit. Schizophrenia Research, 68, 189-201. http://dx.doi .org/10.1016/j.schres.2003.07.007
Goolsby, B. A., Shapiro, K. L., \& Raymond, J. E. (2009). Distractor devaluation requires visual working memory. Psychonomic Bulletin \& Review, 16, 133-138. http://dx.doi.org/10.3758/PBR.16.1.133

Gotlib, I. H., \& Joormann, J. (2010). Cognition and depression: Curren status and future directions. Annual Review of Clinical Psychology, 6 285-312. http://dx.doi.org/10.1146/annurev.clinpsy.121208.131305

Gotoh, F. (2008). Influence of affective valence on working memory processes. International Journal of Psychology, 43, 59-71. http://dx.doi .org/10.1080/00207590701318306

Gotoh, F. (2012). Affective valence of words impacts recall from auditory working memory. Journal of Cognitive Psychology, 24, 117-124. http:// dx.doi.org/10.1080/20445911.2011.589380

Gottfried, J. A., O'Doherty, J., \& Dolan, R. J. (2003). Encoding predictive reward value in human amygdala and orbitofrontal cortex. Science, 301, 1104-1107. http://dx.doi.org/10.1126/science.1087919

Grahek, I., Everaert, J., Krebs, R. M., \& Koster, E. H. W. (2018). Cognitive control in depression: Toward clinical models informed by cognitive neuroscience. Clinical Psychological Science, 6, 464-480. http://dx.doi org/10.1177/2167702618758969

Graziano, P. A., \& Garcia, A. (2016). Attention-deficit hyperactivity disorder and children's emotion dysregulation: A meta-analysis. Clinical Psychology Review, 46, 106-123. http://dx.doi.org/10.1016/j.cpr.2016 .04 .011

Grecucci, A., Soto, D., Rumiati, R. I., Humphreys, G. W., \& Rotshtein, P. (2010). The interrelations between verbal working memory and visual selection of emotional faces. Journal of Cognitive Neuroscience, 22 1189-1200. http://dx.doi.org/10.1162/jocn.2009.21276

Grimm, S., Gärtner, M., Fuge, P., Fan, Y., Weigand, A., Feeser, M., . . . Bajbouj, M. (2015). Variation in the corticotropin-releasing hormone receptor 1 (CRHR1) gene modulates age effects on working memory. Journal of Psychiatric Research, 61, 57-63. http://dx.doi.org/10.1016/j .jpsychires.2014.12.001

Grimm, S., Weigand, A., Kazzer, P., Jacobs, A. M., \& Bajbouj, M. (2012) Neural mechanisms underlying the integration of emotion and working memory. NeuroImage, 61, 1188-1194. http://dx.doi.org/10.1016/j .neuroimage.2012.04.004

Grissmann, S., Faller, J., Scharinger, C., Spüler, M., \& Gerjets, P. (2017) Electroencephalography based analysis of working memory load and affective valence in an N-back task with emotional stimuli. Frontiers in Human Neuroscience. Advance online publication. http://dx.doi.org/10 .3389/fnhum.2017.00616

Grunwald, M., Weiss, T., Mueller, S., \& Rall, L. (2014). EEG changes caused by spontaneous facial self-touch may represent emotion regulating processes and working memory maintenance. Brain Research, 1557, 111-126. http://dx.doi.org/10.1016/j.brainres.2014.02.002

Habel, U., Koch, K., Pauly, K., Kellermann, T., Reske, M., Backes, V., . . . Schneider, F. (2007). The influence of olfactory-induced negative emotion on verbal working memory: Individual differences in neurobehavioral findings. Brain Research, 1152, 158-170. http://dx.doi.org/10 1016/j.brainres.2007.03.048

Hadley, C. B., \& Mackay, D. G. (2006). Does emotion help or hinder immediate memory? Arousal versus priority-binding mechanisms. Journal of Experimental Psychology: Learning, Memory, and Cognition, 32, 79-88. http://dx.doi.org/10.1037/0278-7393.32.1.79

Haldane, M., Jogia, J., Cobb, A., Kozuch, E., Kumari, V., \& Frangou, S. (2008). Changes in brain activation during working memory and facial recognition tasks in patients with bipolar disorder with Lamotrigine monotherapy. European Neuropsychopharmacology, 18, 48-54. http:// dx.doi.org/10.1016/j.euroneuro.2007.05.009

Hamann, S. (2001). Cognitive and neural mechanisms of emotional memory. Trends in Cognitive Sciences, 5, 394-400. http://dx.doi.org/10 .1016/S1364-6613(00)01707-1 
Hamann, S., \& Canli, T. (2004). Individual differences in emotion processing. Current Opinion in Neurobiology, 14, 233-238. http://dx.doi .org/10.1016/j.conb.2004.03.010

Han, H. J., Jung, W. H., Yun, J.-Y., Park, J. W., Cho, K. K., Hur, J.-W., . . Kwon, J. S. (2016). Disruption of effective connectivity from the dorsolateral prefrontal cortex to the orbitofrontal cortex by negative emotional distraction in obsessive-compulsive disorder. Psychological Medicine, 46, 921-932. http://dx.doi.org/10.1017/S0033291715002391

Hedges, L. V. (1982). Estimation of effect size from a series of independent experiments. Psychological Bulletin, 92, 490-499. http://dx.doi .org/10.1037/0033-2909.92.2.490

Hedges, L. V. (1989). An unbiased correction for sampling error in validity generalization studies. Journal of Applied Psychology, 74, 469-477. http://dx.doi.org/10.1037/0021-9010.74.3.469

Hedges, L. V., \& Vevea, J. L. (1998). Fixed- and random-effects models in meta-analysis. Psychological Methods, 3, 486-504. http://dx.doi.org/10 $.1037 / 1082-989$ X.3.4.486

Hillary, F. G., Chiaravalloti, N. D., Ricker, J. H., Steffener, J., Bly, B. M., Lange, G., . . DeLuca, J. (2003). An investigation of working memory rehearsal in multiple sclerosis using fMRI. Journal of Clinical and Experimental Neuropsychology, 25, 965-978. http://dx.doi.org/10.1076/ jcen.25.7.965.16490

Hofmann, S. G., Sawyer, A. T., Fang, A., \& Asnaani, A. (2012). Emotion dysregulation model of mood and anxiety disorders. Depression and Anxiety, 29, 409-416. http://dx.doi.org/10.1002/da.21888

Hood, A., Pulvers, K., Spady, T. J., Kliebenstein, A., \& Bachand, J. (2015). Anxiety mediates the effect of acute stress on working memory performance when cortisol levels are high: A moderated mediation analysis. Anxiety, Stress, and Coping, 28, 545-562. http://dx.doi.org/10.1080/ 10615806.2014.1000880

Horan, W. P., Kring, A. M., \& Blanchard, J. J. (2006). Anhedonia in schizophrenia: A review of assessment strategies. Schizophrenia Bulletin, 32, 259-273. http://dx.doi.org/10.1093/schbul/sbj009

Huang, J., Tan, S. P., Walsh, S. C., Spriggens, L. K., Neumann, D. L., Shum, D. H., \& Chan, R. C. (2014). Working memory dysfunctions predict social problem solving skills in schizophrenia. Psychiatry Research, 220, 96-101. http://dx.doi.org/10.1016/j.psychres.2014.07.043

Hubbard, N. A., Hutchison, J. L., Hambrick, D. Z., \& Rypma, B. (2016). The enduring effects of depressive thoughts on working memory. Journal of Affective Disorders, 190, 208-213. http://dx.doi.org/10.1016/j.jad .2015.06.056

Hubbard, N. A., Hutchison, J. L., Turner, M., Montroy, J., Bowles, R. P., \& Rypma, B. (2016). Depressive thoughts limit working memory capacity in dysphoria. Cognition and Emotion, 30, 193-209. http://dx.doi .org/10.1080/02699931.2014.991694

Hunter, J. E., \& Schmidt, F. L. (2000). Fixed effects vs. random effects meta-analysis models: Implications for cumulative research knowledge. International Journal of Selection and Assessment, 8, 275-292. http:// dx.doi.org/10.1111/1468-2389.00156

Hur, J., Iordan, A. D., Dolcos, F., \& Berenbaum, H. (2017). Emotional influences on perception and working memory. Cognition and Emotion, 31, 1294-1302. http://dx.doi.org/10.1080/02699931.2016.1213703

Husain, M., \& Roiser, J. P. (2018). Neuroscience of apathy and anhedonia: A transdiagnostic approach. Nature Reviews Neuroscience, 19, 470484. http://dx.doi.org/10.1038/s41583-018-0029-9

Iordan, A. D., \& Dolcos, F. (2017). Brain activity and network interactions linked to valence-related differences in the impact of emotional distraction. Cerebral Cortex, 27, 731-749.

Iordan, A. D., Dolcos, S., Denkova, E., \& Dolcos, F. (2013). Sex differences in the response to emotional distraction: An event-related fMRI investigation. Cognitive, Affective \& Behavioral Neuroscience, 13, 116134. http://dx.doi.org/10.3758/s13415-012-0134-6

Iordan, A. D., Dolcos, S., \& Dolcos, F. (2013). Neural signatures of the response to emotional distraction: A review of evidence from brain imaging investigations. Frontiers in Human Neuroscience, 7, 200. http:// dx.doi.org/10.3389/fnhum.2013.00200

Iordan, A. D., Dolcos, S., \& Dolcos, F. (2018). Brain activity and network interactions in the impact of internal emotional distraction. Cerebral Cortex. Advance online publication. http://dx.doi.org/10.1093/cercor/ bhy 129

Ishai, A. (2008). Let's face it: It's a cortical network. NeuroImage, 40, 415-419. http://dx.doi.org/10.1016/j.neuroimage.2007.10.040

Jackson, M. C., Linden, D. E., \& Raymond, J. E. (2014). Angry expressions strengthen the encoding and maintenance of face identity representations in visual working memory. Cognition and Emotion, 28, 278 297. http://dx.doi.org/10.1080/02699931.2013.816655

Jeffries, S., \& Everatt, J. (2004). Working memory: Its role in dyslexia and other specific learning difficulties. Dyslexia, 10, 196-214. http://dx.doi .org/10.1002/dys.278

Jenness, J. L., Rosen, M. L., Sambrook, K. A., Dennison, M. J., Lambert, H. K., Sheridan, M. A., \& McLaughlin, K. A. (2018). Violence exposure and neural systems underlying working memory for emotional stimuli in youth. Development and Psychopathology, 30, 1517-1528. http://dx.doi .org/10.1017/S0954579417001638

Jha, A. P., Stanley, E. A., Kiyonaga, A., Wong, L., \& Gelfand, L. (2010). Examining the protective effects of mindfulness training on working memory capacity and affective experience. Emotion, 10, 54-64. http:// dx.doi.org/10.1037/a0018438

Jiang, Y., Haxby, J. V., Martin, A., Ungerleider, L. G., \& Parasuraman, R. (2000). Complementary neural mechanisms for tracking items in human working memory. Science, 287, 643-646. http://dx.doi.org/10.1126/ science.287.5453.643

Jonides, J., Smith, E. E., Marshuetz, C., Koeppe, R. A., \& Reuter-Lorenz, P. A. (1998). Inhibition in verbal working memory revealed by brain activation. Proceedings of the National Academy of Sciences of the United States of America, 95, 8410-8413. http://dx.doi.org/10.1073/ pnas.95.14.8410

Joormann, J., \& Gotlib, I. H. (2008). Updating the contents of working memory in depression: Interference from irrelevant negative material Journal of Abnormal Psychology, 117, 182-192. http://dx.doi.org/10 .1037/0021-843X.117.1.182

Joormann, J., Levens, S. M., \& Gotlib, I. H. (2011). Sticky thoughts: Depression and rumination are associated with difficulties manipulating emotional material in working memory. Psychological Science, 22, 979-983. http://dx.doi.org/10.1177/0956797611415539

Judah, M. R., Grant, D. M., Lechner, W. V., \& Mills, A. C. (2013). Working memory load moderates late attentional bias in social anxiety. Cognition and Emotion, 27, 502-511. http://dx.doi.org/10.1080/ 02699931.2012 .719490

Kalisch, R. (2009). The functional neuroanatomy of reappraisal: Time matters. Neuroscience and Biobehavioral Reviews, 33, 1215-1226. http://dx.doi.org/10.1016/j.neubiorev.2009.06.003

Kane, M. J., Brown, L. H., McVay, J. C., Silvia, P. J., Myin-Germeys, I., \& Kwapil, T. R. (2007). For whom the mind wanders, and when: An experience-sampling study of working memory and executive control in daily life. Psychological Science, 18, 614-621. http://dx.doi.org/10 $.1111 / \mathrm{j} .1467-9280.2007 .01948 . x$

Kane, M. J., Hambrick, D. Z., \& Conway, A. R. A. (2005). Working memory capacity and fluid intelligence are strongly related constructs: Comment on Ackerman, Beier, and Boyle (2005). Psychological Bulletin, 13, 66-71.

Kellermann, T. S., Sternkopf, M. A., Schneider, F., Habel, U., Turetsky, B. I., Zilles, K., \& Eickhoff, S. B. (2012). Modulating the processing of emotional stimuli by cognitive demand. Social Cognitive and Affective Neuroscience, 7, 263-273. http://dx.doi.org/10.1093/scan/nsq104

Kendzierski, D., Ritter, R. L., Stump, T. K., \& Anglin, C. L. (2015). The effectiveness of an implementation intentions intervention for fruit and 
vegetable consumption as moderated by self-schema status. Appetite, 95 , 228-238. http://dx.doi.org/10.1016/j.appet.2015.07.007

Kensinger, E. A. (2008). Age differences in memory for arousing and nonarousing emotional words. The Journals of Gerontology Series B, Psychological Sciences and Social Sciences, 63, 13-18. http://dx.doi .org/10.1093/geronb/63.1.P13

Kensinger, E. A., \& Corkin, S. (2003). Effect of negative emotional content on working memory and long-term memory. Emotion, 3, 378-393. http://dx.doi.org/10.1037/1528-3542.3.4.378

Kerestes, R., Ladouceur, C. D., Meda, S., Nathan, P. J., Blumberg, H. P., Maloney, K., . . Phillips, M. L. (2012). Abnormal prefrontal activity subserving attentional control of emotion in remitted depressed patients during a working memory task with emotional distracters. Psychological Medicine, 42, 29-40. http://dx.doi.org/10.1017/S0033291711001097

Kerns, J. G., \& Becker, T. M. (2008). Communication disturbances, working memory, and emotion in people with elevated disorganized schizotypy. Schizophrenia Research, 100, 172-180. http://dx.doi.org/10 .1016/j.schres.2007.11.005

Kertz, S. J., Belden, A. C., Tillman, R., \& Luby, J. (2016). Cognitive control deficits in shifting and inhibition in preschool age children are associated with increased depression and anxiety over 7.5 years of development. Journal of Abnormal Child Psychology, 44, 1185-1196. http://dx.doi.org/10.1007/s10802-015-0101-0

Kessel, D., García-Rubio, M. J., González, E. K., Tapia, M., López-Martín, S., Román, F. J., . . Carretié, L. (2016). Working memory of emotional stimuli: Electrophysiological characterization. Biological Psychology, 119, 190-199. http://dx.doi.org/10.1016/j.biopsycho.2016.07.009

King, R., \& Schaefer, A. (2011). The emotional startle effect is disrupted by a concurrent working memory task. Psychophysiology, 48, 269-272. http://dx.doi.org/10.1111/j.1469-8986.2010.01062.x

Klemanski, D. H., Curtiss, J., McLaughlin, K. A., \& Nolen-Hoeksema, S. (2017). Emotion regulation and the transdiagnostic role of repetitive negative thinking in adolescents with social anxiety and depression. Cognitive Therapy and Research, 41, 206-219. http://dx.doi.org/10 .1007/s10608-016-9817-6

Klemen, J., Büchel, C., Bühler, M., Menz, M. M., \& Rose, M. (2010). Auditory working memory load impairs visual ventral stream processing: Toward a unified model of attentional load. Journal of Cognitive Neuroscience, 22, 437-446. http://dx.doi.org/10.1162/jocn.2009.21204

Klink, P. C., Jentgens, P., \& Lorteije, J. A. M. (2014). Priority maps explain the roles of value, attention, and salience in goal-oriented behavior. The Journal of Neuroscience, 34, 13867-13869. http://dx.doi .org/10.1523/JNEUROSCI.3249-14.2014

Kober, H., Barrett, L. F., Joseph, J., Bliss-Moreau, E., Lindquist, K., \& Wager, T. D. (2008). Functional grouping and cortical-subcortical interactions in emotion: A meta-analysis of neuroimaging studies. NeuroImage, 42, 998-1031. http://dx.doi.org/10.1016/j.neuroimage.2008.03 .059

Kohler, C. G., Walker, J. B., Martin, E. A., Healey, K. M., \& Moberg, P. J. (2010). Facial emotion perception in schizophrenia: A meta-analytic review. Schizophrenia Bulletin, 36, 1009-1019. http://dx.doi.org/10 $.1093 / \mathrm{schbul} / \mathrm{sbn} 192$

Könen, T., Dirk, J., \& Schmiedek, F. (2015). Cognitive benefits of last night's sleep: Daily variations in children's sleep behavior are related to working memory fluctuations. Journal of Child Psychology and Psychiatry, 56, 171-182. http://dx.doi.org/10.1111/jcpp.12296

Kopf, J., Dresler, T., Reicherts, P., Herrmann, M. J., \& Reif, A. (2013). The effect of emotional content on brain activation and the late positive potential in a word n-back task. PLOS ONE, 8, e75598. http://dx.doi.org/ 10.1371/journal.pone.0075598

Kostandov, E. A., Kurova, N. S., Cheremushkin, E. A., Petrenko, N. E., Ashkinazi, M. L., \& Yakovenko, I. A. (2009). Relationship between the plasticity of a set to an emotional facial expression and the load on working memory. Neuroscience and Behavioral Physiology, 39, 223 229. http://dx.doi.org/10.1007/s11055-009-9126-6

Koster, E. H. W., De Lissnyder, E., \& De Raedt, R. (2013). Rumination is characterized by valence-specific impairments in switching of attention. Acta Psychologica, 144, 563-570. http://dx.doi.org/10.1016/j.actpsy 2013.09.008

Koster, E. H. W., De Lissnyder, E., Derakshan, N., \& De Raedt, R. (2011) Understanding depressive rumination from a cognitive science perspective: The impaired disengagement hypothesis. Clinical Psychology Review, 31, 138-145. http://dx.doi.org/10.1016/j.cpr.2010.08.005

Krämer, U. M., Mohammadi, B., Doñamayor, N., Samii, A., \& Münte, T. F. (2010). Emotional and cognitive aspects of empathy and their relation to social cognition-An fMRI-study. Brain Research, 1311, 110-120. http://dx.doi.org/10.1016/j.brainres.2009.11.043

Krause-Utz, A., Elzinga, B. M., Oei, N. Y. L., Paret, C., Niedtfeld, I., Spinhoven, P., . . Schmahl, C. (2014). Amygdala and dorsal anterior cingulate connectivity during an emotional working memory task in borderline personality disorder patients with interpersonal trauma history. Frontiers in Human Neuroscience, 8. Retrieved from https://www ncbi.nlm.nih.gov/pmc/articles/PMC4211399/

Krause-Utz, A., Elzinga, B. M., Oei, N. Y. L., Spinhoven, P., Bohus, M., \& Schmahl, C. (2014). Susceptibility to distraction by social cues in borderline personality disorder. Psychopathology, 47, 148-157. http:// dx.doi.org/10.1159/000351740

Krause-Utz, A., Oei, N. Y. L., Niedtfeld, I., Bohus, M., Spinhoven, P. Schmahl, C., \& Elzinga, B. M. (2012). Influence of emotional distraction on working memory performance in borderline personality disorder. Psychological Medicine, 42, 2181-2192. http://dx.doi.org/10.1017/ S0033291712000153

Kret, M. E., \& De Gelder, B. (2012). A review on sex differences in processing emotional signals. Neuropsychologia, 50, 1211-1221. http:// dx.doi.org/10.1016/j.neuropsychologia.2011.12.022

Krieglmeyer, R., Deutsch, R., De Houwer, J., \& De Raedt, R. (2010) Being moved: Valence activates approach-avoidance behavior independently of evaluation and approach-avoidance intentions. Psychological Science, 21, 607-613. http://dx.doi.org/10.1177/0956797610365131

LaBar, K. S., \& Cabeza, R. (2006). Cognitive neuroscience of emotional memory. Nature Reviews Neuroscience, 7, 54-64. http://dx.doi.org/10 $.1038 / \mathrm{nrn} 1825$

Labouvie-Vief, G., Grühn, D., \& Studer, J. (2010). Dynamic integration of emotion and cognition: Equilibrium regulation in development and aging. In R. M. Lerner, M. E. Lamb, \& A. M. Freund (Eds.), The handbook of life-span development (Vol. 2, pp. 79-115). Hoboken, NJ Wiley. Retrieved from http://dx.doi.org/10.1002/9780470880166 hlsd002004

Ladouceur, C. D., Dahl, R. E., Williamson, D. E., Birmaher, B., Ryan, N. D., \& Casey, B. J. (2005). Altered emotional processing in pediatric anxiety, depression, and comorbid anxiety-depression. Journal of Abnormal Child Psychology, 33, 165-177. http://dx.doi.org/10.1007/ s10802-005-1825-z

Ladouceur, C. D., Diwadkar, V. A., White, R., Bass, J., Birmaher, B., Axelson, D. A., \& Phillips, M. L. (2013). Fronto-limbic function in unaffected offspring at familial risk for bipolar disorder during an emotional working memory paradigm. Developmental Cognitive Neuroscience, 5, 185-196. http://dx.doi.org/10.1016/j.den.2013.03.004

Ladouceur, C. D., Schlund, M. W., \& Segreti, A.-M. (2018). Positive reinforcement modulates fronto-limbic systems subserving emotional interference in adolescents. Behavioural Brain Research, 338, 109-117. http://dx.doi.org/10.1016/j.bbr.2017.10.019

Ladouceur, C. D., Silk, J. S., Dahl, R. E., Ostapenko, L., Kronhaus, D. M., \& Phillips, M. L. (2009). Fearful faces influence attentional control processes in anxious youth and adults. Emotion, 9, 855-864. http://dx .doi.org/10.1037/a0017747 
Laier, C., Schulte, F. P., \& Brand, M. (2013). Pornographic picture processing interferes with working memory performance. Journal of Sex Research, 50, 642-652. http://dx.doi.org/10.1080/00224499.2012 .716873

Lamm, C., Pine, D. S., \& Fox, N. A. (2013). Impact of negative affectively charged stimuli and response style on cognitive-control-related neural activation: An ERP study. Brain and Cognition, 83, 234-243. http://dx .doi.org/10.1016/j.bandc.2013.07.012

Lang, P. J., Bradley, M. M., \& Cuthbert, B. N. (2008). International affective picture system (IAPS): Affective ratings of pictures and instruction manual (Technical report). Gainesville, FL: University of Florida.

Lavie, N., Hirst, A., de Fockert, J. W., \& Viding, E. (2004). Load theory of selective attention and cognitive control. Journal of Experimental Psychology: General, 133, 339-354. http://dx.doi.org/10.1037/00963445.133.3.339

LeDoux, J. (2012). Rethinking the emotional brain. Neuron, 73, 653-676. http://dx.doi.org/10.1016/j.neuron.2012.02.004

LeDoux, J. E., \& Brown, R. (2017). A higher-order theory of emotional consciousness. Proceedings of the National Academy of Sciences of the United States of America, 114, E2016-E2025. http://dx.doi.org/10.1073/ pnas. 1619316114

LeMoult, J., Carver, C. S., Johnson, S. L., \& Joormann, J. (2015). Predicting change in symptoms of depression during the transition to university: The roles of BDNF and working memory capacity. Cognitive, Affective \& Behavioral Neuroscience, 15, 95-103. http://dx.doi.org/10.3758/ s13415-014-0305-8

Levens, S. M., Armstrong, L. M., Orejuela-Dávila, A. I., \& Alverio, T. (2017). The two sides of adversity: The effect of distant versus recent adversity on updating emotional content in working memory. Cognition and Emotion, 31, 1243-1251. http://dx.doi.org/10.1080/02699931.2016 .1197099

Levens, S. M., Devinsky, O., \& Phelps, E. A. (2011). Role of the left amygdala and right orbital frontal cortex in emotional interference resolution facilitation in working memory. Neuropsychologia, 49, 32013212. http://dx.doi.org/10.1016/j.neuropsychologia.2011.07.021

Levens, S. M., \& Gotlib, I. H. (2009). Impaired selection of relevant positive information in depression. Depression and Anxiety, 26, 403410. http://dx.doi.org/10.1002/da.20565

Levens, S. M., \& Gotlib, I. H. (2010). Updating positive and negative stimuli in working memory in depression. Journal of Experimental Psychology: General, 139, 654-664. http://dx.doi.org/10.1037/ a0020283

Levens, S. M., \& Gotlib, I. H. (2012). The effects of optimism and pessimism on updating emotional information in working memory. Cognition and Emotion, 26, 341-350. http://dx.doi.org/10.1080/ 02699931.2011 .574110

Levens, S. M., \& Gotlib, I. H. (2015). Updating emotional content in recovered depressed individuals: Evaluating deficits in emotion processing following a depressive episode. Journal of Behavior Therapy and Experimental Psychiatry, 48, 156-163. http://dx.doi.org/10.1016/j.jbtep .2015 .03 .009

Levens, S. M., \& Phelps, E. A. (2008). Emotion processing effects on interference resolution in working memory. Emotion, 8, 267-280. http:// dx.doi.org/10.1037/1528-3542.8.2.267

Levens, S. M., \& Phelps, E. A. (2010). Insula and orbital frontal cortex activity underlying emotion interference resolution in working memory. Journal of Cognitive Neuroscience, 22, 2790-2803. http://dx.doi.org/10 $.1162 /$ jocn.2010.21428

Li, M., Feng, L., Liu, X., Zhang, M., Fu, B., Wang, G., . . Hu, B. (2018). Emotional working memory in patients with major depressive disorder. The Journal of International Medical Research, 46, 1734-1746. http:// dx.doi.org/10.1177/0300060518758225
Li, X., Chan, R. C., \& Luo, Y. J. (2010). Stage effects of negative emotion on spatial and verbal working memory. BMC Neuroscience, 11, 60. http://dx.doi.org/10.1186/1471-2202-11-60

Li, X., Li, X., \& Luo, Y. J. (2006). Differential influences of negative emotion on spatial and verbal working memory: Evidence from eventrelated potential and source current density analysis. NeuroReport, 17, 1555-1559. http://dx.doi.org/10.1097/01.wnr.0000234744.50442.2b

Li, Z., Coles, C. D., Lynch, M. E., Hamann, S., Peltier, S., LaConte, S., \& Hu, X. (2009). Prenatal cocaine exposure alters emotional arousal regulation and its effects on working memory. Neurotoxicology and Teratology, 31, 342-348. http://dx.doi.org/10.1016/j.ntt.2009.08.005

Lilley, S. A., Andrade, J., Turpin, G., Sabin-Farrell, R., \& Holmes, E. A. (2009). Visuospatial working memory interference with recollections of trauma. British Journal of Clinical Psychology, 48, 309-321. http://dx doi.org/10.1348/014466508X398943

Lim, S.-L., Bruce, A. S., \& Aupperle, R. L. (2014). The influence of a working memory task on affective perception of facial expressions. PLOS ONE, 9, e111074. http://dx.doi.org/10.1371/journal.pone.0111074

Linden, D. E., Lancaster, T. M., Wolf, C., Baird, A., Jackson, M. C., Johnston, S. J., . . . Thome, J. (2013). ZNF804A genotype modulates neural activity during working memory for faces. Neuropsychobiology, 67, 84-92. http://dx.doi.org/10.1159/000344001

Linden, S. C., Jackson, M. C., Subramanian, L., Healy, D., \& Linden, D. E. J. (2011). Sad benefit in face working memory: An emotional bias of melancholic depression. Journal of Affective Disorders, 135, 251257. http://dx.doi.org/10.1016/j.jad.2011.08.002

Lindquist, K. A. (2013). Emotions emerge from more basic psychological ingredients: A modern psychological constructionist model. Emotion Review, 5, 356-368. http://dx.doi.org/10.1177/1754073913489750

Lindquist, K. A., Satpute, A. B., Wager, T. D., Weber, J., \& Barrett, L. F. (2016). The brain basis of positive and negative affect: Evidence from a meta-analysis of the human neuroimaging literature. Cerebral Cortex, 26, 1910-1922. http://dx.doi.org/10.1093/cercor/bhv001

Lindquist, K. A., Wager, T. D., Kober, H., Bliss-Moreau, E., \& Barrett, L. F. (2012). The brain basis of emotion: A meta-analytic review. Behavioral and Brain Sciences, 35, 121-143. http://dx.doi.org/10.1017/ S0140525X11000446

Lindström, B. R., \& Bohlin, G. (2011). Emotion processing facilitates working memory performance. Cognition and Emotion, 25, 1196-1204. http://dx.doi.org/10.1080/02699931.2010.527703

Lindström, B. R., \& Bohlin, G. (2012). Threat-relevance impairs executive functions: Negative impact on working memory and response inhibition Emotion, 12, 384-393. http://dx.doi.org/10.1037/a0027305

Liu, D., Wang, L., Wang, Y., \& Jiang, Y. (2016). Conscious access to suppressed threatening information is modulated by working memory. Psychological Science, 27, 1419-1427. http://dx.doi.org/10.1177/ 0956797616660680

LoPresti, M. L., Schon, K., Tricarico, M. D., Swisher, J. D., Celone, K. A., \& Stern, C. E. (2008). Working memory for social cues recruits orbitofrontal cortex and amygdala: A functional magnetic resonance imaging study of delayed matching to sample for emotional expressions. The Journal of Neuroscience, 28, 3718-3728. http://dx.doi.org/10.1523/ JNEUROSCI.0464-08.2008

Lowe, J., MacLean, P. C., Shaffer, M. L., \& Watterberg, K. (2009). Early working memory in children born with extremely low birth weight: Assessed by object permanence. Journal of Child Neurology, 24, 410415. http://dx.doi.org/10.1177/0883073808324533

Luciana, M., Burgund, E. D., Berman, M., \& Hanson, K. L. (2001). Effects of tryptophan loading on verbal, spatial and affective working memory functions in healthy adults. Journal of Psychopharmacology, 15, 219230. http://dx.doi.org/10.1177/026988110101500410

Luksys, G., Ackermann, S., Coynel, D., Fastenrath, M., Gschwind, L., Heck, A., . . . deq Uervain, D. (2014). BAIAP2 is related to emotional 
modulation of human memory strength. PLOS ONE, 9, e83707. http:// dx.doi.org/10.1371/journal.pone.0083707

Luksys, G., Fastenrath, M., Coynel, D., Freytag, V., Gschwind, L., Heck, A., . . deq Uervain, D. J-F. (2015). Computational dissection of human episodic memory reveals mental process-specific genetic profiles. Proceedings of the National Academy of Sciences of the United States of America, 112, E4939-E4948.

Luo, Y., Qin, S., Fernández, G., Zhang, Y., Klumpers, F., \& Li, H. (2014). Emotion perception and executive control interact in the salience network during emotionally charged working memory processing. Human Brain Mapping, 35, 5606-5616. http://dx.doi.org/10.1002/hbm.22573

Maat, A., Cahn, W., Gijsman, H. J., Hovens, J. E., Kahn, R. S., \& Aleman, A. (2014). Open, randomized trial of the effects of aripiprazole versus risperidone on social cognition in schizophrenia. European Neuropsychopharmacology, 24, 575-584. http://dx.doi.org/10.1016/j.euroneuro 2013.12.009

MacKay, D. G., Shafto, M., Taylor, J. K., Marian, D. E., Abrams, L., \& Dyer, J. R. (2004). Relations between emotion, memory, and attention: Evidence from taboo Stroop, lexical decision, and immediate memory tasks. Memory \& Cognition, 32, 474-488. http://dx.doi.org/10.3758/ BF03195840

MacLean, R. R., Nichols, T. T., LeBreton, J. M., \& Wilson, S. J. (2016). Effects of cognitive load on neural and behavioral responses to smokingcue distractors. Cognitive, Affective \& Behavioral Neuroscience, 16, 588-600. http://dx.doi.org/10.3758/s13415-016-0416-5

MacNamara, A., Ferri, J., \& Hajcak, G. (2011). Working memory load reduces the late positive potential and this effect is attenuated with increasing anxiety. Cognitive, Affective \& Behavioral Neuroscience, 11, 321-331. http://dx.doi.org/10.3758/s13415-011-0036-z

MacNamara, A., \& Proudfit, G. H. (2014). Cognitive load and emotional processing in generalized anxiety disorder: Electrocortical evidence for increased distractibility. Journal of Abnormal Psychology, 123, 557565. http://dx.doi.org/10.1037/a0036997

MacNamara, A., Schmidt, J., Zelinsky, G. J., \& Hajcak, G. (2012). Electrocortical and ocular indices of attention to fearful and neutral faces presented under high and low working memory load. Biological Psychology, 91, 349-356. http://dx.doi.org/10.1016/j.biopsycho.2012.08 .005

Mammarella, N., Borella, E., Carretti, B., Leonardi, G., \& Fairfield, B. (2013). Examining an emotion enhancement effect in working memory: Evidence from age-related differences. Neuropsychological Rehabilitation, 23, 416-428. http://dx.doi.org/10.1080/09602011.2013.775065

Mammarella, N., Fairfield, B., De Leonardis, V., Carretti, B., Borella, E., Frisullo, E., \& Di Domenico, A. (2012). Is there an affective working memory deficit in patients with chronic schizophrenia? Schizophrenia Research, 138, 99-101. http://dx.doi.org/10.1016/j.schres.2012.03.028

Mammarella, N., Fairfield, B., Di Domenico, A., D’Onofrio, L., Stuppia, L., \& Gatta, V. (2016). The modulating role of ADRA2B in emotional working memory: Attending the negative but remembering the positive. Neurobiology of Learning and Memory, 130, 129-134. http://dx.doi.org/ 10.1016/j.nlm.2016.02.009

Mammarella, N., Fairfield, B., Frisullo, E., \& Di Domenico, A. (2013). Saying it with a natural child's voice! When affective auditory manipulations increase working memory in aging. Aging \& Mental Health, 17, 853-862. http://dx.doi.org/10.1080/13607863.2013.790929

Mano, Q. R., Brown, G. G., Bolden, K., Aupperle, R., Sullivan, S., Paulus, M. P., \& Stein, M. B. (2013). Curvilinear relationship between phonological working memory load and social-emotional modulation. Cognition and Emotion, 27, 283-304. http://dx.doi.org/10.1080/02699931 2012.712948

Mano, Q. R., Brown, G. G., Mirzakhanian, H., Bolden, K., Cadenhead, K. S., \& Light, G. A. (2014). Not all distraction is bad: Working memory vulnerability to implicit socioemotional distraction correlates with negative symptoms and functional impairment in psychosis. Schizophrenia
Research and Treatment. Advance online publication. http://dx.doi.org/ $10.1155 / 2014 / 320948$

Martin, G. N., \& Chaudry, A. (2014). Working memory performance and exposure to pleasant and unpleasant ambient odor: Is spatial span special? The International Journal of Neuroscience, 124, 806-811. http:// dx.doi.org/10.3109/00207454.2014.890619

Marx, I., Domes, G., Havenstein, C., Berger, C., Schulze, L., \& Herpertz, S. C. (2011). Enhanced emotional interference on working memory performance in adults with ADHD. The World Journal of Biological Psychiatry, 12, 70-75. http://dx.doi.org/10.3109/15622975.2011 .599213

Marx, I., Krause, J., Berger, C., \& Häßler, F. (2014). Dissociable patterns in the control of emotional interference in adults with attention-deficit/ hyperactivity disorder (ADHD) and in adults with alcohol dependence. PLoS ONE, 9, e107750. http://dx.doi.org/10.1371/journal.pone.0107750

Mather, M. (2016). The affective neuroscience of aging. Annual Review of Psychology, 67, 213-238. http://dx.doi.org/10.1146/annurev-psych122414-033540

Mather, M., \& Carstensen, L. L. (2005). Aging and motivated cognition: The positivity effect in attention and memory. Trends in Cognitive Sciences, 9, 496-502. http://dx.doi.org/10.1016/j.tics.2005.08.005

Mather, M., Mitchell, K. J., Raye, C. L., Novak, D. L., Greene, E. J., \& Johnson, M. K. (2006). Emotional arousal can impair feature binding in working memory. Journal of Cognitive Neuroscience, 18, 614-625. http://dx.doi.org/10.1162/jocn.2006.18.4.614

Mather, M., \& Sutherland, M. R. (2011). Arousal-biased competition in perception and memory. Perspectives on Psychological Science, 6, 114 133. http://dx.doi.org/10.1177/1745691611400234

Mathews, A., \& MacLeod, C. (2005). Cognitive vulnerability to emotional disorders. Annual Review of Clinical Psychology, 1, 167-195. http://dx .doi.org/10.1146/annurev.clinpsy.1.102803.143916

Mattarella-Micke, A., Mateo, J., Kozak, M. N., Foster, K., \& Beilock, S. L. (2011). Choke or thrive? The relation between salivary cortisol and math performance depends on individual differences in working memory and math-anxiety. Emotion, 11, 1000-1005. http://dx.doi.org/10.1037/ a0023224

McEvoy, P. M., Mahoney, A. E., \& Moulds, M. L. (2010). Are worry, rumination, and post-event processing one and the same? Development of the repetitive thinking questionnaire. Journal of Anxiety Disorders, 24, 509-519. http://dx.doi.org/10.1016/j.janxdis.2010.03.008

Mehta, M. A., Hinton, E. C., Montgomery, A. J., Bantick, R. A., \& Grasby, P. M. (2005). Sulpiride and mnemonic function: Effects of a dopamine D2 receptor antagonist on working memory, emotional memory and long-term memory in healthy volunteers. Journal of Psychopharmacology, 19, 29-38. http://dx.doi.org/10.1177/0269881105048889

Menon, V. (2011). Large-scale brain networks and psychopathology: A unifying triple network model. Trends in Cognitive Sciences, 15, 483506. http://dx.doi.org/10.1016/j.tics.2011.08.003

Meule, A., Skirde, A. K., Freund, R., Vögele, C., \& Kübler, A. (2012) High-calorie food-cues impair working memory performance in high and low food cravers. Appetite, 59, 264-269. http://dx.doi.org/10.1016/ j.appet.2012.05.010

Mikels, J. A., Larkin, G. R., Reuter-Lorenz, P. A., \& Cartensen, L. L. (2005). Divergent trajectories in the aging mind: Changes in working memory for affective versus visual information with age. Psychology and Aging, 20, 542-553. http://dx.doi.org/10.1037/0882-7974.20.4.542

Mikels, J. A., Reuter-Lorenz, P. A., Beyer, J. A., \& Fredrickson, B. L. (2008). Emotion and working memory: Evidence for domain-specific processes for affective maintenance. Emotion, 8, 256-266. http://dx.doi .org/10.1037/1528-3542.8.2.256

Miller, E. K. (2000). The prefrontal cortex and cognitive control. Nature Reviews Neuroscience, 1, 59-65. http://dx.doi.org/10.1038/35036228 
Miller, E. K., \& Cohen, J. D. (2001). An integrative theory of prefrontal cortex function. Annual Review of Neuroscience, 24, 167-202. http://dx .doi.org/10.1146/annurev.neuro.24.1.167

Mirabolfathi, V., Moradi, A. R., \& Bakhtiari, M. (2016). Emotional working memory in post-traumatic stress disorder and depression. Advances in Cognitive Science, 17, 33-44.

Mitchell, K. J., Mather, M., Johnson, M. K., Raye, C. L., \& Greene, E. J. (2006). A functional magnetic resonance imaging investigation of shortterm source and item memory for negative pictures. NeuroReport, 17, 1543-1547. http://dx.doi.org/10.1097/01.wnr.0000234743.50442.e5

Mitchell, R. L. C. (2007). fMRI delineation of working memory for emotional prosody in the brain: Commonalities with the lexico-semantic emotion network. NeuroImage, 36, 1015-1025. http://dx.doi.org/10 .1016/j.neuroimage.2007.03.016

Mitchell, R. L. C., \& Phillips, L. H. (2007). The psychological, neurochemical and functional neuroanatomical mediators of the effects of positive and negative mood on executive functions. Neuropsychologia, 45, 617-629. http://dx.doi.org/10.1016/j.neuropsychologia.2006.06.030

Miyake, A., \& Shah, P. (Eds.). (1999). Models of working memory: Mechanisms of active maintenance and executive control. New York, NY: Cambridge University Press. http://dx.doi.org/10.1017/ CBO9781139174909

Mobbs, D., Hagan, C. C., Dalgleish, T., Silston, B., \& Prévost, C. (2015). The ecology of human fear: Survival optimization and the nervous system. Frontiers in Neuroscience, 9, 55. http://dx.doi.org/10.3389/fnins .2015 .00055

Moher, D., Liberati, A., Tetzlaff, J., \& Altman, D. G. (2009). Preferred reporting items for systematic reviews and meta-analyses: The PRISMA statement. PLoS Medicine, 6, e1000097. http://dx.doi.org/10.1371/ journal.pmed.1000097

Monfort, V., Bernardin, F., Grosdemange, A., Ducrocq, X., Mathieu, P., \& Bolmont, B. (2013). Paradoxical state anxiety and working memory in a patient with acute stroke. Cognitive and Behavioral Neurology, 26, 195-207. http://dx.doi.org/10.1097/WNN.0000000000000010

Moon, C.-M., \& Jeong, G.-W. (2015). Functional neuroanatomy on the working memory under emotional distraction in patients with generalized anxiety disorder. Psychiatry and Clinical Neurosciences, 69, 609619. http://dx.doi.org/10.1111/pcn.12295

Moore, A. B., Clark, B. A., \& Kane, M. J. (2008). Who shalt not kill? Individual differences in working memory capacity, executive control, and moral judgment. Psychological Science, 19, 549-557. http://dx.doi .org/10.1111/j.1467-9280.2008.02122.x

Moran, T. P. (2016). Anxiety and working memory capacity: A metaanalysis and narrative review. Psychological Bulletin, 142, 831-864. http://dx.doi.org/10.1037/bul0000051

Moreno, M. L., Vanderhasselt, M.-A., Carvalho, A. F., Moffa, A. H., Lotufo, P. A., Benseñor, I. M., \& Brunoni, A. R. (2015). Effects of acute transcranial direct current stimulation in hot and cold working memory tasks in healthy and depressed subjects. Neuroscience Letters, 591, 126-131. http://dx.doi.org/10.1016/j.neulet.2015.02.036

Morey, R. A., Dolcos, F., Petty, C. M., Cooper, D. A., Hayes, J. P., LaBar, K. S., \& McCarthy, G. (2009). The role of trauma-related distractors on neural systems for working memory and emotion processing in posttraumatic stress disorder. Journal of Psychiatric Research, 43, 809-817. http://dx.doi.org/10.1016/j.jpsychires.2008.10.014

Morey, R. A., Hariri, A. R., Gold, A. L., Hauser, M. A., Munger, H. J., Dolcos, F., \& McCarthy, G. (2011). Serotonin transporter gene polymorphisms and brain function during emotional distraction from cognitive processing in posttraumatic stress disorder. BMC Psychiatry, 11, 76. http://dx.doi.org/10.1186/1471-244X-11-76

Morgan, B., Terburg, D., Thornton, H. B., Stein, D. J., \& van Honk, J. (2012). Paradoxical facilitation of working memory after basolateral amygdala damage. PLoS ONE, 7, e38116. http://dx.doi.org/10.1371/ journal.pone.0038116
Moriya, J., Koster, E. H., \& De Raedt, R. (2014). The influence of working memory on visual search for emotional facial expressions. Journal of Experimental Psychology: Human Perception and Performance, 40, 1874-1890. http://dx.doi.org/10.1037/a0037295

Morra, S., Parrella, I., \& Camba, R. (2011). The role of working memory in the development of emotion comprehension. British Journal of Developmental Psychology, 29, 744-764. http://dx.doi.org/10.1348/2044835X.002006

Moscarello, J. M., \& Maren, S. (2018). Flexibility in the face of fear: Hippocampal-prefrontal regulation of fear and avoidance. Current Opinion in Behavioral Sciences, 19, 44-49. http://dx.doi.org/10.1016/j .cobeha.2017.09.010

Mourão-Miranda, J., Volchan, E., Moll, J., de Oliveira-Souza, R., Oliveira, L., Bramati, I., . . Pessoa, L. (2003). Contributions of stimulus valence and arousal to visual activation during emotional perception. NeuroImage, 20, 1955-1963. http://dx.doi.org/10.1016/j.neuroimage.2003.08 .011

Mu, Y. G., Huang, L. J., Li, S. Y., Ke, C., Chen, Y., Jin, Y., \& Chen, Z. P. (2012). Working memory and the identification of facial expression in patients with left frontal glioma. Neuro-Oncology, 14, iv81-iv89. http:// dx.doi.org/10.1093/neuonc/nos215

Mueller, S. C., Cromheeke, S., Siugzdaite, R., \& Boehler, C. (2017). Evidence for the triadic model of adolescent brain development: Cognitive load and task-relevance of emotion differentially affect adolescents and adults. Developmental Cognitive Neuroscience, 26, 91-100. http://dx.doi.org/10.1016/j.den.2017.06.004

Mueller, S. C., Shechner, T., Rosen, D., Nelson, E. E., Pine, D. S., \& Ernst, M. (2015). Incidental threat during visuospatial working memory in adolescent anxiety: An emotional memory-guided saccade task. Depression and Anxiety, 32, 289-295. http://dx.doi.org/10.1002/da.22350

Mulder, H., Pitchford, N. J., \& Marlow, N. (2011). Inattentive behaviour is associated with poor working memory and slow processing speed in very pre-term children in middle childhood. The British Journal of Educational Psychology, 81, 147-160. http://dx.doi.org/10.1348/ $000709910 X 505527$

Müller, U., Mottweiler, E., \& Bublak, P. (2005). Noradrenergic blockade and numeric working memory in humans. Journal of Psychopharmacology, 19, 21-28. http://dx.doi.org/10.1177/0269881105048888

Mullin, B. C., Perlman, S. B., Versace, A., de Almeida, J. R. C., Labarbara, E. J., Klein, C., . . Phillips, M. L. (2012). An fMRI study of attentional control in the context of emotional distracters in euthymic adults with bipolar disorder. Psychiatry Research: Neuroimaging, 201, 196-205. http://dx.doi.org/10.1016/j.pscychresns.2011.09.002

Murty, V. P., Ritchey, M., Adcock, R. A., \& LaBar, K. S. (2010). fMRI studies of successful emotional memory encoding: A quantitative metaanalysis. Neuropsychologia, 48, 3459-3469. http://dx.doi.org/10.1016/j .neuropsychologia.2010.07.030

Nee, D. E., Brown, J. W., Askren, M. K., Berman, M. G., Demiralp, E., Krawitz, A., \& Jonides, J. (2013). A meta-analysis of executive components of working memory. Cerebral Cortex, 23, 264-282. http://dx .doi.org/10.1093/cercor/bhs007

Nee, D. E., Wager, T. D., \& Jonides, J. (2007). Interference resolution: Insights from a meta-analysis of neuroimaging tasks. Cognitive, Affective \& Behavioral Neuroscience, 7, 1-17. http://dx.doi.org/10.3758/ CABN.7.1.1

Nejati, V., Salehinejad, M. A., \& Sabayee, A. (2018). Impaired working memory updating affects memory for emotional and non-emotional materials the same way: Evidence from post-traumatic stress disorder (PTSD). Cognitive Processing, 19, 53-62. http://dx.doi.org/10.1007/ s10339-017-0837-2

Neta, M., \& Whalen, P. J. (2011). Individual differences in neural activity during a facial expression vs. identity working memory task. NeuroImage, 56, 1685-1692. http://dx.doi.org/10.1016/j.neuroimage.2011.02 .051 
Noreen, S., \& Ridout, N. (2010). Short-term memory for emotional faces in dysphoria. Memory, 18, 486-497. http://dx.doi.org/10.1080/ 09658211003762092

Ochsner, K. N., Bunge, S. A., Gross, J. J., \& Gabrieli, J. D. (2002). Rethinking feelings: An FMRI study of the cognitive regulation of emotion. Journal of Cognitive Neuroscience, 14, 1215-1229. http://dx .doi.org/10.1162/089892902760807212

Ochsner, K. N., Gross, J. J., Ochsner, K. N., \& Gross, J. J. (2008). Cognitive emotion regulation: Insights from social cognitive and affective neuroscience. Current Directions in Psychological Science, 17, 153-158. http://dx.doi.org/10.1111/j.1467-8721.2008.00566.x

Ochsner, K. N., Ray, R. R., Hughes, B., McRae, K., Cooper, J. C., Weber, J., . . Gross, J. J. (2009). Bottom-up and top-down processes in emotion generation: Common and distinct neural mechanisms. Psychological Science, 20, 1322-1331. http://dx.doi.org/10.1111/j.1467-9280.2009 .02459.x

Ochsner, K. N., Silvers, J. A., \& Buhle, J. T. (2012). Functional imaging studies of emotion regulation: A synthetic review and evolving model of the cognitive control of emotion. Annals of the New York Academy of Sciences, 1251, E1-E24. http://dx.doi.org/10.1111/j.1749-6632.2012 .06751.X

Oei, N. Y., Everaerd, W. T., Elzinga, B. M., van Well, S., \& Bermond, B. (2006). Psychosocial stress impairs working memory at high loads: An association with cortisol levels and memory retrieval. Stress, 9, 133141. http://dx.doi.org/10.1080/10253890600965773

Oei, N. Y. L., Tollenaar, M. S., Elzinga, B. M., \& Spinhoven, P. (2010). Propranolol reduces emotional distraction in working memory: A partial mediating role of propranolol-induced cortisol increases? Neurobiology of Learning and Memory, 93, 388-395. http://dx.doi.org/10.1016/j.nlm 2009.12.005

Oei, N. Y. L., Tollenaar, M. S., Spinhoven, P., \& Elzinga, B. M. (2009). Hydrocortisone reduces emotional distracter interference in working memory. Psychoneuroendocrinology, 34, 1284-1293. http://dx.doi.org/ 10.1016/j.psyneuen.2009.03.015

Oei, N. Y. L., Veer, I. M., Wolf, O. T., Spinhoven, P., Rombouts, S. A. R. B., \& Elzinga, B. M. (2012). Stress shifts brain activation towards ventral 'affective' areas during emotional distraction. Social Cognitive and Affective Neuroscience, 7, 403-412. http://dx.doi.org/10 $.1093 / \mathrm{scan} / \mathrm{nsr} 024$

Öhman, A., Flykt, A., \& Esteves, F. (2001). Emotion drives attention: Detecting the snake in the grass. Journal of Experimental Psychology: General, 130, 466-478. http://dx.doi.org/10.1037/0096-3445.130.3.466

Okon-Singer, H., Hendler, T., Pessoa, L., \& Shackman, A. J. (2015). The neurobiology of emotion-cognition interactions: Fundamental questions and strategies for future research. Frontiers in Human Neuroscience. Advance online publication. http://dx.doi.org/10.3389/fnhum.2015 .00058

Onraedt, T., \& Koster, E. H. W. (2014). Training working memory to reduce rumination. PLoS ONE, 9, e90632. http://dx.doi.org/10.1371/ journal.pone.0090632

Opmeer, E. M., Kortekaas, R., van Tol, M. J., van der Wee, N. J., Woudstra, S., van Buchem, M. A., . . Aleman, A. (2013). Influence of COMT val158met genotype on the depressed brain during emotional processing and working memory. PLoS ONE, 8, e73290. http://dx.doi .org/10.1371/journal.pone.0073290

Osaka, M., Yaoi, K., Minamoto, T., \& Osaka, N. (2013). When do negative and positive emotions modulate working memory performance? Scientific Reports, 3, 1375. http://dx.doi.org/10.1038/srep01375

Owen, A. M., McMillan, K. M., Laird, A. R., \& Bullmore, E. (2005). N-back working memory paradigm: A meta-analysis of normative functional neuroimaging studies. Human Brain Mapping, 25, 46-59. http:// dx.doi.org/10.1002/hbm.20131

Pallesen, K. J., Brattico, E., Bailey, C. J., Korvenoja, A., \& Gjedde, A. (2009). Cognitive and emotional modulation of brain default operation.
Journal of Cognitive Neuroscience, 21, 1065-1080. http://dx.doi.org/10 $.1162 /$ jocn.2009.21086

Pallesen, K. J., Brattico, E., Bailey, C. J., Korvenoja, A., Koivisto, J., Gjedde, A., \& Carlson, S. (2010). Cognitive control in auditory working memory is enhanced in musicians. PLoS ONE, 5, e11120. http://dx.doi .org/10.1371/journal.pone.0011120

Park, J.-I., Kim, G.-W., Jeong, G.-W., Chung, G. H., \& Yang, J.-C. (2016) Brain activation patterns associated with the effects of emotional distracters during working memory maintenance in patients with generalized anxiety disorder. Psychiatry Investigation, 13, 152-156. http://dx .doi.org/10.4306/pi.2016.13.1.152

Park, S., Gibson, C., \& McMichael, T. (2006). Socioaffective factors modulate working memory in schizophrenia patients. Neuroscience, 139, 373-384. http://dx.doi.org/10.1016/j.neuroscience.2005.06.034

Passarotti, A. M., Ellis, J., Wegbreit, E., Stevens, M. C., \& Pavuluri, M. N. (2012). Reduced functional connectivity of prefrontal regions and amygdala within affect and working memory networks in pediatric bipolar disorder. Brain Connectivity, 2, 320-334. http://dx.doi.org/10 $.1089 /$ brain.2012.0089

Passarotti, A. M., Sweeney, J. A., \& Pavuluri, M. N. (2010). Emotion processing influences working memory circuits in pediatric bipolar disorder and attention-deficit/hyperactivity disorder. Journal of the American Academy of Child \& Adolescent Psychiatry, 49, 1064-1080. http://dx.doi.org/10.1016/j.jaac.2010.07.009

Passarotti, A. M., Sweeney, J. A., \& Pavuluri, M. N. (2011). Fronto-limbic dysfunction in mania pre-treatment and persistent amygdala overactivity post-treatment in pediatric bipolar disorder. Psychopharmacology, 216, 485-499. http://dx.doi.org/10.1007/s00213-011-2243-2

Pauly, K., Seiferth, N. Y., Kellermann, T., Ruhrmann, S., Daumann, B., Backes, V., . . . Habel, U. (2010). The interaction of working memory and emotion in persons clinically at risk for psychosis: An fMRI pilot study. Schizophrenia Research, 120, 167-176. http://dx.doi.org/10 .1016/j.schres.2009.12.008

Pavuluri, M. N., Passarotti, A. M., Fitzgerald, J. M., Wegbreit, E., \& Sweeney, J. A. (2012). Risperidone and divalproex differentially engage the fronto-striato-temporal circuitry in pediatric mania: A pharmacological functional magnetic resonance imaging study. Journal of the American Academy of Child \& Adolescent Psychiatry, 51, 157-170.e5. http:// dx.doi.org/10.1016/j.jaac.2011.10.019

Pe, M. L., Brose, A., Gotlib, I. H., \& Kuppens, P. (2016). Affective updating ability and stressful events interact to prospectively predict increases in depressive symptoms over time. Emotion, 16, 73-82. http:// dx.doi.org/10.1037/emo0000097

Pe, M. L., Koval, P., \& Kuppens, P. (2013). Executive well-being: Updating of positive stimuli in working memory is associated with subjective well-being. Cognition, 126, 335-340. http://dx.doi.org/10.1016/j .cognition.2012.10.002

Pe, M. L., Raes, F., Koval, P., Brans, K., Verduyn, P., \& Kuppens, P. (2013). Interference resolution moderates the impact of rumination and reappraisal on affective experiences in daily life. Cognition and Emotion, 27, 492-501. http://dx.doi.org/10.1080/02699931.2012.719489

Pe, M. L., Raes, F., \& Kuppens, P. (2013). The cognitive building blocks of emotion regulation: Ability to update working memory moderates the efficacy of rumination and reappraisal on emotion. PLOS ONE, 8, e69071. http://dx.doi.org/10.1371/journal.pone.0069071

Pecchinenda, A., Dretsch, M., \& Chapman, P. (2006). Working memory involvement in emotion-based processes underlying choosing advantageously. Experimental Psychology, 53, 191-197. http://dx.doi.org/10 .1027/1618-3169.53.3.191

Pecchinenda, A., \& Heil, M. (2007). Role of working memory load on selective attention to affectively valent information. The European Journal of Cognitive Psychology, 19, 898-909. http://dx.doi.org/10.1080/ 09541440601095388 
Pehlivanoglu, D., Jain, S., Ariel, R., \& Verhaeghen, P. (2014). The ties to unbind: Age-related differences in feature (un)binding in working memory for emotional faces. Frontiers in Psychology, 5, 253. http://dx.doi .org/10.3389/fpsyg.2014.00253

Pereira, M. G., Volchan, E., de Souza, G. G. L., Oliveira, L., Campagnoli, R. R., Pinheiro, W. M., \& Pessoa, L. (2006). Sustained and transient modulation of performance induced by emotional picture viewing. Emotion, 6, 622-634. http://dx.doi.org/10.1037/1528-3542.6.4.622

Perlstein, W. M., Elbert, T., \& Stenger, V. A. (2002). Dissociation in human prefrontal cortex of affective influences on working memoryrelated activity. Proceedings of the National Academy of Sciences of the United States of America, 99, 1736-1741. http://dx.doi.org/10.1073/ pnas. 241650598

Pessoa, L. (2005). To what extent are emotional visual stimuli processed without attention and awareness? Current Opinion in Neurobiology, 15, 188-196. http://dx.doi.org/10.1016/j.conb.2005.03.002

Pessoa, L. (2008). On the relationship between emotion and cognition. Nature Reviews Neuroscience, 9, 148-158. http://dx.doi.org/10.1038/ nrn2317

Pessoa, L. (2009). How do emotion and motivation direct executive control? Trends in Cognitive Sciences, 13, 160-166. http://dx.doi.org/10 .1016/j.tics.2009.01.006

Pessoa, L., \& Adolphs, R. (2010). Emotion processing and the amygdala: From a 'low road' to 'many roads' of evaluating biological significance. Nature Reviews Neuroscience, 11, 773-783. http://dx.doi.org/10.1038/ nrn2920

Pessoa, L., \& Ungerleider, L. G. (2004). Neuroimaging studies of attention and the processing of emotion-laden stimuli. Progress in Brain Research, 144, 171-182. http://dx.doi.org/10.1016/S0079-6123(03) 14412-3

Peterson, E., \& Welsh, M. C. (2014). The development of hot and cool executive functions in childhood and adolescence: Are we getting warmer? In S. Goldstein \& J. A. Naglieri (Eds.), Handbook of executive functioning (pp. 45-65). New York, NY: Springer New York. http://dx .doi.org/10.1007/978-1-4614-8106-5_4

Pfeifer, J. H., \& Allen, N. B. (2012). Arrested development? Reconsidering dual-systems models of brain function in adolescence and disorders. Trends in Cognitive Sciences, 16, 322-329. http://dx.doi.org/10.1016/j .tics.2012.04.011

Phelps, E. A. (2004). Human emotion and memory: Interactions of the amygdala and hippocampal complex. Current Opinion in Neurobiology, 14, 198-202. http://dx.doi.org/10.1016/j.conb.2004.03.015

Phelps, E. A. (2006). Emotion and cognition: Insights from studies of the human amygdala. Annual Review of Psychology, 57, 27-53. http://dx .doi.org/10.1146/annurev.psych.56.091103.070234

Phillips, L. H., Channon, S., Tunstall, M., Hedenstrom, A., \& Lyons, K. (2008). The role of working memory in decoding emotions. Emotion, 8, 184-191. http://dx.doi.org/10.1037/1528-3542.8.2.184

Phillips, L. K., Giuliano, A. J., Lee, E. H., Faraone, S. V., Tsuang, M. T., \& Seidman, L. J. (2011). Emotion-cognition interaction in people at familial high risk for schizophrenia: The impact of sex differences. Journal of Abnormal Psychology, 120, 993-998. http://dx.doi.org/10 1037/a0023542

Pio de Almeida, L. S., Jansen, K., Köhler, C. A., Pinheiro, R. T., da Silva, R. A., \& Bonini, J. S. (2012). Working and short-term memories are impaired in postpartum depression. Journal of Affective Disorders, 136, 1238-1242. http://dx.doi.org/10.1016/j.jad.2011.09.031

Poldrack, R. A. (2006). Can cognitive processes be inferred from neuroimaging data? Trends in Cognitive Sciences, 10, 59-63. http://dx.doi .org/10.1016/j.tics.2005.12.004

Poldrack, R. A. (2011). Inferring mental states from neuroimaging data: From reverse inference to large-scale decoding. Neuron, 72, 692-697. http://dx.doi.org/10.1016/j.neuron.2011.11.001
Postle, B. R. (2016). How does the brain keep information "in mind"? Current Directions in Psychological Science, 25, 151-156. http://dx.doi .org/10.1177/0963721416643063

Pourtois, G., Schettino, A., \& Vuilleumier, P. (2013). Brain mechanisms for emotional influences on perception and attention: What is magic and what is not. Biological Psychology, 92, 492-512. http://dx.doi.org/10 .1016/j.biopsycho.2012.02.007

Power, M. J., \& Dalgleish, T. (2015). Cognition and emotion: From order to disorder (3rd ed.). Hove, UK: Psychology Press. http://dx.doi.org/10 .4324/9781315708744

Prehn, K., Schulze, L., Rossmann, S., Berger, C., Vohs, K., Fleischer, M., . . . Herpertz, S. C. (2013). Effects of emotional stimuli on working memory processes in male criminal offenders with borderline and antisocial personality disorder. The World Journal of Biological Psychiatry, 14, 71-78. http://dx.doi.org/10.3109/15622975.2011.584906

Prencipe, A., Kesek, A., Cohen, J., Lamm, C., Lewis, M. D., \& Zelazo, P. D. (2011). Development of hot and cool executive function during the transition to adolescence. Journal of Experimental Child Psychology, 108, 621-637. http://dx.doi.org/10.1016/j.jecp.2010.09.008

Putman, P., Hermans, E. J., \& van Honk, J. (2007). Exogenous cortisol shifts a motivated bias from fear to anger in spatial working memory for facial expressions. Psychoneuroendocrinology, 32, 14-21. http://dx.doi .org/10.1016/j.psyneuen.2006.09.010

Qi, S., Ding, C., \& Li, H. (2014). Neural correlates of inefficient filtering of emotionally neutral distractors from working memory in trait anxiety. Cognitive, Affective \& Behavioral Neuroscience, 14, 253-265. http://dx .doi.org/10.3758/s13415-013-0203-5

Quinlan, P. T., Yue, Y., \& Cohen, D. J. (2017). The processing of images of biological threats in visual short-term memory. Proceedings. Biological Sciences. Advance online publication. http://dx.doi.org/10.1098/ rspb.2017.1283

Quinn, M. E., \& Joormann, J. (2015a). Control when it counts: Change in executive control under stress predicts depression symptoms. Emotion, 15, 522-530. http://dx.doi.org/10.1037/emo0000089

Quinn, M. E., \& Joormann, J. (2015b). Stress-induced changes in executive control are associated with depression symptoms examining the role of rumination. Clinical Psychological Science, 3, 628-636. http://dx.doi .org/10.1177/2167702614563930

R Core Team. (2013). R: A language and environment for statistical computing. $R$ Foundation for Statistical Computing. Retrieved from http://www.R-project.org

Rebetez, M. M. L., Rochat, L., Billieux, J., Gay, P., \& Van der Linden, M (2015). Do emotional stimuli interfere with two distinct components of inhibition? Cognition and Emotion, 29, 559-567. http://dx.doi.org/10 $.1080 / 02699931.2014 .922054$

Reed, A. E., Chan, L., \& Mikels, J. A. (2014). Meta-analysis of the age-related positivity effect: Age differences in preferences for positive over negative information. Psychology and Aging, 29, 1-15. http://dx doi.org/10.1037/a0035194

Reinecke, A., Becker, E. S., \& Rinck, M. (2009). Selective visual working memory in fear of spiders: The role of automaticity and materialspecificity. Journal of Anxiety Disorders, 23, 1053-1063. http://dx.doi .org/10.1016/j.janxdis.2009.07.007

Reinecke, A., Rinck, M., \& Becker, E. S. (2006). Spiders crawl easily through the bottleneck: Visual working memory for negative stimuli. Emotion, 6, 438-449. http://dx.doi.org/10.1037/1528-3542.6.3.438

Reinecke, A., Soltau, C., Hoyer, J., Becker, E. S., \& Rinck, M. (2012). Treatment sensitivity of implicit threat evaluation, avoidance tendency and visual working memory bias in specific phobia. Journal of Anxiety Disorders, 26, 321-328. http://dx.doi.org/10.1016/j.janxdis.2011.12.010

Reinholdt-Dunne, M. L., Mogg, K., \& Bradley, B. P. (2013). Attention control: Relationships between self-report and behavioural measures, and symptoms of anxiety and depression. Cognition and Emotion, 27, 430-440. http://dx.doi.org/10.1080/02699931.2012.715081 
Richter, S., Gorny, X., Machts, J., Behnisch, G., Wüstenberg, T., Herbort, M. C., . . . Schott, B. H. (2013). Effects of AKAP5 Pro100Leu genotype on working memory for emotional stimuli. PLOS ONE, 8, e55613. http://dx.doi.org/10.1371/journal.pone.0055613

Robinaugh, D. J., Crane, M. E., Enock, P. M., \& McNally, R. J. (2016). Training the removal of negative information from working memory: A preliminary investigation of a working memory bias modification task. Cognition and Emotion, 30, 570-581. http://dx.doi.org/10.1080/ 02699931.2015 .1014312

Robinson, K. E., Pearson, M. M., Cannistraci, C. J., Anderson, A. W., Kuttesch, J. F., Jr., Wymer, K., . . . Compas, B. E. (2015). Functional neuroimaging of working memory in survivors of childhood brain tumors and healthy children: Associations with coping and psychosocial outcomes. Child Neuropsychology, 21, 779-802. http://dx.doi.org/10 .1080/09297049.2014.924492

Román, F. J., García-Rubio, M. J., Privado, J., Kessel, D., López-Martín, S., Martínez, K., . . . Colom, R. (2015). Adaptive working memory training reveals a negligible effect of emotional stimuli over cognitive processing. Personality and Individual Differences, 74, 165-170. http:// dx.doi.org/10.1016/j.paid.2014.10.014

Rosenberg, H., Dethier, M., Kessels, R. P., Westbrook, R. F., \& McDonald, S. (2015). Emotion perception after moderate-severe traumatic brain injury: The valence effect and the role of working memory, processing speed, and nonverbal reasoning. Neuropsychology, 29, 509-521. http:// dx.doi.org/10.1037/neu0000171

Rothstein, H. R., Sutton, A. J., \& Borenstein, M. (2005). Publication bias in meta-analysis. Chichester, UK: Wiley. http://dx.doi.org/10.1002/ 0470870168

Rypma, B., \& D'Esposito, M. (2000). Isolating the neural mechanisms of age-related changes in human working memory. Nature Neuroscience, 3, 509-515. http://dx.doi.org/10.1038/74889

Sabatinelli, D., Fortune, E. E., Li, Q., Siddiqui, A., Krafft, C., Oliver, W. T., . . Jeffries, J. (2011). Emotional perception: Meta-analyses of face and natural scene processing. NeuroImage, 54, 2524-2533. http:// dx.doi.org/10.1016/j.neuroimage.2010.10.011

Sabharwal, A., Szekely, A., Kotov, R., Mukherjee, P., Leung, H.-C., Barch, D. M., \& Mohanty, A. (2016). Transdiagnostic neural markers of emotion-cognition interaction in psychotic disorders. Journal of Abnormal Psychology, 125, 907-922. http://dx.doi.org/10.1037/abn0000196

Sah, P., Faber, E. S. L., Lopez De Armentia, M., \& Power, J. (2003). The amygdaloid complex: Anatomy and physiology. Physiological Reviews, 83, 803-834. http://dx.doi.org/10.1152/physrev.00002.2003

Salimi-Khorshidi, G., Smith, S. M., Keltner, J. R., Wager, T. D., \& Nichols, T. E. (2009). Meta-analysis of neuroimaging data: A comparison of image-based and coordinate-based pooling of studies. NeuroImage, 45, 810-823. http://dx.doi.org/10.1016/j.neuroimage.2008.12.039

Salvadore, G., Cornwell, B. R., Sambataro, F., Latov, D., Colon-Rosario, V., Carver, F., . . Zarate, C. A., Jr. (2010). Anterior cingulate desynchronization and functional connectivity with the amygdala during a working memory task predict rapid antidepressant response to ketamine. Neuropsychopharmacology, 35, 1415-1422. http://dx.doi.org/10.1038/ npp. 2010.24

Sander, M. C., Lindenberger, U., \& Werkle-Bergner, M. (2012). Lifespan age differences in working memory: A two-component framework. Neuroscience and Biobehavioral Reviews, 36, 2007-2033. http://dx.doi .org/10.1016/j.neubiorev.2012.06.004

Satpute, A. B., Badre, D., \& Ochsner, K. N. (2014). Distinct regions of prefrontal cortex are associated with the controlled retrieval and selection of social information. Cerebral Cortex, 24, 1269-1277. http://dx .doi.org/10.1093/cercor/bhs408

Satpute, A. B., Kang, J., Bickart, K. C., Yardley, H., Wager, T. D., \& Barrett, L. F. (2015). Involvement of sensory regions in affective experience: A meta-analysis. Frontiers in Psychology, 6, 1860. http://dx.doi .org/10.3389/fpsyg.2015.01860
Saunders, N., Downham, R., Turman, B., Kropotov, J., Clark, R., Yumash R., \& Szatmary, A. (2015). Working memory training with tDCS improves behavioral and neurophysiological symptoms in pilot group with post-traumatic stress disorder (PTSD) and with poor working memory. Neurocase, 21, 271-278. http://dx.doi.org/10.1080/13554794.2014 .890727

Sawaguchi, T., \& Goldman-Rakic, P. S. (1991). D1 dopamine receptors in prefrontal cortex: Involvement in working memory. Science, 251, 947950. http://dx.doi.org/10.1126/science. 1825731

Saxton, B. T., Myhre, S. K., Siyaguna, T., \& Rokke, P. D. (2018). Do arousal and valence have separable influences on attention across time? Psychological Research. Advance online publication. http://dx.doi.org/ 10.1007/s00426-018-0995-6

Schaefer, A., Braver, T. S., Reynolds, J. R., Burgess, G. C., Yarkoni, T., \& Gray, J. R. (2006). Individual differences in amygdala activity predict response speed during working memory. The Journal of Neuroscience, 26, 10120-10128. http://dx.doi.org/10.1523/JNEUROSCI.2567-06 .2006

Scheibe, S., \& Carstensen, L. L. (2010). Emotional aging: Recent findings and future trends. The Journals of Gerontology. Series B, Psychologica Sciences and Social Sciences, 65B, 135-144. http://dx.doi.org/10.1093/ geronb/gbp 132

Schenkel, L. S., Passarotti, A. M., Sweeney, J. A., \& Pavuluri, M. N (2012). Negative emotion impairs working memory in pediatric patients with bipolar disorder type I. Psychological Medicine, 42, 2567-2577. http://dx.doi.org/10.1017/S0033291712000797

Scherer, K., Dan, E., \& Flykt, A. (2006). What determines a feeling's position in affective space? A case for appraisal. Cognition and Emotion, 20, 92-113. http://dx.doi.org/10.1080/02699930500305016

Schmeichel, B. J., Volokhov, R. N., \& Demaree, H. A. (2008). Working memory capacity and the self-regulation of emotional expression and experience. Journal of Personality and Social Psychology, 95, 15261540. http://dx.doi.org/10.1037/a0013345

Schmidt, F. L., Oh, I. S., \& Hayes, T. L. (2009). Fixed- versus randomeffects models in meta-analysis: Model properties and an empirical comparison of differences in results. British Journal of Mathematical \& Statistical Psychology, 62, 97-128. http://dx.doi.org/10.1348/ $000711007 X 255327$

Schneider, I. K., Veenstra, L., van Harreveld, F., Schwarz, N., \& Koole, S. L. (2016). Let's not be indifferent about neutrality: Neutral ratings in the International Affective Picture System (IAPS) mask mixed affective responses. Emotion, 16, 426-430. http://dx.doi.org/10.1037/ emo0000164

Schoenbaum, G., \& Roesch, M. (2005). Orbitofrontal cortex, associative learning, and expectancies. Neuron, 47, 633-636. http://dx.doi.org/10 .1016/j.neuron.2005.07.018

Schupp, H. T., Flaisch, T., Stockburger, J., \& Junghöfer, M. (2006). Emotion and attention: Event-related brain potential studies. Progress in Brain Research, 156, 31-51. http://dx.doi.org/10.1016/S00796123(06)56002-9

Schweizer, S., \& Dalgleish, T. (2011). Emotional working memory capacity in posttraumatic stress disorder (PTSD). Behaviour Research and Therapy, 49, 498-504. http://dx.doi.org/10.1016/j.brat.2011.05.007

Schweizer, S., \& Dalgleish, T. (2013). What are the critical ingredients of affective working memory training? Comment on Engen and Kanske. The Journal of Neuroscience, 33, 12152-12153.

Schweizer, S., \& Dalgleish, T. (2016). The impact of affective contexts on working memory capacity in healthy populations and in individuals with PTSD. Emotion, 16, 16-23. http://dx.doi.org/10.1037/emo0000072

Schweizer, S., Grahn, J., Hampshire, A., Mobbs, D., \& Dalgleish, T. (2013). Training the emotional brain: Improving affective control through emotional working memory training. The Journal of Neuroscience, 33, 5301-5311. http://dx.doi.org/10.1523/JNEUROSCI.2593-12 .2013 
Schweizer, S., Hampshire, A., \& Dalgleish, T. (2011). Extending braintraining to the affective domain: Increasing cognitive and affective executive control through emotional working memory training. PLoS ONE, 6, e24372. http://dx.doi.org/10.1371/journal.pone.0024372

Schweizer, S., Navrady, L., Breakwell, L., Howard, R. M., Golden, A.-M., Werner-Seidler, A., \& Dalgleish, T. (2018). Affective enhancement of working memory is maintained in depression. Emotion, 18, 127-137. http://dx.doi.org/10.1037/emo0000306

Scott, J. C., Matt, G. E., Wrocklage, K. M., Crnich, C., Jordan, J., Southwick, S. M., . . S Schweinsburg, B. C. (2015). A quantitative meta-analysis of neurocognitive functioning in posttraumatic stress disorder. Psychological Bulletin, 141, 105-140. http://dx.doi.org/10.1037/ a0038039

Seeley, W. W., Menon, V., Schatzberg, A. F., Keller, J., Glover, G. H., Kenna, H., ... Greicius, M. D. (2007). Dissociable intrinsic connectivity networks for salience processing and executive control. The Journal of Neuroscience, 27, 2349-2356. http://dx.doi.org/10.1523/JNEUROSCI $.5587-06.2007$

Segal, A., Kessler, Y., \& Anholt, G. E. (2015). Updating the emotional content of working memory in social anxiety. Journal of Behavior Therapy and Experimental Psychiatry, 48, 110-117. http://dx.doi.org/ 10.1016/j.jbtep.2015.02.012

Sessa, P., Luria, R., Gotler, A., Jolicœur, P., \& Dell'acqua, R. (2011). Interhemispheric ERP asymmetries over inferior parietal cortex reveal differential visual working memory maintenance for fearful versus neutral facial identities. Psychophysiology, 48, 187-197. http://dx.doi.org/ 10.1111/j.1469-8986.2010.01046.x

Shackman, A. J., Sarinopoulos, I., Maxwell, J. S., Pizzagalli, D. A., Lavric, A., \& Davidson, R. J. (2006). Anxiety selectively disrupts visuospatial working memory. Emotion, 6, 40-61. http://dx.doi.org/10.1037/15283542.6.1.40

Sharbanee, J. M., Stritzke, W. G., Wiers, R. W., Young, P., Rinck, M., \& MacLeod, C. (2013). The interaction of approach-alcohol action tendencies, working memory capacity, and current task goals predicts the inability to regulate drinking behavior. Psychology of Addictive Behaviors, 27, 649-661. http://dx.doi.org/10.1037/a0029982

Shaw, P., Stringaris, A., Nigg, J., \& Leibenluft, E. (2014). Emotion dysregulation in attention deficit hyperactivity disorder. The American Journal of Psychiatry, 171, 276-293. http://dx.doi.org/10.1176/appi.ajp .2013 .13070966

Shenton, M. E., Dickey, C. C., Frumin, M., \& McCarley, R. W. (2001). A review of MRI findings in schizophrenia. Schizophrenia Research, 49, 1-52. http://dx.doi.org/10.1016/S0920-9964(01)00163-3

Shi, Z., Gao, X., \& Zhou, R. (2014). Emotional working memory capacity in test anxiety. Learning and Individual Differences, 32, 178-183. http://dx.doi.org/10.1016/j.lindif.2014.03.011

Shi, Z., Gao, X., \& Zhou, R. (2015). Frontal theta activity during working memory in test anxiety. NeuroReport, 26, 228-232. http://dx.doi.org/10 .1097/WNR.0000000000000334

Silver, H., \& Feldman, P. (2005). Evidence for sustained attention and working memory in schizophrenia sharing a common mechanism. The Journal of Neuropsychiatry and Clinical Neurosciences, 17, 391-398. http://dx.doi.org/10.1176/jnp.17.3.391

Silver, H., Feldman, P., Bilker, W., \& Gur, R. C. (2003). Working memory deficit as a core neuropsychological dysfunction in schizophrenia. The American Journal of Psychiatry, 160, 1809-1816. http://dx.doi.org/10 .1176/appi.ajp.160.10.1809

Simione, L., Calabrese, L., Marucci, F. S., Belardinelli, M. O., Raffone, A., \& Maratos, F. A. (2014). Emotion based attentional priority for storage in visual short-term memory. PLOS ONE, 9, e95261. http://dx.doi.org/ 10.1371/journal.pone.0095261

Simon, E. B., Oren, N., Sharon, H., Kirschner, A., Goldway, N., OkonSinger, H., . . . Hendler, T. (2015). Losing neutrality: The neural basis of impaired emotional control without sleep. The Journal of Neurosci- ence, 35, 13194-13205. http://dx.doi.org/10.1523/JNEUROSCI.131415.2015

Skodol, A. E., Oldham, J. M., Bender, D. S., Dyck, I. R., Stout, R. L., Morey, L. C., . . Gunderson, J. G. (2005). Dimensional representations of $D S M-I V$ personality disorders: Relationships to functional impairment. The American Journal of Psychiatry, 162, 1919-1925. http://dx .doi.org/10.1176/appi.ajp.162.10.1919

Smith, E. E., \& Jonides, J. (1999). Storage and executive processes in the frontal lobes. Science, 283, 1657-1661. http://dx.doi.org/10.1126/ science.283.5408.1657

Smith, M. J., Horan, W. P., Cobia, D. J., Karpouzian, T. M., Fox, J. M., Reilly, J. L., \& Breiter, H. C. (2014). Performance-based empathy mediates the influence of working memory on social competence in schizophrenia. Schizophrenia Bulletin, 40, 824-834. http://dx.doi.org/ 10.1093/schbul/sbt084

Smith, N. K., Cacioppo, J. T., Larsen, J. T., \& Chartrand, T. L. (2003). May I have your attention, please: Electrocortical responses to positive and negative stimuli. Neuropsychologia, 41, 171-183. http://dx.doi.org/10 .1016/S0028-3932(02)00147-1

Snyder, H. R. (2013). Major depressive disorder is associated with broad impairments on neuropsychological measures of executive function: A meta-analysis and review. Psychological Bulletin, 139, 81-132. http:// dx.doi.org/10.1037/a0028727

Spachtholz, P., Kuhbandner, C., \& Pekrun, R. (2014). Negative affect improves the quality of memories: Trading capacity for precision in sensory and working memory. Journal of Experimental Psychology: General, 143, 1450-1456. http://dx.doi.org/10.1037/xge0000012

Speed, B. C., Nelson, B. D., Perlman, G., Klein, D. N., Kotov, R., \& Hajcak, G. (2015). Personality and emotional processing: A relationship between extraversion and the late positive potential in adolescence. Psychophysiology, 52, 1039-1047. http://dx.doi.org/10.1111/psyp .12436

Spinhoven, P., Drost, J., van Hemert, B., \& Penninx, B. W. (2015). Common rather than unique aspects of repetitive negative thinking are related to depressive and anxiety disorders and symptoms. Journal of Anxiety Disorders, 33, 45-52. http://dx.doi.org/10.1016/j.janxdis.2015 .05 .001

Spitzer, B., Gloel, M., Schmidt, T. T., \& Blankenburg, F. (2014). Working memory coding of analog stimulus properties in the human prefrontal cortex. Cerebral Cortex, 24, 2229-2236. http://dx.doi.org/10.1093/ cercor/bht084

Stegmayer, K., Usher, J., Trost, S., Henseler, I., Tost, H., Rietschel, M., . . Gruber, O. (2015). Disturbed cortico-amygdalar functional connectivity as pathophysiological correlate of working memory deficits in bipolar affective disorder. European Archives of Psychiatry and Clinical Neuroscience, 265, 303-311. http://dx.doi.org/10.1007/s00406-014-0517-5

Stiernströmer, E. S., Wolgast, M., \& Johansson, M. (2016). Effects of facial expression on working memory. International Journal of Psychology, 51, 312-317. http://dx.doi.org/10.1002/ijop.12194

Storbeck, J., Davidson, N. A., Dahl, C. F., Blass, S., \& Yung, E. (2015). Emotion, working memory task demands and individual differences predict behavior, cognitive effort and negative affect. Cognition and Emotion, 29, 95-117. http://dx.doi.org/10.1080/02699931.2014.904222

Storbeck, J., \& Watson, P. (2014). Verbal makes it positive, spatial makes it negative: Working memory biases judgments, attention, and moods. Emotion, 14, 1072-1086. http://dx.doi.org/10.1037/a0037327

Stout, D. M., Shackman, A. J., Johnson, J. S., \& Larson, C. L. (2015). Worry is associated with impaired gating of threat from working memory. Emotion, 15, 6-11. http://dx.doi.org/10.1037/emo0000015

Stout, D. M., Shackman, A. J., Pedersen, W. S., Miskovich, T. A., \& Larson, C. L. (2017). Neural circuitry governing anxious individuals' mis-allocation of working memory to threat. Scientific Reports, 7, 8742 http://dx.doi.org/10.1038/s41598-017-08443-7 
Straube, T., Trippe, R., Schmidt, S., Weiss, T., Hecht, H., \& Miltner, W. H. (2011). Dissociation of acquisition and expression of fear conditioned responses under working memory load. Emotion, 11, 209-213. http:// dx.doi.org/10.1037/a0021157

Strauss, G. P., Lee, B. G., Waltz, J. A., Robinson, B. M., Brown, J. K., \& Gold, J. M. (2012). Cognition-emotion interactions are modulated by working memory capacity in individuals with schizophrenia. Schizophrenia Research, 141, 257-261. http://dx.doi.org/10.1016/j.schres .2012 .08 .010

Stussi, Y., Pourtois, G., \& Sander, D. (2018). Enhanced Pavlovian aversive conditioning to positive emotional stimuli. Journal of Experimental Psychology: General, 147, 905-923. http://dx.doi.org/10.1037/ xge0000424

Takahashi, H., Yamada, M., \& Suhara, T. (2012). Functional significance of central D1 receptors in cognition: Beyond working memory. Journal of Cerebral Blood Flow and Metabolism, 32, 1248-1258. http://dx.doi .org/10.1038/jcbfm.2011.194

Talmi, D. (2013). Enhanced emotional memory: Cognitive and neural mechanisms. Current Directions in Psychological Science, 22, 430436. http://dx.doi.org/10.1177/0963721413498893

Talmi, D., Schimmack, U., Paterson, T., \& Moscovitch, M. (2007). The role of attention and relatedness in emotionally enhanced memory. Emotion, 7, 89-102. http://dx.doi.org/10.1037/1528-3542.7.1.89

Tamietto, M., \& de Gelder, B. (2010). Neural bases of the non-conscious perception of emotional signals. Nature Reviews Neuroscience, 11, 697-709. http://dx.doi.org/10.1038/nrn2889

Tamm, G., Kreegipuu, K., Harro, J., \& Cowan, N. (2017). Updating schematic emotional facial expressions in working memory: Response bias and sensitivity. Acta Psychologica, 172, 10-18. http://dx.doi.org/ 10.1016/j.actpsy.2016.11.002

Tavares, T. P., Logie, K., \& Mitchell, D. G. V. (2016). Opposing effects of perceptual versus working memory load on emotional distraction. Experimental Brain Research, 234, 2945-2956. http://dx.doi.org/10.1007/ s00221-016-4697-2

Tavitian, L. R., Ladouceur, C. D., Nahas, Z., Khater, B., Brent, D. A., \& Maalouf, F. T. (2014). Neutral face distractors differentiate performance between depressed and healthy adolescents during an emotional working memory task. European Child \& Adolescent Psychiatry, 23, 659-667. http://dx.doi.org/10.1007/s00787-013-0492-9

Taylor, S. E. (1991). Asymmetrical effects of positive and negative events: The mobilization-minimization hypothesis. Psychological Bulletin, 110, 67-85. http://dx.doi.org/10.1037/0033-2909.110.1.67

Tempesta, D., De Gennaro, L., Presaghi, F., \& Ferrara, M. (2014). Emotional working memory during sustained wakefulness. Journal of Sleep Research, 23, 646-656. http://dx.doi.org/10.1111/jsr.12170

Terfehr, K., Wolf, O. T., Schlosser, N., Fernando, S. C., Otte, C., Muhtz, C., . . Wingenfeld, K. (2011). Hydrocortisone impairs working memory in healthy humans, but not in patients with major depressive disorder. Psychopharmacology, 215, 71-79. http://dx.doi.org/10.1007/s00213010-2117-z

Thermenos, H. W., Goldstein, J. M., Milanovic, S. M., Whitfield-Gabrieli, S., Makris, N., Laviolette, P., . . . Seidman, L. J. (2010). An fMRI study of working memory in persons with bipolar disorder or at genetic risk for bipolar disorder. American Journal of Medical Genetics. Part B, Neuropsychiatric Genetics, 153b, 120-131.

Thermenos, H. W., Makris, N., Whitfield-Gabrieli, S., Brown, A. B., Giuliano, A. J., Lee, E. H., . . Seidman, L. J. (2011). A functional MRI study of working memory in adolescents and young adults at genetic risk for bipolar disorder: Preliminary findings. Bipolar Disorders, 13, 272286. http://dx.doi.org/10.1111/j.1399-5618.2011.00920.x

Thiruchselvam, R., Hajcak, G., \& Gross, J. J. (2012). Looking inward: Shifting attention within working memory representations alters emotional responses. Psychological Science, 23, 1461-1466. http://dx.doi .org/10.1177/0956797612449838
Thomas, P. M., Jackson, M. C., \& Raymond, J. E. (2014). A threatening face in the crowd: Effects of emotional singletons on visual working memory. Journal of Experimental Psychology: Human Perception and Performance, 40, 253-263. http://dx.doi.org/10.1037/a0033970

Tollenaar, M. S., Ruissen, M., Elzinga, B. M., \& de Bruijn, E. R. A. (2017). Does oxytocin lead to emotional interference during a working memory paradigm? Psychopharmacology, 234, 3467-3474. http://dx.doi.org/10 .1007/s00213-017-4737-z

Tomasi, D., Ernst, T., Caparelli, E. C., \& Chang, L. (2006). Common deactivation patterns during working memory and visual attention tasks: An intra-subject fMRI study at 4 Tesla. Human Brain Mapping, 27, 694-705. http://dx.doi.org/10.1002/hbm.20211

Tottenham, N., Tanaka, J. W., Leon, A. C., McCarry, T., Nurse, M., Hare, T. A., . . Nelson, C. (2009). The NimStim set of facial expressions: Judgments from untrained research participants. Psychiatry Research, 168, 242-249. http://dx.doi.org/10.1016/j.psychres.2008.05.006

Townsend, J., \& Altshuler, L. L. (2012). Emotion processing and regulation in bipolar disorder: A review. Bipolar Disorders, 14, 326-339. http://dx.doi.org/10.1111/j.1399-5618.2012.01021.x

Trémeau, F. (2006). A review of emotion deficits in schizophrenia. Dia logues in Clinical Neuroscience, 8, 59-70.

Trezise, K., \& Reeve, R. A. (2014). Working memory, worry, and algebraic ability. Journal of Experimental Child Psychology, 121, 120-136. http://dx.doi.org/10.1016/j.jecp.2013.12.001

Truong, L., \& Yang, L. (2014). Friend or foe? Decoding the facilitative and disruptive effects of emotion on working memory in younger and older adults. Frontiers in Psychology, 5, 94. http://dx.doi.org/10.3389/fpsyg .2014 .00094

Tsai, C., \& McNally, R. J. (2014). Effects of emotionally valenced working memory taxation on negative memories. Journal of Behavior Therapy and Experimental Psychiatry, 45, 15-19. http://dx.doi.org/10.1016/j .jbtep.2013.07.004

Uher, R., Brooks, S. J., Bartholdy, S., Tchanturia, K., \& Campbell, I. C. (2014). Increasing cognitive load reduces interference from masked appetitive and aversive but not neutral stimuli. PLoS ONE, 9, e94417. http://dx.doi.org/10.1371/journal.pone.0094417

van den Hout, M. A., Eidhof, M. B., Verboom, J., Littel, M., \& Engelhard, I. M. (2014). Blurring of emotional and non-emotional memories by taxing working memory during recall. Cognition and Emotion, 28 717-727. http://dx.doi.org/10.1080/02699931.2013.848785

van den Hout, M. A., Engelhard, I. M., Beetsma, D., Slofstra, C., Hornsveld, H., Houtveen, J., \& Leer, A. (2011). EMDR and mindfulness. Eye movements and attentional breathing tax working memory and reduce vividness and emotionality of aversive ideation. Journal of Behavior Therapy and Experimental Psychiatry, 42, 423-431. http://dx.doi.org/ 10.1016/j.jbtep.2011.03.004

Vanderhasselt, M.-A., Brunoni, A. R., Loeys, T., Boggio, P. S., \& De Raedt, R. (2013). Nosce te ipsum-Socrates revisited? Controlling momentary ruminative self-referent thoughts by neuromodulation of emotional working memory. Neuropsychologia, 51, 2581-2589. http://dx .doi.org/10.1016/j.neuropsychologia.2013.08.011

Van Dillen, L. F., \& Derks, B. (2012). Working memory load reduces facilitated processing of threatening faces: An ERP study. Emotion, 12, 1340-1349. http://dx.doi.org/10.1037/a0028624

Van Dillen, L. F., \& Koole, S. L. (2007). Clearing the mind: A working memory model of distraction from negative mood. Emotion, 7, 715-723. http://dx.doi.org/10.1037/1528-3542.7.4.715

Vermeulen, N., Niedenthal, P. M., Pleyers, G., Bayot, M., \& Corneille, O. (2014). Emotion-specific load disrupts concomitant affective processing. Quarterly Journal of Experimental Psychology: Human Experimental Psychology, 67, 1655-1660. http://dx.doi.org/10.1080/17470218.2014 .905610 
Viechtbauer, W. (2007). Accounting for heterogeneity via random-effects models and moderator analyses in meta-analysis. Journal of Psychology, $215,104-121$.

Viechtbauer, W. (2010). Conducting meta-analyses in R with the metafor package. Journal of Statistical Software, 36, 1-48. http://dx.doi.org/10 $.18637 /$ jss.v036.i03

Vincent, J. L., Kahn, I., Snyder, A. Z., Raichle, M. E., \& Buckner, R. L. (2008). Evidence for a frontoparietal control system revealed by intrinsic functional connectivity. Journal of Neurophysiology, 100, 3328-3342. http://dx.doi.org/10.1152/jn.90355.2008

Visu-Petra, L., Ţincaş, I., Cheie, L., \& Benga, O. (2010). Anxiety and visual-spatial memory updating in young children: An investigation using emotional facial expressions. Cognition and Emotion, 24, 223240. http://dx.doi.org/10.1080/02699930903387546

Vogt, J., De Houwer, J., \& Crombez, G. (2011). Multiple goal management starts with attention: Goal prioritizing affects the allocation of spatial attention to goal-relevant events. Experimental Psychology, 58, 55-61. http://dx.doi.org/10.1027/1618-3169/a000066

Vogt, J., De Houwer, J., Crombez, G., \& Van Damme, S. (2013). Competing for attentional priority: Temporary goals versus threats. Emotion, 13, 587-598. http://dx.doi.org/10.1037/a0027204

Vugs, B., Hendriks, M., Cuperus, J., \& Verhoeven, L. (2014). Working memory performance and executive function behaviors in young children with SLI. Research in Developmental Disabilities, 35, 62-74. http://dx.doi.org/10.1016/j.ridd.2013.10.022

Vuilleumier, P. (2002). Facial expression and selective attention. Current Opinion in Psychiatry, 15, 291-300. http://dx.doi.org/10.1097/ 00001504-200205000-00011

Vuilleumier, P. (2005). How brains beware: Neural mechanisms of emotional attention. Trends in Cognitive Sciences, 9, 585-594. http://dx.doi .org/10.1016/j.tics.2005.10.011

Vuilleumier, P., \& Huang, Y.-M. (2009). Emotional attention: Uncovering the mechanisms of affective biases in perception. Current Directions in Psychological Science, 18, 148-152. http://dx.doi.org/10.1111/j.14678721.2009.01626.x

Vuontela, V., Carlson, S., Troberg, A. M., Fontell, T., Simola, P., Saarinen, S., \& Aronen, E. T. (2013). Working memory, attention, inhibition, and their relation to adaptive functioning and behavioral/emotional symptoms in school-aged children. Child Psychiatry and Human Development, 44, 105-122. http://dx.doi.org/10.1007/s10578-012-0313-2

Wager, T. D., Lindquist, M., \& Kaplan, L. (2007). Meta-analysis of functional neuroimaging data: Current and future directions. Social Cognitive and Affective Neuroscience, 2, 150-158. http://dx.doi.org/10 .1093/scan/nsm015

Wagner, A., Simmons, A. N., Oberndorfer, T. A., Frank, G. K. W., McCurdy-McKinnon, D., Fudge, J. L., . . Kaye, W. H. (2015). Altered sensitization patterns to sweet food stimuli in patients recovered from anorexia and bulimia nervosa. Psychiatry Research: Neuroimaging, 234, 305-313. http://dx.doi.org/10.1016/j.pscychresns.2015.10.010

Wang, M., \& Saudino, K. J. (2013). Genetic and environmental influences on individual differences in emotion regulation and its relation to working memory in toddlerhood. Emotion, 13, 1055-1067. http://dx.doi.org/ 10.1037/a0033784

Wanmaker, S., Geraerts, E., \& Franken, I. H. A. (2015). A working memory training to decrease rumination in depressed and anxious individuals: A double-blind randomized controlled trial. Journal of Affective Disorders, 175, 310-319. http://dx.doi.org/10.1016/j.jad.2014.12.027

Wass, S., Porayska-Pomsta, K., \& Johnson, M. H. (2011). Training attentional control in infancy. Current Biology, 21, 1543-1547. http://dx.doi .org/10.1016/j.cub.2011.08.004

Weigand, A., Grimm, S., Astalosch, A., Guo, J. S., Briesemeister, B. B., Lisanby, S. H., . . Bajbouj, M. (2013). Lateralized effects of prefrontal repetitive transcranial magnetic stimulation on emotional working mem- ory. Experimental Brain Research, 227, 43-52. http://dx.doi.org/10 .1007/s00221-013-3483-7

Weigand, A., Richtermeier, A., Feeser, M., Guo, J. S., Briesemeister, B. B., Grimm, S., \& Bajbouj, M. (2013). State-dependent effects of prefrontal repetitive transcranial magnetic stimulation on emotional working memory. Brain Stimulation, 6, 905-912. http://dx.doi.org/10.1016/j.brs.2013 .06 .004

Wells, A., \& Matthews, G. (2015). Attention and emotion (2nd ed.). New York, NY: Psychology Press.

Whalen, P. J., \& Phelps, E. A. (2009). The human amygdala. New York, NY: Guilford Press.

Wilson, S. J., Sayette, M. A., Fiez, J. A., \& Brough, E. (2007). Carry-over effects of smoking cue exposure on working memory performance. Nicotine \& Tobacco Research, 9, 613-619. http://dx.doi.org/10.1080/ 14622200701243144

Wilson-Mendenhall, C. D., Barrett, L. F., \& Barsalou, L. W. (2013). Neural evidence that human emotions share core affective properties. Psychological Science, 24, 947-956. http://dx.doi.org/10.1177/ 0956797612464242

Wingert, K. M., Blais, C., Ball, B. H., \& Brewer, G. A. (2018). Working memory cannot regulate overt emotional capture. Acta Psychologica, 185, 52-64. http://dx.doi.org/10.1016/j.actpsy.2017.12.007

Wolf, C., Jackson, M. C., Kissling, C., Thome, J., \& Linden, D. E. J. (2011). Dysbindin-1 genotype effects on emotional working memory. Molecular Psychiatry, 16, 145-155. http://dx.doi.org/10.1038/mp.2009 .129

Wolf, C., Linden, S., Jackson, M. C., Healy, D., Baird, A., Linden, D. E., \& Thome, J. (2011). Brain activity supporting working memory accuracy in patients with paranoid schizophrenia: A functional magnetic resonance imaging study. Neuropsychobiology, 64, 93-101. http://dx.doi .org/10.1159/000323800

Wolfe, C. D., \& Bell, M. A. (2007). The integration of cognition and emotion during infancy and early childhood: Regulatory processes associated with the development of working memory. Brain and Cognition, 65, 3-13. http://dx.doi.org/10.1016/j.bandc.2006.01.009

Xie, W., Li, H., Ying, X., Zhu, S., Fu, R., Zou, Y., \& Cui, Y. (2017). Affective bias in visual working memory is associated with capacity. Cognition and Emotion, 31, 1345-1360.

Xin, F., \& Lei, X. (2015). Competition between frontoparietal control and default networks supports social working memory and empathy. Social Cognitive and Affective Neuroscience, 10, 1144-1152. http://dx.doi.org/ $10.1093 /$ scan/nsu 160

Yang, H., Yang, S., \& Isen, A. M. (2013). Positive affect improves working memory: Implications for controlled cognitive processing. Cog nition and Emotion, 27, 474-482. http://dx.doi.org/10.1080/02699931 .2012 .713325

Yang, P., Wang, M., Jin, Z., \& Li, L. (2015). Visual short-term memory load modulates the early attention and perception of task-irrelevant emotional faces. Frontiers in Human Neuroscience, 9, 490. http://dx.doi .org/10.3389/fnhum.2015.00490

Yiend, J. (2010). The effects of emotion on attention: A review of attentional processing of emotional information. Cognition and Emotion, 24 3-47. http://dx.doi.org/10.1080/02699930903205698

Yogo, M., \& Fujihara, S. (2008). Working memory capacity can be improved by expressive writing: A randomized experiment in a Japanese sample. British Journal of Health Psychology, 13, 77-80. http://dx.doi .org/10.1348/135910707X252440

Yoon, K. L., Kutz, A. M., LeMoult, J., \& Joormann, J. (2017). Working memory in social anxiety disorder: Better manipulation of emotional versus neutral material in working memory. Cognition and Emotion, 31, 1733-1740. http://dx.doi.org/10.1080/02699931.2016.1257482

Yoon, K. L., LeMoult, J., \& Joormann, J. (2014). Updating emotional content in working memory: A depression-specific deficit? Journal of 
Behavior Therapy and Experimental Psychiatry, 45, 368-374. http://dx .doi.org/10.1016/j.jbtep.2014.03.004

Zetsche, U., Bürkner, P.-C., \& Schulze, L. (2018). Shedding light on the association between repetitive negative thinking and deficits in cognitive control. A meta-analysis. Clinical Psychology Review, 63, 56-65. http:// dx.doi.org/10.1016/j.cpr.2018.06.001

Zhang, J.-N., Xiong, K.-L., Qiu, M.-G., Zhang, Y., Xie, B., Wang, J., . . . Zhang, J.-J. (2013). Negative emotional distraction on neural circuits for working memory in patients with posttraumatic stress disorder. Brain Research, 1531, 94-101.

Ziaei, M., Peira, N., \& Persson, J. (2014). Brain systems underlying attentional control and emotional distraction during working memory encoding. NeuroImage, 87, 276-286. http://dx.doi.org/10.1016/j neuroimage.2013.10.048

Ziaei, M., Salami, A., \& Persson, J. (2017). Age-related alterations in functional connectivity patterns during working memory encoding of emotional items. Neuropsychologia, 94, 1-12. http://dx.doi.org/10.1016/ j.neuropsychologia.2016.11.012

Received January 12, 2018

Revision received February 4, 2019

Accepted February 9, 2019

\section{Members of Underrepresented Groups: Reviewers for Journal Manuscripts Wanted}

If you are interested in reviewing manuscripts for APA journals, the APA Publications and Communications Board would like to invite your participation. Manuscript reviewers are vital to the publications process. As a reviewer, you would gain valuable experience in publishing. The P\&C Board is particularly interested in encouraging members of underrepresented groups to participate more in this process.

If you are interested in reviewing manuscripts, please write APA Journals at Reviewers@apa.org. Please note the following important points:

- To be selected as a reviewer, you must have published articles in peer-reviewed journals. The experience of publishing provides a reviewer with the basis for preparing a thorough, objective review.

- To be selected, it is critical to be a regular reader of the five to six empirical journals that are most central to the area or journal for which you would like to review. Current knowledge of recently published research provides a reviewer with the knowledge base to evaluate a new submission within the context of existing research.

- To select the appropriate reviewers for each manuscript, the editor needs detailed information. Please include with your letter your vita. In the letter, please identify which APA journal(s) you are interested in, and describe your area of expertise. Be as specific as possible. For example, "social psychology" is not sufficient-you would need to specify "social cognition" or "attitude change" as well.

- Reviewing a manuscript takes time (1-4 hours per manuscript reviewed). If you are selected to review a manuscript, be prepared to invest the necessary time to evaluate the manuscript thoroughly.

APA now has an online video course that provides guidance in reviewing manuscripts. To learn more about the course and to access the video, visit http://www.apa.org/pubs/journals/resources/ review-manuscript-ce-video.aspx. 


\section{University Library}

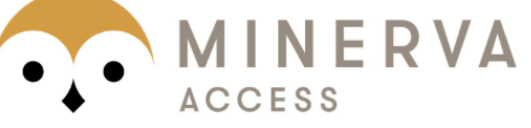

A gateway to Melbourne's research publications

Minerva Access is the Institutional Repository of The University of Melbourne

Author/s:

Schweizer, S;Satpute, AB;Atzil, S;Field, AP;Hitchcock, C;Black, M;Barrett, LF;Dalgleish, T

Title:

The Impact of Affective Information on Working Memory: A Pair of Meta-Analytic Reviews of Behavioral and Neuroimaging Evidence

Date:

2019-06-01

Citation:

Schweizer, S., Satpute, A. B., Atzil, S., Field, A. P., Hitchcock, C., Black, M., Barrett, L. F. \& Dalgleish, T. (2019). The Impact of Affective Information on Working Memory: A Pair of MetaAnalytic Reviews of Behavioral and Neuroimaging Evidence. PSYCHOLOGICAL BULLETIN, 145 (6), pp.566-609. https://doi.org/10.1037/bul0000193.

Persistent Link:

http://hdl.handle.net/11343/296700

License:

CC BY 